\title{
WestVirginiaUniversity
}

THE RESEARCH REPOSITORY @ WVU

Graduate Theses, Dissertations, and Problem Reports

2006

\section{Does physical disability truly create impairment in adjustment to college life?}

Jennifer R. Hurst

West Virginia University

Follow this and additional works at: https://researchrepository.wvu.edu/etd

\section{Recommended Citation}

Hurst, Jennifer R., "Does physical disability truly create impairment in adjustment to college life?" (2006). Graduate Theses, Dissertations, and Problem Reports. 4232.

https://researchrepository.wvu.edu/etd/4232

This Dissertation is protected by copyright and/or related rights. It has been brought to you by the The Research Repository @ WVU with permission from the rights-holder(s). You are free to use this Dissertation in any way that is permitted by the copyright and related rights legislation that applies to your use. For other uses you must obtain permission from the rights-holder(s) directly, unless additional rights are indicated by a Creative Commons license in the record and/ or on the work itself. This Dissertation has been accepted for inclusion in WVU Graduate Theses, Dissertations, and Problem Reports collection by an authorized administrator of The Research Repository @ WVU.

For more information, please contact researchrepository@mail.wvu.edu. 
Does Physical Disability Truly Create Impairment In Adjustment To College Life?

Jennifer R. Hurst, M.S., ATC

\author{
Dissertation submitted to \\ the School of Physical Education \\ at West Virginia University \\ in partial fulfillment of the requirements for the degree of
}

\author{
Doctor of Education \\ in \\ Sport \& Exercise Psychology \\ Samuel Zizzi, Ed.D., Chair \\ Margaret Glenn, Ed.D. \\ Andrew Ostrow, Ph.D. \\ Jaci Webb-Dempsey, Ed.D. \\ Ann Richards, Ph.D. \\ School of Physical Education \\ Morgantown, West Virginia \\ 2006
}

Key Words: Adjustment to College, Students with Physical Disability, Athletes with Disabilities, Social Support, Coping Style, Self-Efficacy 


\section{ABSTRACT \\ Does Physical Disability Truly Create Impairment In Adjustment To College Life?}

\section{Jennifer R. Hurst}

This research utilized a mixed methods design to explore the differences between students with and without disabilities in perceived social support, coping style, self efficacy, and college adjustment. In addition, the influence of athletic participation on the above variables was examined in the sub-sample of students with disabilities. Neither survey nor interview results supported any differences between students with disabilities and students without disabilities on the study variables. Results suggested that discrepancies in college outcome variables (i.e. matriculation and persistence) were not a result of differences in disability status, but are the result of differences in adjustment, perceived social support, self efficacy, and coping style. Quantitative results found the strongest correlations between self-efficacy, coping style, and adjustment factors. Qualitatively, students reporting more adjustment difficulties perceived more challenges within the week, fewer factors that lent to stress management, and more factors that added to the experience of stress. A more active coping style, the use of reframing techniques, and perception of shared social reality support were associated with fewer adjustment difficulties. Interview results also suggested participation in athletics for students with disabilities provided several incentives, such as academic motivation, increased self-efficacy, and campus integration that could lend to adjustment. 


\section{DEDICATION}

To all of the students that participated in this research-

Without your efforts and cooperation this dissertation would not have been possible. It is my sincerest hope that I have genuinely represented your voices. May this research serve to increase the understanding of what supports ALL college students to be successful and reach their own goals and dreams.

To Melissa, Amanda, Emma, and Carrie -

Thank you for your friendship and support in the most important journey of my life. 


\section{ACKNOWLEDGEMENTS}

There were many people who provided their support, guidance, and cooperation to bring this dissertation to completion. I would like to take this opportunity to thank them and acknowledge their contributions.

First, I would like to acknowledge, Dr. Sam Zizzi who has served as my advisor and dissertation chair through out my doctoral work. Thank you for all of your support and encouragement in helping me to complete my goals. I appreciate your willingness to treat me as a collaborative partner and the respect you showed for my knowledge and contributions in our work together.

I would also like to say thank you to Dr. Margaret Glenn; however "thank you" just seems like such an understatement for the contribution you made to my personal and professional development. I could not have made it through my doctoral work without you and thank you for everything that you so generously gave to me.

I would also like to thank Dr. Andrew Ostrow for his help and feedback in the development of this dissertation. The leadership you provided our program helped to make my experience at WVU rewarding and productive.

I extend my gratitude to Dr. Jaci Webb-Dempsey for your special role as my qualitative expert. Thank you for introducing me to a whole new world of research and for the engaging conversations on our trips back and forth to Kyser, WV.

I also want to thank Dr. Ann Richards for the role she played in this process. Thank you for your time, feedback, and encouragement along the way.

To the coaches of the wheelchair basketball teams and directors of the disability services offices on the respective campuses, I want to extend my deepest gratitude for their willingness to help me out. Special thanks to Jim Glatch who helped to introduce me to the sport of wheelchair basketball and whose help was integral to making this dissertation happen.

Special thanks goes to my family: Mom, Dad, and Elizabeth. I appreciate your support in finishing my education and I could not have made it without your support. Mom, thank you for the editing help!!

Also, thank you to Nicole Williams and Carolyn McCarty for all of their help with transcribing and data entry.

Thank you to all of my friends and colleagues I met during my time at West Virginia for their support and encouragement.

Lastly, I want to extend my deepest gratitude to Melissa, Amanda, Emma, and Carrie. Ladies, thank you for keeping me sane, believing in me, and showing me just how powerful friendship can be. I love you all. 


\section{TABLE OF CONTENTS}

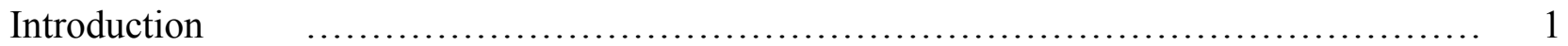

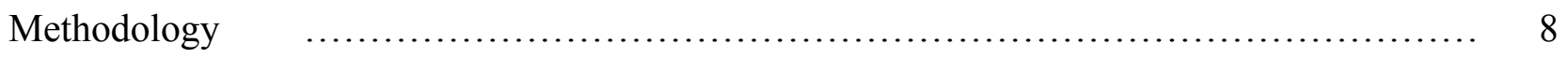

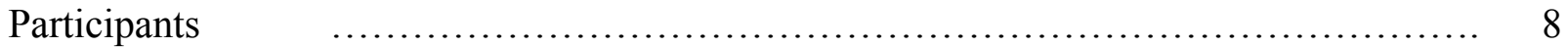

Instrumentation $\quad$....................................................... 12

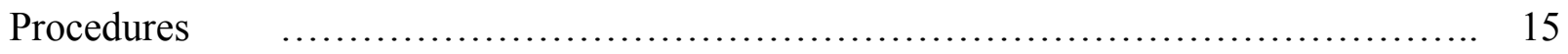

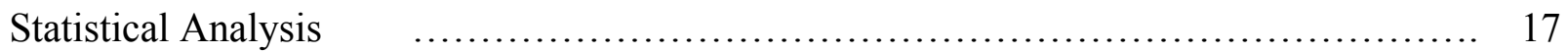

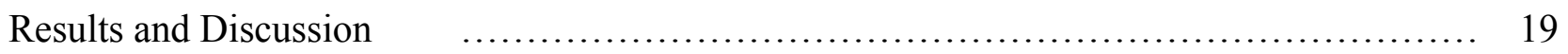

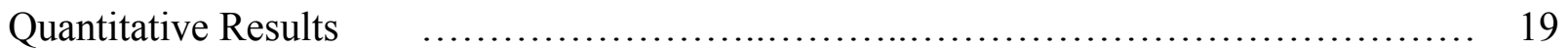

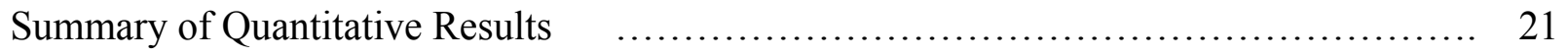

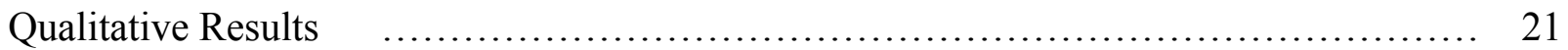

Process of college adjustment $\quad$......................................... 21

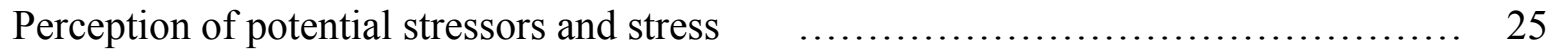

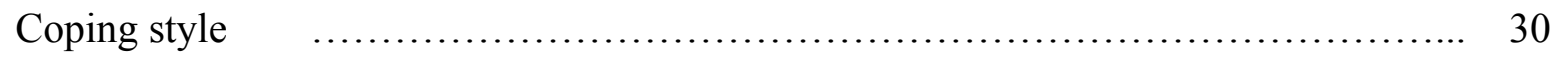

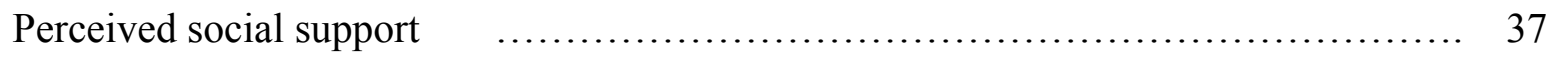

Influence of sport participation $\quad$.............................................. 40

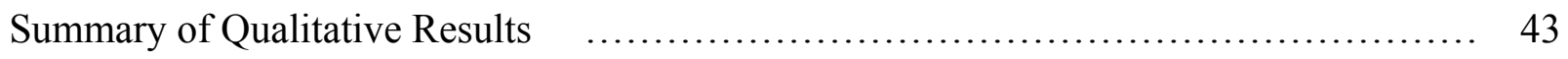

Overall Conclusions $\quad$.......................................................... 44

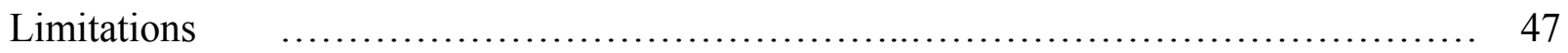

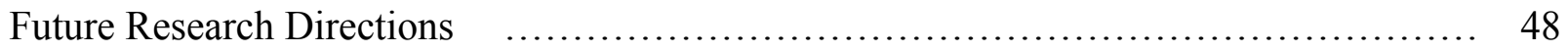

References $\quad$................................................................. 50

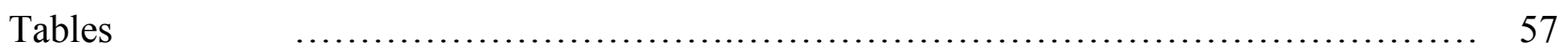

Appendices $\quad$. 


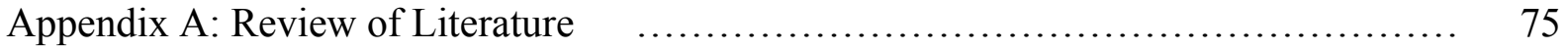

Appendix B: Additional Methods $\quad$................................................ 110

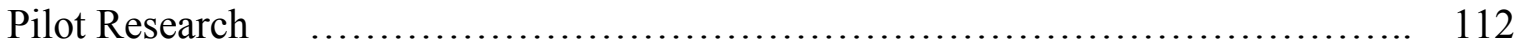

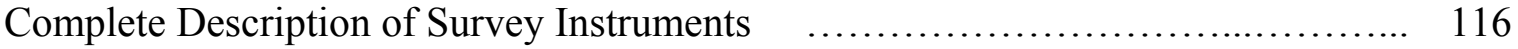

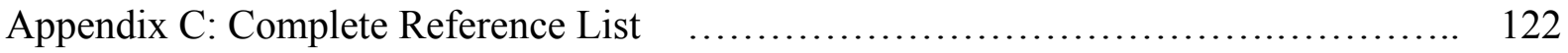

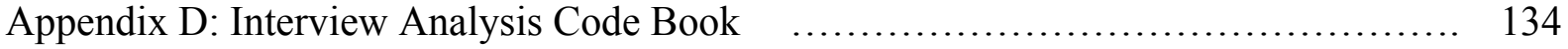

Appendix E: Inter personal Support Evaluation List - College Form $\quad \ldots \ldots \ldots \ldots \ldots \ldots . \ldots 153$

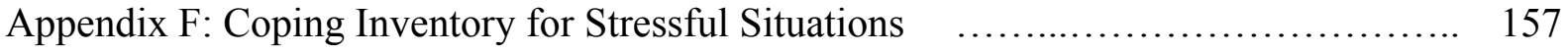

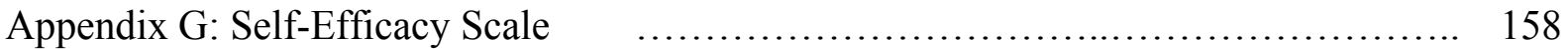

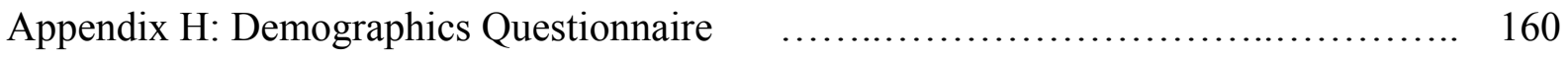

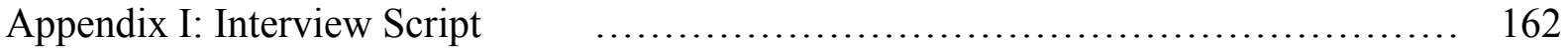

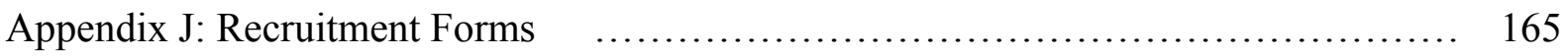

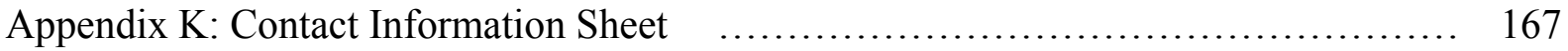

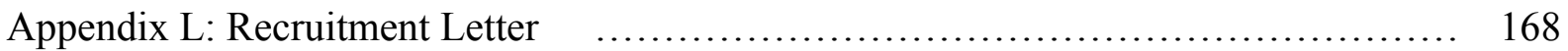

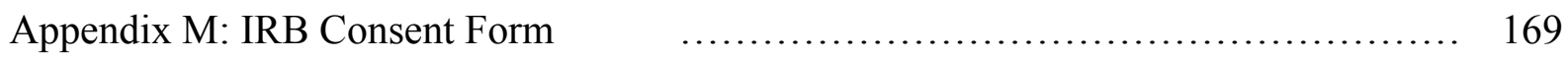




\section{LIST OF TABLES}

Table 1: Demographic Characteristics of Total Student Population

Table 2: Descriptive Statistics of Dependent Variables for Total Student

Population

Table 3: Descriptive Statistics of Dependent Variables for Samples Included in

Subanalysis

Table 4: Correlation Matrix of Study Variables

Table 5: Demographic Characteristic of Interview Sample

Table 6: Comparison of Emergent Themes Related to Reported Typical Weekly Activities

Table 7: Comparison of Emergent Themes Related to Perceived Challenges

Within a Typical Week

Table 8: Comparison of Emergent Themes Related to Perceived Resources for Managing Weekly Challenges

Table 9: Comparison of Emergent Themes Related to Factors Perceived to Create Stress

Table 10: Comparison of Emergent Themes Related to Factors Perceived to Aid in Managing Stress

Table 11: Comparison of Emergent Themes Related to Perceived Social Support

Table 12: Comparison of Emergent Themes Related to Coping Style for Managing Academic Stress

Table 13: Comparison of Emergent Themes Related to Coping Style for Managing Relationship Stress

Table 14: Comparison of Emergent Themes Related to Coping Style for Managing a Life Event Where Participant Felt Like Quitting

Table 15: Comparison of Emergent Themes Related to Expectations for College and Adjustment Difficulties 


\section{Introduction}

Students with disabilities now represent nearly ten percent of all college students (National Council on Disability, 2003) and 6\% of first-time freshmen attending four-year institutions in the fall of 2000 self-reported a disability (Henderson, 2001). Unfortunately, increased acceptance into postsecondary institutions does not automatically translate into matriculation for these students. When compared to their non-disabled peers, students with disabilities experience less successful postsecondary outcomes (National Council on Disability, 2003). It is important to learn more about the barriers that exist for students with disabilities and potential resources that will assist them in achieving successful outcomes. A first step is to determine what factors are influential in the adjustment to and functioning in postsecondary environments for students with and without disabilities.

\section{Adjustment to Postsecondary Educational Environments}

The determinants of success in postsecondary education have consumed psychological and educational researchers for decades (Robbins et al., 2004). Pascarella and Terenzini (1991) suggested that the development of theoretical frameworks for the college adjustment process might have been the single most important evolution in student development literature from the 1970 's to the 1990's.

Tinto’s (1988) theory discusses the importance of disengaging from old roles and communities and investing in new roles, norms, and relationships in the college community. The impetus for Tinto's work and much of the research conducted within the domain of college adjustment focuses on the initial transition into the college environment during the freshmen year. This focus is logical considering that attrition rates are highest during the freshmen year. 
However, longer term retention and eventual matriculation involves much more than one year. A student's need to adjust to changing and progressing roles and responsibilities continues throughout his or her tenure in college. The theoretical work of Medalie (1981) addresses a more developmentally comprehensive framework for the concept of student adjustment.

Medalie (1981) suggests the structure of college life imposes certain life tasks upon students that are best addressed in a regular sequence. The environmental demands of college continually confront students with decisions and changes. Medalie proposes that some of the maladaptive behavior of college students, which could lead to attrition, may result from a failure to adequately address the psychosocial tasks of each phase of the college life cycle. Similar to Tinto's theory, Medalie considers the two most important concepts of the freshmen year: divestment from the past and investment in a new life. Sophomore year heralds the commitment to a major and a focus on increasing mastery. Junior year sees an increase in expectations for the level of work, students start to envision an end to college, and some bridges to the adult world are made. The major developmental task of the senior year is to anticipate and make realistic plans for the future while permitting oneself to experience the sadness associated with the disengagement from the now familiar and secure college world.

Overall, it seems clear that a student's ability to continually adjust and integrate into the social and academic culture of college will influence his or her ability to persist and eventually matriculate. However, adjustment theories do not provide a sufficient working framework for understanding the mechanisms by which specific psychosocial variables may contribute to the adjustment and eventual matriculation of college students. Lazarus \& Folkman's (1984) Transactional Model of Stress can provide this needed framework. 


\section{Transactional Model of Stress}

Central to effective adjustment is the management of the stress and the uncertainty inherent in learning new roles and managing new environmental and personal demands (Schlossberg, Waters, \& Goodman, 1995). The Transactional Model of Stress (TMS) provides an operational framework for understanding how personal, emotional, and social factors contribute to the adjustment process (Lazarus and Folkman, 1984). The TMS is a recursive process initially stimulated by a potentially stressful event, such as changing roles or increased demands. The primary appraisal occurs first, in which students determine if the new demand is in fact a threat or a challenge. Simultaneously, a secondary appraisal transpires in which students evaluate their options and ability to deal with the potential stress. The resulting feedback will determine if the situation is perceived as threatening and if the stressful situation exceeds perceived resources to cope or if the new demand can be managed.

The primary and secondary appraisals are influenced by personal and environmental variables. Relevant personal variables include: (1) personality traits; (2) values and beliefs; (3) existing coping and life skills: and (4) coping style. Environmental variables include: (1) timing; (2) predictability; (3) duration of the stressors; (4) options; and (5) social support. Coping style, social support, and self-efficacy may be the most modifiable of these potential personal and environmental variables. Research has supported that physical disability status may affect the development of coping style and skills, perceived social support, and self-efficacy (Elliott, Herrick, Witty, 1992; Livneh \& Wilson, 2003; Martin \& Mushett, 1996; Smith, Ray, Wetchler, Mihail, 1998). 


\section{Coping Style}

Compas (1987) described coping styles as methods of coping that characterize individuals' reactions to stress either across different situations or over time in the same situation. Previous research suggested an individual's coping style will significantly influence his or her adjustment to stress in the college environment (Owens, 1999). An active coping style, which includes behaviors such as directly acting on a problem or collecting information to understand a situation better, has been suggested as facilitative in the adjustment process to college (Leong \& Bonz, 1997).

Cairns and Baker's (1993) review of literature on adjustment to spinal cord injury generally support active or task oriented coping styles as facilitating better adjustment to physical disability compared with passive coping styles. In addition, the review suggested that individual's perceptual beliefs also contributed to the behavioral outcomes of coping. Selfefficacy is one such perceptual belief that could impact the behavioral aspects of the coping process. Self-Efficacy

Self-efficacy, according to Bandura, is the belief that one can perform a particular behavior. Bandura (1977) believed that self-efficacy was the most powerful determinant of behavioral change because these beliefs determined the initial decision to perform a behavior, the effort expended, and persistence in the face of adversity. In fact, meta-analysis research examining the influence of psychosocial variables on retention and G.P.A in college found academic self-efficacy to be the best predictor of these college outcomes (Robbins et al., 2004). Theoretically, self-efficacy beliefs could influence an individual's cognitive appraisal of stressful 
situations (e.g., perception of personal resources) thus influencing efforts to cope (Lazarus and Folkman, 1984).

Research literature addressing self-efficacy and disability status generally supports selfefficacy as an important influence in adjustment; however, it is less clear if disability status directly effects an individual's development of self-efficacy (Blake, 2002; Saracoglu, Minden, and Wilchesky, 1989). In a sample of 127 adults with spinal cord injury (SCI), Hampton (2004) found self-efficacy accounted for additional and unique variance in subjective well being scores; suggesting the important role self-efficacy may play in adjustment processes. In addition to selfefficacy, perceived social support also accounted for additional and unique variance in the subjective well being of individuals with SCI.

\section{Perceived Social Support}

Social support is a third psychosocial factor that may have a moderating effect on stress adaptation and adjustment. Many studies have documented the positive relationships between various measures of social support and psychological adjustment (Bianco \& Ekland, 2001; Brissette, Scheier, \& Carver, 2002; Cohen, 1988; Lu \& Argyle, 1992); however, social support is proving to be a complex phenomenon. Current theoretical literature suggests that social support may include trait-like components as well as more dynamic state-like factors that influence coping in different ways (Bianco \& Ekland, 2001). Lakey and Cassady (1990) proposed the concept of "perceived social support" which is defined as: "a cognitive personality variable in which stable, organized beliefs about the quality of one's interpersonal relationships lead to biased interpretation and recall of social interactions" (p. 338). This construct was based on Beck's work involving the influence of self-schemas on information processing. The authors conducted two research studies to explore the hypothesis that perceived social support operated 
much like a personality self-schema that guided memory for and interpretation of actual supportive behaviors. The data supported four major findings: (1) the correlation patterns for perceived social support resembled that of a cognitive personality variable; (2) low perceived social support was correlated with perceiving supportive attempts as less helpful; (3) low perceived social support was correlated with recalling fewer instances of helpful supportive behavior; and (4) perceived support was associated with psychological distress, but enacted support (i.e. received support) was not.

Social support has been identified as a significant moderator of the detrimental effects of stressful situations for many people (Elliott \& Gramling, 1990). Assertiveness, a component of self-advocacy skills, is one interpersonal factor identified as important in the provision of social support. Research supports a connection between personal assertiveness and the effective provision of supportive relationships with others (Elliott \& Gramling, 1990). Findings reveal a potentially interesting connection with self-advocacy skills, a construct that has gained significant attention in the disability literature over the past decade.

\section{Athletic Participation}

For students to develop effective self-advocacy skills, they need hands on experiences that allow them to make decisions and experience the consequences of those decisions (National Council on Disability, 2003). Athletic participation may offer one environment that provides these needed opportunities to develop self-advocacy, in addition to self-efficacy and coping resources. For individuals who are commonly relegated to positions of dependence, sport provides an environment in which participants can make contributions, collaborate, and build self-confidence in their ability to set and accomplish goals (Wheeler, Malone, Van Vlack, Nelson \& Steadward, 1996). Research conducted within disability sport also suggests that it has 
considerable incentives. Disability sport is associated with enhanced self-esteem, and is a perceived option for transcending impairment by some athletes (Wheeler et al., 1999). Each of these identified incentives offers a potential environment that supports social connectedness and the development of transferable skills that could positively impact college students with physical disabilities.

The purpose of the current research investigation was to explore the differences between students with and without physical disabilities in perceived social support, coping style, self efficacy, and college adjustment. In addition, the influence of athletic participation on the above variables was examined in the sub-sample of students with physical disabilities. Individuals who utilize wheelchairs were the focus of this research project. Functionality and visibility are two factors of physical disability that have gained increased interest as predictors of psychosocial adaptation (Livneh \& Wilson, 2003). Wheelchair users generally have a greater degree of limited functioning and are more visible to others, as opposed to mental health conditions or learning disabilities. Limiting the disability sample to wheelchair users was one way to reasonably control for these two factors. Finally, this research utilized a mixed methods design to triangulate quantitative results and further explore adjustment concepts.

Hypotheses

In exploring the possible differences between perceived social support, coping style, self efficacy, and self-advocacy between students with and without physical disabilities, the following hypotheses were proposed:

1. There will be differences between the three sub-groups of college students' levels of perceived social support. 
a. Student athletes with physical disabilities will have higher perceived social support than student non-athletes with physical disabilities.

2. There will be differences between the three sub-populations of college students in their dispositions toward task-oriented, emotion-oriented, and avoidance-oriented coping style.

3. There will be differences between the three sub-populations of college students in their scores for self-efficacy.

a. Student athletes with physical disabilities will have higher self-efficacy scores than students without disabilities or student non-athletes with physical disabilities.

4. Adjustment scores will be positively correlated with higher perceived social support in the three sub-samples of college students.

5. Adjustment scores will be positively correlated with total self-efficacy scores in the three sub-samples of college students.

6. A stronger disposition toward a task oriented coping style will positively correlate with adjustment scores in the three sub-samples of college students.

7. Students with physical disabilities who do not participate in athletics will have the lowest perceived social support, total self-efficacy, and adjustment scores.

\section{Methods}

\section{Participants and Recruitment}

Three sub-groups of college students were recruited for each phase of the research project: (1) students with physical disabilities participating in intercollegiate athletics students; (2) students with physical disabilities who do not participate in intercollegiate athletics; and (3) college students without disabilities. Three universities, providing definite access to all three student samples, were utilized to obtain the sufficient sample size. The desired power for the 
survey phase, which determines sample size, was set at 0.80 . Setting the desired power to 0.80 provides for an $80 \%$ chance of making a correct decision about whether a real difference exists between the variables (Thomas, Lochbaum, Landers, \& He, 1997). In reviewing literature related to this project, small to moderate effect sizes were discovered (between 0.28 to 0.55 ) in previous data comparing populations of college students with and without disabilities (Elliott, Herrick, and Witty, 1992; Pensgaard, Roberts, \& Ursin, 1999). Based on this previous data, an attempt to recruit a minimum of 25 students was made for the physical disability sub-group samples. The physical disability sample was then matched as well as possible to students without disabilities on gender, athletic status, and year in school factors.

Recruitment of students with physical disabilities. Recruitment of students with physical disabilities who participate in intercollegiate athletics occurred at a regularly scheduled intercollegiate wheelchair basketball tournament. Initial contact with the coaches was made via telephone and email. The nature of the research project, the participation requirements, and the benefits of participation were explained. Following coach approval, a meeting with the team members was scheduled around the tournament itinerary. One specific concern with this subgroup was to limit participants' feelings of obligation to participate in the research due to recruitment through their sports team. For this reason the coaching staff was not present following initial introductions at the team meetings. In addition, the voluntary nature of the study was emphasized to the group and assurance that participation would not affect their status as an athlete or student was reiterated. Some athletes did choose not to participate, but it was less than $3 \%$.

Recruitment of students with physical disabilities who did not participate in intercollegiate athletics occurred through the Disability Services offices on each respective 
campus. Directors of the Disability Services office at each campus were contacted prior to the data collection to obtain support for the project. Individual on-campus meetings were completed with the directors to provide an opportunity to discuss the research and arrange for distribution of the recruitment materials. Each Disability Services Office identified the students within their system that met the study recruitments, as outlined by the researcher, and served as a conduit for the recruitment process. This process allowed for the anonymity and privacy of the students and their protected health information. Students identified as meeting the study criteria received both a mailed and an emailed invitation letter to participate in the study. It should be noted that one institution chose not to mail out the recruitment letter to students opting only to distribute the email to students. As a result, a lower number of non-athlete students with physical disabilities were recruited from this institution. Finally, interview participants were provided with recruitment flyers to give to other friends or acquaintances that met study recruitments. This method did illicit a few more responses to the website.

Recruitment of students without disabilities. Originally a snowball sampling method was attempted to obtain the matched sample of students without disabilities. Within the survey packets of the students with physical disabilities, a recruitment form was provided for each student to identify the names, phone and email of three to four people who were similar to them in gender and year in school who also attended his or her university. In addition, student athletes with physical disabilities were asked to identify matching individuals who did not have disabilities and who participated in intercollegiate athletics. Using the recruitment forms to solicit referrals to student athletes without disabilities proved to be highly ineffective and produced no recommendations from the student athletes. In addition, during online collection 
from the non-athletes with physical disabilities, the snowball recruitment method yielded few potential participants.

Therefore, the researcher sought and obtained IRB approval for two modifications to the sampling method to recruit students without disabilities. The first modification was designed to recruit student athletes without disabilities at the institutions. Coaches were contacted via email about the study and asked if they would be willing to forward the recruitment message onto their athletes. In addition, meetings were set up with available coaches during on-campus visits to discuss the study and elicit their support in distributing the recruitment information to the athletes. Particular focus was placed on recruitment of the men's and women's basketball teams at each school, as the majority of the student athletes with physical disabilities were basketball players.

The second modification made was designed to recruit student non-athletes without disabilities. Professors were contacted via email, in much the same way as the coaches, explaining the study and asking if they would be willing to pass along the recruitment email to the current students within their classes. Professors were identified via the course schedules for the current semester available through the university website. A purposive sampling of courses was made that included both general education courses and upper level courses in an attempt to yield a wide range of students.

Recruitment for interviews. Five individuals from each of the three student sub-groups were invited to participate in an individual interview. Recruitment of these individuals occurred through a separate contact form included with the survey packet. Both the paper and web-based survey packets provided a brief introduction to the purpose of the interview, requirements for participation, and the benefits of participating. Interested participants were asked to provide their 
name and preferred contact information on the form. This form was turned in separately from the survey packet. Therefore, when potential students were contacted for interview, the researcher asked the student's gender and year in school. As an incentive, those subjects who completed the individual interview could receive ten dollars.

A purposive sampling process was utilized to select the interview participants to meet two specific criteria. First, at least one male and one female student were included in each of the three interview groups. Second, an effort was made to include at least one first year and one senior student in each group as well. Sixty-three students in all indicated interest in participating in the interview. Thirty-two students were initially contacted for interviews, of which 26 volunteered to participate. Fifteen individuals were chosen based on the above selection criteria for interview. However, one person chosen for interview failed to complete the interview process.

\section{Instrumentation}

Demographic questionnaire. A demographic questionnaire (see Appendix I) was utilized to capture information on each participant. The questionnaire captured information on gender, age, year in school, physical disability characteristics, and intercollegiate athletic participation. The demographics questionnaire also contained a series of five questions that attempted to capture the students' perception of their current level of college adjustment in four major areas (i.e. Academic, Social, Personal/Emotional, and Institutional/Goal Achievement). The questions were written generally, so as to apply to any level of student, not just freshmen. Internal consistency was calculated for the total adjustment scale for both the physical disability and non disability populations ( 0.59 and 0.62 , respectively). Since neither of the internal reliability measures reached a 0.70 level, the researcher determined that the created items did not reliably 
hold together as a total scale. Therefore, analysis was completed utilizing each individual question.

Perceived social support measure. The Interpersonal Support Evaluation List - College Version (ISEL) (Cohen \& Hoberman, 1983) (see Appendix E) is a 48-item self-report survey that measures an individual's perceived availability of potential social resources. In addition to providing an overall support measure, the ISEL measures four separate functions of social support: tangible support, appraisal support, self-esteem support, and belonging support. The internal reliability (Cronbach alpha) for the total scale is .86. Cronbach alphas for the subscale ranged between .68 and .77. Construct validity (Brookings and Bolton, 1988) and concurrent validity (Barrera, 1981; Barrera, Sandler, \& Ramsay, 1980; Cohen and Hoberman, 1983) was established for the ISEL. In the present sample, total scale reliability was .97 for the physical disability population and .95 for the non-disability population. Subscale internal consistencies ranged between .71 and .95 for both sample groups and generally showed greater internal consistency than the previously mentioned studies.

Coping style. The Coping Inventory for Stressful Situations (CISS) (see Appendix F) is a 48-item self-report instrument utilized for measuring multidimensional coping (Endler \& Parker, 1999). Three coping dimensions are evaluated with the CISS: Task, Emotion and Avoidance. Respondents are asked to rate their level of engagement in each of the 48-items on a Likert-type rating scale ranging from (1) "Not at all" to (5) "Very much." The internal reliability coefficients ranged between .85 and .95 for each of the three scales. Six week test re-test reliabilities were reported at .51 to .74 (Endler \& Parker, 1990). In addition, the CISS has demonstrated good concurrent and construct validity and has been normed on both college undergraduate and 
disability populations (Endler \& Parker, 1994). In the current sample, subscale alphas ranged from .79 (distraction) to .90 (emotion), thus showing adequate to good internal reliabilities.

Self-efficacy measure. The Self-Efficacy Scale (Sherer et al., 1982) (see Appendix G) is a 23-item instrument consisting of two subscales, general self-efficacy and social self-efficacy. Sherer et al. (1982) established both reliability and validity for the Self-Efficacy Scale. Cronbach alpha coefficients of .86 and .71 were obtained for the General Self-efficacy subscale and Social Self-efficacy subscale, respectively. Factorial validity (Choi, 2003) and construct validity (Sherer \& Adams, 1983; Sherer et al., 1982) were established in previous research.

Internal consistency values were determined for the Self-Efficacy total scale and general and social subscales. Results indicated less than optimal internal consistency within the sample groups. The Cronbach Alpha value within the physical disability sample for the total scale was only 0.68 and 0.61 within the non-disability sample. The low alphas were a result of significantly lower internal consistency values for the social subscale in both the physical disability and nondisability samples ( 0.49 and 0.38 respectively) than found in previous research (Sherer et al., 1982). Internal consistency for the general subscale reached 0.76 in the physical disability sample and 0.73 in the non-disability sample. Therefore, the decision was made to utilize only the general subscale as the measure for self-efficacy instead of the total score of the SelfEfficacy Scale.

Interview script. Potential questions for the interview script (see Appendix I) were generated based on a review of the relevant literature to query self-advocacy, coping with stress, social support, and adjustment. Questions were then reviewed for wording and sequencing based on recommendations made by Patton (2002) in his discussion of qualitative interviewing. A 
preliminary script was presented to two faculty experts, both with experience in qualitative interviewing, for suggestions and feedback.

The researcher utilized six students, five females and one male, to pilot the interview script. Participants completed one interview session with the researcher. Each interview was recorded utilizing a standard microcassette recorder. Following completion of the interviews, the tapes were transcribed verbatim and then reviewed for accuracy. Responses were examined to confirm the content that each question was eliciting from the participants. A meeting was held with the researcher's committee member most experienced in qualitative research to re-examine the question strategy based on participant feedback and data collected from the interviews.

Four major changes were made to the interview script based on the piloting process. First, the order and wording of the questions surrounding self-advocacy skills were revised to elicit more useful content in a more fluid manner. Second, within the social support section, the researcher added a prompt to help clarify the type of support the student was receiving from different sources. The third change made to the interview questions was the addition of a question regarding the student's expectations for their first semester in college. Lastly, changes were made to gain a more longitudinal perspective on the student's adjustment process. The researcher felt that the new questioning would obtain information that would be more effective in supporting or contrasting Medalie's (1984) transition theory. For more in depth information regarding the piloting and changes made to the interview script, please see Appendix C.

\section{Procedures}

To facilitate data collection the consent form and survey instrument packet were translated into an online web page format. The online data collection system was piloted prior to 
the start of the study. For further information regarding the survey pilot research please see Appendix C.

Survey research. Data collection for student-athletes with physical disabilities occurred within scheduled meetings at a wheelchair basketball tournament. The following protocol was utilized at each meeting. A brief introduction of the research project was given to the team members. Following any initial questions, the researcher distributed the consent form to the group and any questions about the consent or study procedures were answered. The voluntary nature of the study was emphasized to the group and assurance that participation would not affect their status as an athlete and/or student was reiterated.

Following the introduction of the consent form, the distribution of survey packets proceeded. Instructions for each survey were given and participants were given the opportunity to review the survey packet. The survey packets were arranged in a random order to limit the number of individuals filling out the same forms at the same time so that one respondent's answer to a particular survey item was less likely to influence a second respondent's. Those individuals who chose not to participate were asked to simply leave their consent form and survey packets blank and given the option to leave. Students choosing to participate were asked to sign the consent form and complete the survey packet. Once completed, participants turned in the signed consent form, survey packet, recruitment form, and interest sheet for the follow-up interview to the researcher. Those students completing the survey packets had the option to enter a drawing for $\$ 25$ cash.

Student non-athletes with physical disabilities participated in the project via the website. Interested students logged onto the study website, completed the online consent, and then completed the surveys. Survey results were submitted to the researcher's email account. Once 
surveys were completed, participants were redirected to another page where they could complete the recruitment form, and interview interest sheet. This data was then submitted and transferred to a separate email account held by the researcher as to keep it separate from the survey results. The same procedure was utilized for data collection with students without disabilities.

Interviews. The following procedure was utilized for all interviews. The day of the interview, following initial greetings, interviewees were given a general overview of the nature of the interview and its procedures. Any questions regarding these topics were answered at that time. Each participant was asked for permission to record the interview. Each session was taped utilizing a microcassette recorder. The researcher followed the same question strategy for each participant. Follow-up questions and probes were utilized with each participant depending on the answers being provided. Following completion of the interview, participants were thanked for their cooperation and received ten dollars. Subsequently, interviews were transcribed for content analysis.

\section{Statistical Analyses}

To match the physical disability group with the most comparable sample of students without disabilities a list of the physical disability sample was generated identifying each subjects: (1) gender, (2) school attended, (3) athletic participation status, and (4) year in school. The same procedure was completed on the non-disability sample. Next, all athletes within the non-disability sample were matched up as closely as possible with a student with a disability. All remaining unmatched students with physical disabilities were then paired with a student without a disability in the following manner. Students were first matched with someone of the same gender, same year in school, and same school attended. If this were not possible, they were then matched with someone of the same gender, same year in school, and different school attended. 
The last resort was to match students who were of the same gender, a different year in school, and a different school attended.

Due to the smaller sample size used in this study, appropriate power was not reached to effectively employ multivariate procedures in the data analysis. Therefore, a series of ANOVAs were utilized, instead of MANOVAs, to test for group differences on the dependent variables. An total of ten ANOVAs were run utilizing three group levels and the following dependent variables: task-oriented coping style, emotion-oriented coping style, avoidance oriented coping style, total score for perceived social support, general self-efficacy score, and the five adjustment question scores.

Repeated use of ANOVAs with the same sample can increase the experimentwise error rate, unless a Bonferroni technique is utilized to adjust the alpha level. Therefore, the adjusted alpha level was set at .005 for the analyses. In addition, due to the recruitment difficulties, the likelihood of obtaining more heterogeneous samples with greater variance increased. To accommodate this dilemma, the researcher checked for assumption violations of the ANOVAs utilizing the Levene statistic. Analysis revealed one statistically significant value for one of the adjustment scores. Therefore, a Tamhane's T2 post hoc test was utilized to compare possible group mean differences for that factor; a Tukey's test was utilized for all other dependent variables. In addition, a correlation matrix was performed to explore the relationships between the dependent variables.

Qualitative analysis. Tape-recorded interviews were transcribed verbatim into written text and proofed for accuracy. Data was analyzed by sample group and major variable category. A repetitive process, using three passes of all questions, were used to code responses into first and second order data categories within each variable. New data was constantly compared to 
existing categories to determine whether it represented a new category or subcategory. To qualify as a first order category at least 3 students within each sample group had to contribute to the response category. Themes were created from the response commonalities, while unique variable interpretations of the students were preserved as sub-categories.

Following data coding, two analyses perspectives were taken. First, comparisons were made within the variable categories to explore possible differences in major emergent themes between the subgroups of students. Second, an intrapersonal perspective was taken to explore the possible relationships of an individual's emergent themes had to his or her description of their college adjustment.

Results and Discussion

\section{Quantitative Results}

A total of 168 students responded to the survey component of the study. However, due to incomplete data, 19 subjects were excluded, resulting in 149 subjects included in the data analysis. Demographic characteristics for the sample groups can be found in Table 1. Descriptive statistics for the dependent variables for the total sample are contained in Table 2. A matched sub-sample of 102 students was utilized to explore the influence of disability status and athletic participation on the dependent variables. This sample contained all student athletes with physical disabilities, all non-athletes with physical disabilities, and 51 students without disabilities that included 22 athletes. Table 3 contains descriptive statistics for the dependent variables of the three sample groups.

Results of the ANOVA analysis indicated there were no significant differences between the three student groups on any of the ten dependent variables, thus hypotheses were not supported in this area. No differences were found between the physical disability samples and 
the non-disability sample or between the athletes with physical disabilities and the non-athletes with physical disabilities. Therefore, one correlation matrix was run to explore the relationships between the dependent variables of the sample (see Table 4).

The general self-efficacy score showed moderate positive correlations with four of the five adjustment questions. Students' level of mental well being showed the strongest correlation $(r=.525, p<.001)$, followed by academic adjustment $(r=.408, p<.001)$, social adjustment $(r=$ $.353, p<.001)$, and physical health $(r=.353, p<.001)$. In addition, general self-efficacy had a moderately positive correlation $(\mathrm{r}=.558, \mathrm{p}<.001)$ with the task coping scale of the CISS and a moderately negative correlation $(\mathrm{r}=-.429, \mathrm{p}<.001)$ with the emotion coping scale of the CISS. General self-efficacy also showed a weak, yet significant correlation $(r=.226, p<.05)$ with total perceived social support. These correlations support the hypothesis for a positive correlation between adjustment scores and self-efficacy.

Task coping scores displayed significant, moderate correlations with the students' level of academic adjustment $(\mathrm{r}=.283, \mathrm{p}<.01)$ and their level of mental well being $(\mathrm{r}=.312, \mathrm{p}<$ $.001)$, thus supporting another research hypothesis. Emotion coping scores showed significant negative correlations with three of the adjustment questions. The strongest correlation was seen in relation to students' level of mental well being $(r=-.455, \mathrm{p}<.001)$, followed by their level of physical health $(r=-.314, p=.001)$, and their level of social adjustment $(r=-.278, p<.01)$. Finally, students' level of social adjustment was positively correlated with their total social support score $(\mathrm{r}=.330, \mathrm{p}=.001)$. This results provided partial support for a positive correlation between adjustment scores and total perceived social support as hypothesize. 


\section{Summary of Quantitative Results}

No significant differences were found between the student subgroups on the dependent variables. However, significant correlations were found between the dependent variables. In support of hypotheses, general self-efficacy displayed the strongest correlations with the adjustment variables, as well as with task coping. Emotion coping style was negatively related to adjustment variables. Total social support displayed the weakest relationship with adjustment variables, correlating most significantly with social adjustment and providing partial support for study hypotheses.

\section{Qualitative Results}

A total of 14 students were interviewed for this portion of the project. Students' designated pseudonyms and demographic data are presented in Table 5. Comparison of emergent themes between the student groups are presented in Table 6 through Table 15. The interview script is located in Appendix I.

The process of college adjustment. Student athletes with physical disabilities reported fewer difficulties related to their freshman year adjustment to college than the other two student groups. In general those students who experienced more adjustment difficulties had expectations for college that were not met, experienced difficulty fitting into a social group on campus, their most significant social support source did not exist on campus, and they lacked a source of mentoring support.

Two students without disabilities did experience a significant adjustment "crisis"; however both occurred during their sophomore, not freshmen years. As suggested by Medalie (1981), the source of the adjustment difficulty stemmed from unresolved divestment from the 
student's family and investment in the campus environment that should occur during the first year. The following sequence of quotes exemplifies the circumstance.

Interviewer: How was it adjusting your first semester of college?

SND3: I managed, I perceived it to be really hard... I still got good grades, even though...in my mind I wasn't smart enough...My freshmen year I didn't have a lot of outside friends...I wasn't roommates with the friends who I was talking about. So, I had a new roommate and people who I met in the dorm... besides like those people, I didn't really talk to a lot of people.

Interviewer: Did you get involved in any organizations on campus?

SND3: I was involved for a little while, but then I just left, because I wasn't really into the group... I felt lonely a lot.

The student came back for the beginning of her sophomore year and left during the month of October.

Why I left? First of all I didn't like what I was studying, then I had a lot of issues like with my parents, they were always arguing about me to stop what I was doing, because when I was in psychology and teaching, they didn't like either one of those. So I felt a lot of pressure trying to do what they wanted me to do, so then I just lost it...I got depressed and sick...I just felt hopeless (SND3).

Nearly $85 \%$ of students leave college voluntarily, even when academic performance is not a concern (Tinto, 1987; 1993). Consistent with previous research, long term adjustment and persistence to graduation may correlate more significantly with emotional-personal and social aspects of adjustment (Gerdes and Mallinckrodt, 1994). The experience of negative affect, such as depression and anxiety, have been negatively correlated with factors related to healthy 
adjustment (McKemy, 1996; Pappas \& Loring, 1985), and could be influenced by the lack of perceived social support (Hays \& Oxley, 1986; Mallinckrodt, 1986).

Interview data supported a relationship between successful adjustment and the psychosocial variables of self-efficacy, social support, and a commitment to academic goals (Robbins et al., 2004). The following quote, from the previous student, highlights the role of these psychosocial factors had in her decision to return and finish her degree:

Even though I was really depressed and stuff I really did want to finish school. I just didn't want to finish in the path that I was going for, psychology or teaching. And I didn't really want to do that, so then when I went back I'm like I'm just going to try something else. So I tried Sociology and really fell in love with that... my personality changed a lot. I was more willing to talk to people, I was more outgoing. I felt less pressured about the expectations [from her parents] that I was telling you about... I just felt a lot better about myself and where I was at... I started taking [sociology] classes and meeting different people, I just felt more motivated and happier. More right. I was thinking more in terms of pleasing myself then worrying about other people. Like my family and things, so I just felt more confident (SND3).

The interview data supported Medalie's (1981) assertion that resolution of the divestment/investment life task will influence a student's persistence and adjustment within the college environment. Failure to address this life task could lead to continual adjustment problems beyond the first year of college and possible attrition. Further support for Medalie's (1981) theory of the mini-life cycles of college adjustment was substantiated in the interviews with the 
seniors and graduate student of the sample. During their sophomore years the students described the process of choosing a major and forming some commitments to future goals.

I started out Computer Science. Um, I'm too much of a people person to be sitting behind a computer for hours upon hours. Switched that to Business Management. Figured out there was way too much math for me...now I'm Sports Administration [changed at the end of sophomore year] and that's finally, obviously, where I'm graduating...But that was just, you know, trying to balance, trying to figure out where I wanted to be. Hmmmm...a headache (SD3).

By junior year an increased seriousness toward their studies and a looking ahead to life in the adult world occurred for one of the students.

Even before my accident I kind of started to realize - you have two years left here. You need to start doing something or you may not graduate. I did start to buckle down. Right before my accident happened I was going to class I was doing all my work. I was only going out on Friday and Saturday night. I was staying away from doing all the extra curricular activities and just concentrating more on my studies $(S A D 1)$.

With the advent of senior year, the students describe a new more intense focus on life outside of college.

Just more aiming toward the overall career goals now and pushing, the Junior year was more here and now. Now, I'm at a point looking towards tomorrow, looking towards making those necessary adjustments for the future, graduate school, job searches just in case, trying to find a place to live by myself and not at my Mom and Dad's house, financially, looking tomorrow towards the future (SD3). 
However, the customary apprehension and acute anxiety of pending graduation was present. I'm a little nervous. Like I'm kind of in the process right now of applying for grad school, and I need to take the GRE and all that stuff. It's such a mountain to climb... it's like part of me just wants to just keep putting it off and putting it off, like, “oh, it won't happen if I just keep putting it off," but, that'll come back and bite me in the ass later (SAD5).

All in all, the data gathered from these senior students supported Medalie's (1981) conception of college adjustment as an ongoing series of mini-life cycles. Thus, this particular theory of college adjustment appears to have some validity within both this physical disability and non-disability populations. The next section focuses on emergent data on factors supporting or inhibiting adjustment within these same populations, including: perceptions of stress, coping styles and self-advocacy skills, perceived social support, and athletic participation. Differences found between the student subgroups will be discussed first, followed by how the variables' emergent themes relate to adjustment.

Perception of potential stressors and stress. In examining factors relating to sources of stress, some similarities and differences emerged between the student groups. In general, the main stressor identified by the student athletes with physical disabilities revolved around sport participation. For the first year students, the stress related to sport involved learning to balance different activities with their sport. One student commented, “...just trying to balance everything I guess. Trying to balance school with friends and basketball and all that (SAD3)." However, the more experienced students within the sub-group expressed more about managing the already accepted sacrifices that came with sport participation and maintaining their academic standing: 
...trying to make sure I am on top of things school wise and stuff. I do a pretty good job of it... it makes it a little bit difficult since I have practice very morning I can't stay up really late at night or I'd just be dead at practice...I get up so early and I have practice and then I have to have time for like lifting, or if there's other... team meetings and stuff I have to do. There's just other things I have to do in addition to practice and lifting (SAD5).

The discrepancy in the sources of stress between less and more experienced student athletes appropriately reflects adjustment theory (Medalie, 1981). All less experienced athletes were first year students and the learning of and balancing of new roles would be a central focus and primary source of stress. However, the more senior students were experienced in their roles and stress originated more from performing the roles well as opposed to learning to balance them. Despite possible stressors arising from sport participation, student athletes perceived few challenges or hassles within their typical week. One student athlete commented: "there's really not too much hassles. Getting motivated to do it I guess is the hardest part. But once you get up and get going it is pretty easy to do (SAD3)." In addition, student athletes displayed confidence in their ability to manage the common environmental issues (e.g. stigma associated with disability, access issues related to physical limitations) that emerged for most students with physical disabilities (athletes and non-athletes). "Depending on where I am, there are a lot of places that are inaccessible and that's kind of a challenge... we do a pretty good job of being able to adapt and overcome things like that (SAD4)."

However, most students with physical disabilities expressed recognition of the general accessibility provided on their campuses. Difficulties tended to stem from specific physical limitations associated with their disability. For example, one student remarked: 
My biggest thing is my arms don't move a lot, so I have trouble getting between floors. I can't do the elevator and I have to have someone press it for me. And it would be with doors, but they have the automatic doors and you can use a clicker button (SD4).

Experiencing stress over completing course work and other academic related responsibilities was an emergent theme for all the student groups. For student athletes, management of coursework was particularly stressful while in season and having to travel: ...when we are in season it is a lot more difficult, because we are practicing six days a week and there are times when you are leaving on a Wednesday afternoon and not coming back until Sunday. So just trying to make sure that I have everything done not only for that week when you are leaving, but also making sure I had done for school for when we come back (SAD1).

For student non-athletes with physical disabilities and students without disabilities, coursework stress was more associated with time management/procrastination issues:

Classes that is another biggie... some classes more than other classes, especially in political science since I am starting to get the actual core classes. It's tough. I don't know. Just being me, 'cause I have a tendency to procrastinate (SD2). Another difference between student athletes with physical disabilities and the other two student groups was a greater frequency of perceived internal characteristics (e.g., personality trait or self-initiated activity) that aided in the management of stress. "Yeah, the positive attitude is a necessity when it comes to things like that [managing stress]...if something stresses you out and you continue to let it bother you, and boil and boil, it's only going to add more stress...that's not 
my style (SAD4)." Another student athlete discussed a type of laissez-faire attitude in managing academic stress:

I don't let myself get too stressed out...I take school very seriously and I study a lot, but sometimes I'm just like, ‘man screw it. I don't care...I didn't do as well on that paper...whatever.' I mean I definitely study hard... stay on top of things usually, but...I kind of tend to let things roll off my back pretty easily too (SAD5). Internal characteristics also served to exacerbate stress for other students. One student without a disability expressed her perfectionist quality as adding to her stress level: "I'm definitely an overachiever. I expect the very best from myself and nothing but, which you know, causes me to really stress out for an exam that I might not do well on (SND1)." Another student non-athlete with a physical disability identified worrying as an internal characteristic that added to his stress:

I know I shouldn't worry about things that are out of my control, but sometimes you worry about, 'oh is the teacher going to like what I said? Is he going to disagree with me and give me an F?' I can't do anything about it, but I still worry about it (SD1).

According to adjustment theory, an increased perception of personal self-efficacy contributes to more positive adjustment outcomes (Schlossberg et al., 1995). Student athletes with physical disabilities reported more internal characteristics that aided in their management of stress. The higher recognition of positive internal characteristics potentially reflects an increased self-efficacy in the student athletes with physical disabilities. Past research has found positive correlations between self-efficacy and college adjustment (Saracoglu, Minden, \& Wilchesky, 
1989; Robbins et al., 2004), as well as self-efficacy and adjustment to spinal cord injury (Hampton, 2004).

When considering the relationship between stress and adjustment, the interview data revealed two potential differences between those students who experienced adjustment difficulties and those that did not. First, those students who reported little or no adjustment difficulties shared the perception of having few challenges within their typical week. However, this theme does not preclude the presence of potential stressors, but a lack of perception of these stressors as a threat. The following quote exemplifies this relationship: "I think a lot of things happen to me and I really don't look at them as challenges. I just kinda get over it and move on instead of harping on it or trying to figure out why it happened (SAD1)." Previous research has supported moderate negative correlations between negative daily life events and adjustment (Sanders \& DuBois, 1996). Therefore, perception of fewer challenges within the week may have contributed to experiencing fewer adjustment difficulties.

Second, those students who had more adjustment difficulties typically reported more factors that added to their stress and identified internal characteristics that adding to stress levels.

Oh, I think I have personality traits that add to my stress, because I definitely like want to do everything perfect so...I'll stress out just working on something because, you know oh it's not good enough at this point or it's not good enough at that point...I just I don't deal well with stress a lot (SND4).

In contrast, those individuals experiencing little to no adjustment difficulties reported internal characteristics that lent to the management of stress. 
...I try to plan out my next day.... and find out what's positive in those days. So, when I'm having a bad day I try to think of either what's coming that day or the next day and that will boost your spirits. I don't have too many bad days (SD3).

The following results may support a link between the primary and secondary appraisal processes of the TMS (Lazarus \& Folkman, 1984) and college adjustment. According to the interview data, students who experienced fewer adjustment difficulties perceived less challenges (i.e. primary appraisal) and more resources for managing challenges (i.e. secondary appraisal), which is associated with the experience of less stress. Past research has indicated that higher stress is correlated with decreased psychological and emotional adjustment in college (Frazier \& Schauben, 1994; Skowron, Wester, \& Azen, 2004). Therefore, the Transactional Model of Stress may be a valid operational framework for understanding the link between stress and adjustment in students with and without physical disabilities.

Coping style. Data analysis revealed no differences between the student sub-groups in regards to coping style or other coping variables. However, substantial differences did exist between those students who described significant adjustment difficulties and those that described little to no difficulties. In general, those individuals who experienced little to no difficulties tended to display more of a task oriented coping style in managing stressful situations, supporting previous research (Leong \& Bonz, 1997; Livneh \& Wilson, 2003).

Most students utilized a combination of active and passive coping strategies to manage academic stress. Even individuals who displayed a dominant task coping style occasionally used passive coping strategies to manage academic stress.

Ah, if I feel like my school work is getting to where its stressing me out too much, I just put it down and go play video games...If I've got a lot to do within one 
week, like finals are coming up. So, I've got a lot of studying to do. What I'll do is that I'll set aside like just a couple hours everyday and I'll go study during that time. As soon as that times up though, I'm done with it. If I'm right in the middle of something or whatever, I go ahead and I just put it down, 'cause I need to get away from it (SAD3).

Another emergent theme for individuals who experienced more adjustment difficulties was an apparent lower self-efficacy level for managing academic stress. For instance, one student commented when asked how she tended to manage academic stress:

Curl up in a ball and cry. Oh man, academic stress, well God, sometimes it's like you try every single way. Some, I try to be really assertive about it for the most part and like make a plan and okay you need to work on this at this time. It doesn't always work out that way (SND4).

In contrast, another student displayed a higher sense of self-efficacy in managing his academic stress:

Usually my academic stress only comes when I'm missing an assignment or I'm late with an assignment or something like that. So, as soon as I turn in that assignment that needed to be in, or as soon as I get done with that ten page paper, or as soon as I get done reading that five hundred page book the stress is gone (SAD4).

Past research has suggested that perceptual beliefs, such as self-efficacy, contribute to the behavioral outcomes of coping (Cairns \& Baker, 1993). The interview data supported a relationship between self-efficacy and the style of coping students utilized in managing academic 
stress. Typically those students who displayed a task coping style in completing academic work also displayed a higher self-efficacy for managing academic stress.

A larger contrast between students who did and did not experience adjustment difficulties was evident when examining their coping strategies for interpersonal stress. Typically, students who experienced few difficulties employed active coping strategies, highlighted by the use of assertive behaviors.

Whenever there's a stressful situation going on between me and someone else, its just best to get it out in the air and kind of talk about it... when they're just kept not talked about...not discuss it, then they tend to just add more stress. I like to just kind of get those things, like I said out in the air, and talk about them, and they're not even an issue anymore (SAD4).

However, once again even students employing a more active coping style mentioned the importance of initially avoiding the situation. Yet, this avoidance served the purpose of reducing their initial emotional reaction so they could confront the issue better.

For the students who experienced adjustment difficulties a consistent pattern of avoidance, passive coping strategies, and aggressive behavioral responses were found. Ignoring one's own feelings and non-assertive behavior highlighted this student's description of her coping method: "Honestly, most the time I just try to swallow my own feelings and just let it go (SND1)." One student with a physical disability described aggressive behavior in conjunction with avoidance: “I get very irritable...I try not to get like that, but it's just like I can't help it. Whenever I'm stressed out, I will bite into somebody...I can't help that...that's why I try to stay away... (SD2)" A student athlete with a physical disability reported: "my anger will get the best 
of me, and I'll get in peoples' faces (SAD2)." Yet to avoid an angry outburst he would "lock myself in my room and just calm myself down and just ignore people (SAD2).”

Another coping strategy enacted to manage social stress was self-advocacy skills. Several students identified behaviors that would be considered self-advocacy during their interviews. One student described several elements of self-advocacy when speaking about how he manages stressful interpersonal situations:

I would have to say that I do the best that I can to make sure we have some sort of understanding, make sure you know how I feel and I know how you feel and try to come to some medium...We may never see eye to eye, which a lot of times we don't, but um we do the best we can to come to a medium somewhere (SD3). Another interesting finding related to self-advocacy skills surrounded the possible importance of these coping skills in resolving the divestment/investment struggle related to adjustment to college. One student interviewed indicated that she had actually quit and left school halfway through her first semester sophomore year. She returned to campus at the start of the second semester the same academic year. Based on this student's explanation of her circumstances, she was struggling to divest herself from her family's expectations and previous relationships to invest into new relationships and her own career direction. This student cited advocating for herself as a major contribution to allowing her to coping with adjusting to new roles in college.

I'm doing that [advocating] a lot now and I'm actually succeeding a lot more now, because I'm getting a lot more questions about it. Like with my family and everybody I know about going into Sociology. I'm going to go specifically into social work, and since I've had really good grades and everything when I was 
younger and my family expects me to do something, you know, that makes more money. So, they had a problem with me changing my major. They also had a problem with me, actually before I even came to [her institution], they had a problem with me coming here, because they wanted me to just go to a school to live with them, or a school nearer to where I lived, a cheaper school, and I had to pretty much argue with them all the time about I'm doing what I really want to do. I was pretty much my only support group for sticking with what I wanted to do (SND3).

Whereas self-advocacy skills are more consistent with an active coping style, denial coping is more of an emotional or passive coping style. Most students utilized denial coping to manage different situations. However, there was a subtle yet important difference between less adjusted and better adjusted students. For instance, when asked if he had ever been treated unfairly a well adjusted student athlete responded:

I don't know if I can really think of an instance specifically, but it definitely happens, and like sometimes because of my disability, sometimes just because it happens...I just kind of let it roll off, roll off my shoulder (SAD4).

Obviously the athlete acknowledges he gets treated unfairly for something he cannot control and just ignores it. However, he takes a potentially important second step as he adds: "That sort of thing happens to everybody. Maybe a little more so with the person with the disability or maybe not, but it definitely happens and I don't really let it bother me (SAD4)." The athlete is enacting denial or avoidance coping, but he is pairing it with a cognitive restructuring statement that normalizes the experience for him. A second student athlete with a disability offered another example when he discussed the stigma he sometimes experienced due to his physical disability. 
He indicated, "Just wheeling across campus people would always look and stare at you (SAD1)." However, he also utilized a cognitive restructuring, but in a different way: "I didn't really care anymore. I am like, you know, think what you want, you probably don't even realize half the stuff I am able to do (SAD1).”

Students who experienced greater adjustment difficulties also utilized denial coping strategies. However, they were not taking the second step of enacting a cognitive restructuring to counteract possible negative affect. For example, one student with a physical disability mentioned that he felt animosity from other students, because he got to register earlier than they did because of his disability. When asked if he ever tried to confront and explain to the other students the purpose of the privilege, he responded: "You can talk, but people don't hear you, so it is just more them making comments...I mean it doesn't really affect me, but it is just knowing they get mad cause we get something before them (SD1)." The student makes an attempt to manage the circumstance with denial coping, yet made no positive reconstruction of the situation. For another girl who felt she was being unfairly harassed by other students enacted a slightly different coping response, but with a potential similar result:

I just ignore it to the best of my ability, you know lock myself in my room, call a friend, and go 'you'll never guess what's going on, you can't believe it'. I've been known to call my parents, and sniff-sniff 'I'm in tears and you'll never guess what's happening.' [said in a crying voice] (SND1).

In this instance, the student tried to resolve associated negative affect by catharsis alone. In both of the previous instances, the enacted denial coping measures were not accompanied by any positive re-framing effort. Previous research suggests reframing techniques are associated with an increased likelihood of graduation (Owens, 1999). The reframing technique may be serving to 
protect the student's ego and maintain a sense of self-efficacy even in the face of uncontrollable situations. Many coping measures do not account for reframing techniques, including the coping style measure used in this study.

A final finding within the data was the recognition of coping behaviors that were "mixed" in nature. Mixed coping behaviors were those strategies (e.g. seeking social support and denial) that appeared to serve as both active and passive coping. For instance, a student athlete who had considered quitting his team due to difficulties with his teammates described the following coping efforts:

I basically just talked with coach and he told me, he got me to see that there was light at the end of the tunnel...he helped me realize that it will get better and not to quit, because if I quit it would make everyone else win, and me failing myself, and I don't want to do that to myself (SAD2).

In this instance the seeking of social support served an active purpose in helping the athlete to reconsider his appraisal of the situation and ability to manage it. Endler and Parker (1994) have referred to seeking support from others as behaviors consistent with an avoidance coping style, suggesting more of a passive coping strategy. However, the sub-theme of seeking social support was connected to both active and passive coping themes within the interview data. This dual contribution of social support suggests its mixed role in coping outcomes.

The determinant factor on whether a mixed coping behavior contributes positively or negatively to coping outcomes may reside in its contribution to the stress appraisal process. For instance, if seeking social support assists an individual in actively re-appraising a situation in a more positive manner, then the social support would contribute to more successful coping 
outcomes. However, if seeking social support does not stimulate re-appraisal of a situation or even reinforces a negative appraisal, then social support will undermine successful coping. Perceived social support. Only one major difference in perceived social support was found between the student sub-groups. Only student-athletes with physical disabilities identified coaches and teammates as a source of support. Teammates tended to be viewed like friends or family to the athletes and served as a significant source of belonging support.

I spend a majority of my time with my teammates. And, I see them everyday, and I will have to say that I rely on them more, I guess, and like especially in the competitive sense too, just because you all rely on each other to go out there and be competitive with each other, and then off the court we're all friends, and if we ever need anything, we can talk to each other, and, I have to say I rely on my teammates the most (SAD4).

Support from coaches tended to focus on listening and appraisal support: "[Coach] is there for anything I need basically. This year he helped me out with my schedule and he's given me advice on a lot of different issues...(SAD3)"

All but one student identified family, generally consisting of at least one parental figure, as a perceived source of support. Parents tended to provide tangible support (i.e. money), listening, and emotional support. Family in general provided students with a sense of belonging: “Hell, it's [family] where I'm from...the best I can explain it, is that it gives me a sense of self (SND2)."

Twelve of the fourteen students interviewed mentioned friends that provided support. Friends were perceived as an important source of belonging support and distraction for fun: “...my friends are very supportive in helping me...they're always there for me, and they provide 
me with entertainment, such as diversion, and they're really what's important to me...(SND2)" Friends also served to provide another type of support called shared social reality (Pines, Aronson, \& Kafry, 1981), a type of support that provides the sense one is not alone in his or her struggles and others share similar thoughts and experiences. This support can best be exemplified by the following quote from a student athlete with a physical disability:

[College] was the first time that I had ever been around a lot of other people in chairs and stuff, and so that made me like a lot more confident. It was like, "oh my God, I'm not the only one that," you know, paraplegics sometimes have, you know, might pee themselves. Like, it happens, it's part of being disabled and suddenly it was like, "oh my God, I'm not the only one that pissed myself, oh man, that makes me feel so much better. I mean it's embarrassing but man, it's a part of life and a big part of it just like learning to laugh about it. Like if, we were at a training camp last weekend and one night we were all sitting around and we were basically sharing stories about times we had pissed ourselves. Like, "oh well you think that's funny, I got a better one.” Like, “one time..." like, everyone's trying to like one up each other with these funny stories of like, inconvenient times to have an accident. It was pretty funny. But it's good that you can like laugh about it now because in high school I was the only one I knew who had that problem, and it was like, oh my God, so embarrassing (SAD5).

When considering the possible relationship between perceived social support and adjustment difficulties, several interesting trends emerged from the data. First, those individuals who experienced fewer adjustment difficulties reported sources of shared social reality support. This support served to help normalize their experiences and feel connected to their peers around 
them. Students who had experienced more difficulty adjusting to college did not report any sources of shared social reality support and in general perceived themselves as different from their peers. For example, one student who wanted to quit school two weeks before her interview made the following comments about her social adjustment to college life:

I was kind of like in the party dorm and I was a lot more geeky, study, and then like weird. So the people on my floor I just really didn't click with...I didn't really get along as far as like the other college students on campus. Like for a long time on campus I was like where are the other intellectuals, there's like somebody else that must realize how stupid a lot of these students are being (SND4).

Research conducted with students with and without disabilities suggested that perceived social support from friends has a more significant impact on college student's anxiety levels than social support from family (Winterowd, Street, \& Boswell, 1998). Interestingly, the student who provided the previous quotation reported family support as her dominate social resource and that she experienced significant difficulty with anxiety. Shared social reality support among peers may influence adjustment to college indirectly by buffering the experience of anxiety associated with college adjustment. Students with adjustment difficulties also tended to report off-campus social resources as their most supportive resources. Therefore, interview results support previous research (Brissette, Scheier, \& Carver) that suggests the importance of integration into the social community of a university and identification of a satisfying peer group influence college adjustment (Brissette, Scheier, \& Carver, 2002).

Data collected from one student interview revealed the importance of perceived social support versus received social support. This student expressed his belief that he had no available 
social support resources as expressed in his response to the researcher's inquiry about the people who supported him:

I'm going to say probably just my girlfriend. She listens to me to an extent, but she's stressed out on her own level...I really don't have anyone that helps me destress, I guess. Really, I just have to deal with it on my own. My parents are too busy, you know, worrying about my brother and sister. That's it though. I mean, I don't feel there is anyone I can talk to, that I can go to and feel like I could just blow off some steam, but not have them judge me at the same time (SD2).

Within his interview the student expresses the presence of several possible sources of social support, but as exemplified earlier, he just did not perceive them as supportive. What made this phenomenon even more interesting was that this individual, by far, perceived the most challenges in his average week, reported no factors that aided in management of his stress, yet listed the most factors that contributed to his stress level. In addition, when asked to recount a time that he had reached the end of his rope and thought he might not be able to continue, he responded with: "Which times?" Multiple instances were provided for times he felt he was treated unfairly and reported significant adjustment problems his freshman year of college. Past research has suggested that perceived social support protects individuals from the pathogenic effects of high levels of stress (Cohen \& Hoberman, 1983), and this theme was certainly reflected in the interview data.

Influence of sport participation. Several themes emerged from the data when exploring the influence that athletic participation had on the college experience for the student athletes with physical disabilities. First, athletic participation served as a structure for managing the student 
athlete's time. "Participating in athletics does give me some type of structure," which then, "helped a bit with the time management and all that (SAD2)."

Second, athletics provided the student athletes with motivation to maintain their grades and stay in college. "I have to stay on top of it [school work] if I want to keep playing and stuff. I don't want to end up riding the bench because I let some things fall through the cracks (SAD5)." For another student athlete, sport "makes you want to work at your grades (SAD4)" and a freshmen athlete felt that if he didn't have sports "[he] would have flunked out by now (SAD2)."

A related emergent theme from the data revolved around sport providing motivation to be in college and working toward a degree. For a freshman male, basketball "gives me a reason to be here, and to want to stay here (SAD1)." For another freshman male:

If I didn't participate in athletics, I'm not even sure that I would be in college. I want more than anything really to get a college degree and be successful...I love my sport that I play, and it just gives me the motivation to kind of succeed in academics and get that degree (SAD4).

This theme highlights the concept of institutional attachment and goal commitment that has been found to positively influence college adjustment and persistence to graduation (Baker \& Siryk, 1984; Pascarella \& Chapman, 1983; Wessell Engle, \& Smidchens, 1978). Sport participation is serving as a catalyst to incorporate the student athletes into the college environment and support their commitment to completing a degree at that university.

Sport also served to create situations that allowed the athlete's to build confidence in themselves and abilities. For one student athlete, participation in sport fostered a competitive edge: "Being an athlete...gives me that competitive drive in myself...I don't want to be beaten...so I try that much harder not to be defeated and overcome... I just want to excel and just 
be successful in everything I can do (SAD4)." For another athlete who acquired his physical disability during his junior year of college, sport served as a source of self-efficacy: "I am probably going to play athletics for the rest of my life. Just because it is somewhat of a therapy for me. It makes me feel like a normal person and that I am able to do things (SAD1)." Sport participation also provides a source for positive identity development and belonging as reflected by this freshmen student athlete: "if I wasn't in athletics, I would probably be somewhere in Alabama, and just another guy on campus...this team is recognized on campus...I'll roll by with a wheelchair basketball shirt on and people will say, 'hey, we heard about you' (SAD3).” These results support previous research that was conducted with retired athletes with disabilities, suggesting sport was a vital opportunity to experience and develop personal competence, a way of combating marginalization, and provided an outlet that aided in social integration (Wheeler et al., 1996).

A fourth emergent theme from the data was sport's role in providing experiences that would not otherwise be possible. Two of the student athletes interviewed participated in the 2004 Summer Paralympic Games in Athens, Greece. For one athlete, being on the Paralympic team "was just the most incredible thing I've ever been a part of (SAD4)." The opportunity for travel has provided each of the athletes with an outlet to meet other people and visit places they might not otherwise.

I've been to Argentina and Greece through the national team...I have friends from all over the country... any state I probably have somebody that I know that's from there...I've meet so many cool people and have connections pretty much anywhere I go (SAD5). 
A last emergent theme found related to sport participation was the existence of a readymade social network, as exemplified by a senior student athlete:

It's kind of like your friends are set out for you. You travel with them; you're around them so much. There's a group of twelve people I know so much about and that I'm so close to and it just, like they're family. I know if I ever need anything I can go to my teammates or my coach (SAD5).

All in all, the present qualitative data supports emergent themes from a previous qualitative study examining sport participation among students with physical disabilities (Blinde \& Taub, 1999). Like participants in the Blinde and Taub study, the current student athletes saw sport as an opportunity to: connect and bond with others; increase social skills; broaden social experiences; facilitate self-confidence and a strong belief in self; increase awareness of one's potential, perceptions of independence, control over one's life, and sense of accomplishment; and foster the achievement of goals in and out of sport.

\section{Summary of Qualitative Results}

Interview data supported Medalie's (1981) Mini-Life Cycles as a salient theoretical framework for understanding adjustment in both students utilizing wheelchairs and nondisability student populations. Student's experiences reflected the life tasks that Medalie described for each of the traditional years of the college experience. In addition, interview data supported the importance of the divestment/investment life task (Medalie, 1981; Tinto, 1993) and its potential to carry beyond the student's first year.

When examining differences between student groups, student athletes with physical disabilities reported fewer adjustment difficulties, reported fewer challenges within their week, and perceived more resources for managing stress to the other two student groups. No 
differences were found between the student groups in relation to coping styles or perceived social support. Some evidence did emerge from the data that might suggest student athletes with physical disabilities possessed a higher self-efficacy for managing stress than the other two student groups. Overall, interview data supported participation in athletics as a potential source of self-efficacy, social connectedness, and achievement motivation for student with physical disabilities.

Data related to differences between students who experienced fewer adjustment difficulties and those that experienced more resulted in a several interesting trends. Generally, students reporting more adjustment difficulties also perceived more challenges within the week, fewer factors that lent to stress management, and more factors that added to the experience of stress. In regards to coping style, a more active coping style and the use of reframing techniques were associated with fewer adjustment difficulties. In addition, the perception of shared social reality support was an emergent theme for students with fewer adjustment difficulties.

\section{Overall Conclusions}

\section{The Influence of Disability Status}

One major conclusion of this study was the consistent finding that physical disability status had no effect upon the variables explored in this study. Neither survey nor interview results supported any differences between students with physical disabilities and students without disabilities on the study variables. Therefore, results suggest that discrepancies in college adjustment are not a result of differences in disability status, but are the result of differences in adjustment, perceived social support, self-efficacy, and coping style.

An important note of caution must be addressed in relation to the previous results. All of the institutions sampled in this study have well developed disability services organizations and 
resources on campus for students with disabilities. These institutions are considered some of the most accessible for students with physical disabilities in the country. This may suggest that when accessibility issues are addressed within the postsecondary environment, students with physical disabilities, wheelchair user in particular, are just as capable of successfully adjusting to college and completing their degree. Therefore, environmental barriers may represent the most significant issue when examining college adjustment for students with physical disabilities as opposed to inherent differences in developmental or psychosocial factors.

\section{Influence of Athletic Participation}

Interview results suggested participation in athletics for students with physical disabilities provided several incentives, such as academic motivation, structure, and campus integration that could lend to adjustment. Most student athletes interviewed experienced few adjustment difficulties. Data suggested those who adjusted well to college life did so because of higher selfefficacy for stress management and active coping styles. Self-efficacy had the highest correlations with the adjustment variables and well as the strongest positive correlation with task coping. The opportunities provided in sport participation may assist in the development of selfefficacy, thus indirectly affecting a student's adjustment to college.

\section{The Process of College Adjustment}

Interview results provided support for the changing needs of students as they progress through their college experience. In addition, the importance of resolving the divestment/investment life task was substantiated by interview results. Based on interview results, academic performance is a poor indicator of adjustment difficulties. Those students who display lower self-advocacy skills, fewer active coping behaviors, and more reliance on offcampus and home-oriented social support resources may be most at risk for withdrawal. Even if 
students persist beyond their first year, possible withdrawal still exists until the investment/divestment life task is resolved.

The psychosocial variables explored in this study may influence college adjustment both directly and indirectly through their contribution to stress management. A link between the Transactional Model of Stress (Lazarus \& Folkman, 1984) and adjustment was suggested in the interview data. Quantitative analysis provided additional support for the role stress management may play in adjustment. The level of mental well being, the adjustment variable most likely to reflect the influence of stress, displayed the strongest correlations with the other adjustment variables. Therefore, the TMS could serve as an operational framework for understanding the contribution personal and environmental variables play in the adjustment process in college samples with and without physical disabilities.

\section{Coping and Adjustment}

Past coping research has identified two major functions of coping: problem-focused or active responses and emotion-focused or passive responses (Endler \& Parker, 1994; Lazarus \& Folkman, 1984). While active coping focuses on altering the person-environment relationships, passive coping's aim is to manage emotional distress. Therefore, the result has been to categorize coping behaviors as either active or passive. However, interview data suggested that some coping behaviors (i.e. seeking social support and denial coping) maybe be "mixed" in their contribution toward active or passive coping. For instance, within the interview data the subtheme of seeking social support contributed to both active and passive coping themes. As discussed earlier, the contribution seeking social support has on coping outcomes may occur through its effect on the re-appraisal of a situation. Therefore, seeking social support would not have a direct effect upon coping outcomes, but an indirect one. 
Quantitative results provided further evidence for social support's indirect link to coping outcomes. The CISS - Avoidance scale, which contains behaviors such as seeking social support, did not correlate with any of the adjustment variables. This suggests no direct relationship between avoidance coping and adjustment, a coping outcome. However, total social support did have a low to moderate positive correlation with general self-efficacy. In fact, the correlation between general self-efficacy and social support was due to a single correlation with only one specific social support sub-scale, self-esteem support. Cobb (1976) has argued that esteem support might encourage a person to go out and master a problem or confront a challenge. In this case, the support is serving to increase the individual's feelings of self-efficacy or self-worth, which might positively alter one's appraisal of a situation.

In addition, interview data supported coping style as more of a personality trait that should be viewed along a one-dimensional continuum. Even students who displayed more of a tendency toward active coping reported some passive coping. As well, those students displaying more of a tendency towards passive coping reported some active coping behaviors. Therefore, individuals most likely rest some where along the continuum between all active coping and all passive coping, not just in one group or another. Potentially the closer an individual lies to an extreme end of the scale, the more dominant those associated behaviors will be and the less flexibility one will have in the management of stressful situations.

\section{Limitations}

Concurrent triangulation design can result in well-validated and substantiated findings (Creswell et al., 2003). However, limitations existed that must be taken into account when considering the results. By utilizing convenient sampling in the quantitative component and purposive sampling in the qualitative component, generalizability is compromised and results 
should be considered within the context of the study. Also, the way that students were matched for the sub-analysis, gender effects were accounted for between students with and without physical disabilities. However, discrepancy in the number of males and females in each of the physical disability sub-groups may have caused a gender effect when considering the influence of athletic participation within the physical disability sample.

An effort was made by the researcher to control for the possibility that students had other disabilities within the "non-disability" sample. However, the way in which disability was controlled for would not have detected for the presence of co-morbid mental health conditions within the samples of students with physical disabilities. In addition, undiagnosed or unreported mental health conditions, such as depression and anxiety, in both the disability and non-disability samples could have affected the results. According to past research, depression and anxiety can adversely effect students' adjustment to college (Gerdes \& Mallinckrodt, 1994).

Another limitation of this study was the less than ideal psychometric properties of the adjustment and self-efficacy instruments. As mentioned earlier, the lower Cronbach alpha levels of the adjustment scale resulted in analysis of each individual adjustment question. There are inherent difficulties in utilizing a scale based in a single item. In addition, the self-efficacy instrument utilized in the study did not prove to be reliable in this sample of students. Only the general subscale was utilized as it did show acceptable reliability within the sample. These measurement difficulties dictate that quantitative results should be viewed with caution.

\section{Future Research Directions}

First, investigators could focus on the development of a reliable and valid adjustment instrument that could be effectively utilized with more than a freshmen population. Potential differences between older and younger students may be explored and the relationship with 
different psychosocial variables can be established. Second, additional research should be done investigating the link between the Transactional Model of Stress and adjustment to college. Identification of other personal and environment variables that may influence college adjustment should be explored. Third, additional research should be conducted to compare the influence of sport participation with other extracurricular activities to investigate what unique contributions sport participation may make to the development of students with physical disabilities. The research line could also be extended to include other disability student populations. Fourth, researchers might consider further investigation into different coping behaviors, such as social support, and its "mixed" relationship to coping outcomes. Utilization of the TMS, may serve as a productive operational framework. For instance, perceived social support may directly influence coping efforts through its contribution to perceived resources. However, the actually seeking of social support may serve to influence coping outcomes indirectly through its influence on constructs like self-efficacy. Lastly, researchers should continue to explore the role that environmental barriers may play in the determination for college outcomes for students with disabilities. More accessible institutions, such as the ones included in this study, may lead to different outcomes compared to those who are not as accessible. Intervention studies that focus on increasing accessibility to students with physical disabilities might assist in determining the influence environmental barriers have on college student adjustment. 


\section{References}

Baker, R. \& Siryk, B. (1984). Measuring adjustment to college. Journal of Counseling Psychology, 31, 179-189.

Bandura, A. (1977). Self-efficacy: Toward a unified theory of behavior change. Psychological Review, 94, 191-215.

Barrera, M. (1981). Social Support in the adjustment of pregnant adolescents: Assessment issues. In B. Gottlieb (Ed.), Social networks and social support. Beverly Hills: Sage Publications.

Barrera, M., Sandler, I., \& Ramsay, T. (1980). Preliminary development of a scale of social support: Studies on college students. American Journal of Community Psychology, 9, 435-447.

Bianco, T., \& Eklund, R. (2001). Conceptual considerations for social support research in sport and exercise settings. Journal of Sport and Exercise Psychology, 23, 85-108.

Blake, T. (2002). Self-esteem and self-efficacy of college students with disabilities. College Student Journal, 36, 214-221.

Blinde, E. \& Taub, D. (1999). Personal empowerment through sport and physical fitness activity: Perspectives from male college students with physical and sensory disabilities. Journal of Sport Behavior, 22, 181-203.

Brissette, I., Scheier, M., \& Carver, C. (2002). The role of optimism in social network development, coping, and psychological adjustment to life transition. Journal of Personality and Social Psychology, 82, 102-111.

Brookings, J. \& Bolton, B. (1988). Confirmatory factor analysis of the Interpersonal Support Evaluation List. American Journal of Community Psychology, 16, 137-147. 
Cairns, D. \& Baker, J. (1993). Adjustment to spinal cord injury: A review of coping styles contributing to the process. Journal of Rehabilitation, 30- 33.

Choi, N. (2003). Further examination of the Self-Efficacy Scale. Psychological Reports, 92, 473480.

Cobb, S. (1976). Social support as a moderator of life stress. Psychosomatic Medicine, 38, 300314.

Cohen, S. (1988). Psychosocial models of the role of social support in the etiology of physical disease. Health Psychology, 7, 269-297.

Cohen, S., \& Hoberman, H. (1983). Positive events and social supports as buffers of life change stress. Journal of Applied Social Psychology, 13, 99-125.

Compas, B. (1987). Stress and coping during childhood and adolescence. Psychological Bulletin, 101, 393-403.

Creswell, J., Plano Clark, V., Gutmann, M., \& Hanson, W. (2003). Advanced mixed methods research designs. In A. Tashakkori \& C. Teddlie (Eds.), Handbook of mixed methods in social and behavioral research (pp. 189-208). Thousand Oaks, CA: Sage Publications.

Elliot, T. \& Gramling, S. (1990). Personal assertiveness and the effects of social support among college students. Journal of Counseling Psychology, 37, 427-436.

Elliott, T., Herrick, S., \& Witty, T. (1992). Problem-solving appraisal and the effects of social support among college students and persons with physical disabilities. Journal of Counseling Psychology, 39, 219-226.

Endler, N. \& Parker, J. (1990). Multidemensional assessment of coping: A critical evaluation. Journal of Personality and Social Psychology, 58, 844-854.

Endler, N. \& Parker, J. (1994). Assessment of multidimensional coping: Task, emotional, and 
avoidance strategies. Psychological Assessment, 6, 50-60.

Endler, N. \& Parker, J. (1999). CISS: Coping Inventory for Stressful Situations manual (2 $2^{\text {nd }}$ ed.). New York: Multi-Health Systems.

Frazier, P. \& Schauben, L. (1994). Stressful life events and psychological adjustment among female college students. Measurement \& Evaluation in Counseling \& Development, 27, 280-292.

Gerdes, H. \& Mallinckrodt, B. (1994). Emotional, social, and academic adjustment of college students: A longitudinal study of retention. Journal of Counseling \& Development, 72, 281-288.

Hampton, N. (2004). Subject well-being among people with spinal cord injuries: The role of selfefficacy, perceived social support, and perceived health. Rehabilitation Counseling Bulletin, 41, 31-37.

Hays, R. \& Oxley, D. (1986). Social network development and functioning during a life transition. Journal of Personality and Social Psychology, 50, 305-313.

Henderson, C. (2001). 2001 College freshmen with disabilities: A biennial statistical profile (Cooperative Agreement No. H326H980002). Washington. DC: HEATH Center of American Council on Education.

Hunter, J. \& Schmidt, F. (1990). Methods of meta-analysis: Correcting error and bias in research findings. Newbury Park, CA: Sage Publications.

Lakey, B., \& Cassady, P. (1990). Cognitive processes in perceived social support. Journal of Personality and Social Psychology, 59, 337-343.

Lazarus, R., \& Folkman, S. (1984). Stress, appraisal, and coping. New York : Springer Pub. Co.

Livneh, H., \& Wilson, L. (2003). Coping strategies as predictors and mediators of disability- 
related variables and psychosocial adaptation: An exploratory investigation. Rehabilitation Counseling Bulletin, 46, 194-208.

Leong, F. \& Bonz, M. (1997). Coping styles as predictors of college adjustment among freshmen. Counseling Psychology Quarterly, 10, 211-221.

Lu, L., \& Argyle, M. (1992). Receiving and giving support: Effects on relationship and wellbeing. Counseling Psychology Quarterly, 5, 123-134.

Mallinckrodt, B. (1988). Student retention, social support, and dropout intention: Comparison of black and white students. Journal of College Student Development, 29, 60-64.

Martin, J., \& Mushett, C. (1996). Social support mechanisms among athletes with disabilities. Adapted Physical Activity Quarterly, 13, 74-84.

McKemy, M. (1996). Resilience in college students with physical disabilities. Unpublished dissertation.

Medalie, J. (1981). The college years as a mini-life cycle: Developmental tasks and adaptive options. JACHA, 30, 75-79.

National Council on Disability. (2003, September). People with disabilities and postsecondary education. Retrieved September 30, 2003 from http://www,ncd.gov/newsroom/pubications/education.html.

Owens, S. (1999). Stress and coping in college seniors: Using a graduation transition workshop to facilitate adaptation to life change. Dissertation Abstracts International, 59 (8-B), 4479.

Pappas, J. \& Loring, R. (1985). Returning learner. In Lnoel, R Levitz, \& D. Saluri (Eds.), Increasing student retention: Effective programs and practices for reducing the dropout rate (pp. 138-161). San Francisco, CA: Jossey-Bass. 
Pascarella, E. \& Chapman, D. (1983). A multiinstitutional, path analytic validation of Tinto's model of college withdraw. American Educational Research Journal, 20, 87-102.

Pascarella, E. \& Terenzini, P. (1991). How college affects students. San Francisco, CA: JosseyBass.

Patton, M. (2002). Qualitative research and evaluation methods ( $3^{\text {rd }}$ ed.). Thousand Oaks, CA: Sage Publications.

Pensgaard, A., Roberts, G., \& Ursin, H. (1999). Motivational factors and coping strategies of Norwegian paralympic and Olympic winter sport athletes. Adapted Physical Activity Quarterly, 16, 238-250.

Pines, A., Aroson, E., \& Kafry, D. (1981). Burnout from tedium to personal growth. New York: Free Press.

Robbins, S., Lauver, K., Le, H., Davis, D., Langley, R., \& Carlstrom, A. (2004). Do psychosocial and study skill factors predict college outcomes? A meta-analysis. Psychological Bulletin, $130,261-288$.

Sanders, K. \& DuBois, D. (1996). Individual and socio-environmental predictors of adjustment to college among students with disabilities. Journal of Postsecondary Education and Disability, 12, 28-42.

Saracoglu, B., Minden, H., \& Wilchesky, M. (1989). The adjustment of students with learning disabilities to university and its relationship to self-esteem and self-efficacy. Journal of Learning Disabilities, 22, 590-592.

Schlossberg, N., Waters, E., \& Goodman, J. (1995). Counseling adults in transition: Linking practice with theory $\left(2^{\text {nd }}\right.$ ed.). New York: Springer Publishing Co.

Sherer, M. \& Adams, C. (1983). Construct validation of the Self-Efficacy Scale. Psychological 
Reports, 53, 899-902.

Sherer, M., Maddux, J., Mercandante, B., Prentice-Dunn, S., Jacobs, B., \& Rogers, R. (1982). The Self-Efficacy Scale: Construction and validation. Psychological Reports, 51, 663671.

Skowron, E., Wester, S., \& Azen, R. (2004). Differentiation of self mediates college stress and adjustment. Journal of Counseling \& Development, 82, 69-82.

Smith, J., Ray, R., Wetcher, J., \& Mahail, T. (1998). Levels of fusion, triangulation, and adjustment in families of college students with physical and cognitive disabilities. American Journal of Family Therapy, 26, 29-38.

Thomas, J., Lochbaum, M., Landers, D., \& He, C. (1997). Planning significant and meaningful research in exercise science: Estimating sample size. Research Quarterly for Exercise and Sport, 68, 33-43.

Tinto, V. (1987). Leaving college. Chicago, IL: University of Chicago Press.

Tinto, V. (1988). Stages of student departure: Reflections on the longitudinal character of setudent leaving. The Journal of Higher Education, 59, 438-455.

Tinto, V. (1993). Leaving College: Rethinking the causes and cures of student attrition. Chicago, IL: University of Chicago Press.

Wessell, T., Engel, k., \& Smidchens, V. (1978). Reducing attrition on the college campus, NASPA Journal, 16, 26-32.

Wheeler, G., Malone, L., Van Vlack, S., Nelson, E., \& Steadward, R. (1996). Retirement from disability sport: A pilot study. Adapted Physical Activity Quarterly, 13, 382-399.

Wheeler, G., Steadward, R., Legg, D., Hutzler, Y., Campbell, E., \& Johnson, A. (1999). Personal investment in disability sport careers: An international study. Adaptive Physical Activity 
Quarterly, 16, 219-237.

Wolpe, J. (1958). Psychotherapy by reciprocal inhibition. Stanford, CA: Stanford University Press.

Wolpe, J. \& Lazarus, A. (1966). Behavior therapy techniques. New York: Pargamon Press. 
Table 1

Demographic Characteristics of Total Student Population

\begin{tabular}{|c|c|c|c|c|c|c|c|c|}
\hline & & & \multicolumn{2}{|c|}{ Non-Athletes } & \multicolumn{2}{|c|}{ Athletes } & \multicolumn{2}{|c|}{ Non-Athletes } \\
\hline & \multicolumn{2}{|c|}{ Athletes with } & \multicolumn{2}{|c|}{ with } & \multicolumn{2}{|c|}{ without } & \multicolumn{2}{|c|}{ without } \\
\hline & \multicolumn{2}{|c|}{ Disabilities } & \multicolumn{2}{|c|}{ Disabilities } & \multicolumn{2}{|c|}{ Disabilities } & \multicolumn{2}{|c|}{ Disabilities } \\
\hline & \multicolumn{2}{|c|}{$(\mathrm{n}=31)$} & \multicolumn{2}{|c|}{$(n=20)$} & \multicolumn{2}{|c|}{$(n=22)$} & \multicolumn{2}{|c|}{$(n=76)$} \\
\hline Male & 23 & $(74.2 \%)$ & 7 & $(35 \%)$ & 9 & $(40.9 \%)$ & 26 & $(34.2 \%)$ \\
\hline Female & 8 & $(25.8 \%)$ & 13 & $(65 \%)$ & 13 & $(59.1 \%)$ & 50 & $(65.8 \%)$ \\
\hline \multicolumn{9}{|l|}{ University Size } \\
\hline 8,000 students & 8 & $(25.8 \%)$ & 7 & $(35 \%)$ & 8 & $(36.4 \%)$ & 22 & $(28.9 \%)$ \\
\hline 11,000 students & 6 & $(19.4 \%)$ & 9 & $(45 \%)$ & 11 & $(50.0 \%)$ & 31 & $(40.8 \%)$ \\
\hline 40,000 students & 17 & $(54.8 \%)$ & 4 & $(20 \%)$ & 3 & $(13.6 \%)$ & 26 & $(34.2 \%)$ \\
\hline \multicolumn{9}{|l|}{ Year in school } \\
\hline Freshmen & 5 & $(16.1 \%)$ & 3 & $(15 \%)$ & 11 & $(50.0 \%)$ & 27 & $(35.5 \%)$ \\
\hline Sophomore & 5 & $(16.1 \%)$ & 8 & $(40 \%)$ & 6 & $(27.3 \%)$ & 13 & $(17.1 \%)$ \\
\hline Junior & 9 & $(29.0 \%)$ & 2 & $(10 \%)$ & 3 & $(13.6 \%)$ & 9 & $(11.8 \%)$ \\
\hline Senior & 9 & $(29.0 \%)$ & 3 & $(15 \%)$ & 2 & $(9.1 \%)$ & 19 & $(25.0 \%)$ \\
\hline Graduate Student & 3 & $(9.7 \%)$ & 4 & $(20 \%)$ & 0 & & 8 & $(10.5 \%)$ \\
\hline Mean Age & 21.4 & & 24.5 & & 19.4 & & 21.5 & \\
\hline \multicolumn{9}{|l|}{$\%$ time in wheelchair } \\
\hline Up to $50 \%$ & 9 & $(29 \%)$ & 7 & $(35 \%)$ & & & & \\
\hline $51 \%$ to $100 \%$ & 22 & $(71 \%)$ & 13 & $(65 \%)$ & & & & \\
\hline
\end{tabular}


Table 2

Descriptive Statistics of Dependent Variables for Total Student Population

\begin{tabular}{|c|c|c|c|c|c|c|c|c|}
\hline & & & \multicolumn{2}{|c|}{ Non-Athletes } & \multicolumn{2}{|c|}{ Athletes } & \multicolumn{2}{|c|}{ Non-Athletes } \\
\hline & \multicolumn{2}{|c|}{ Athletes with } & \multicolumn{2}{|c|}{ with } & \multicolumn{2}{|c|}{ without } & \multicolumn{2}{|c|}{ without } \\
\hline & \multicolumn{2}{|c|}{ Disabilities } & \multicolumn{2}{|c|}{ Disabilities } & \multicolumn{2}{|c|}{ Disabilities } & \multicolumn{2}{|c|}{ Disabilities } \\
\hline & \multicolumn{2}{|c|}{$(\mathrm{n}=31)$} & \multicolumn{2}{|c|}{$(n=20)$} & \multicolumn{2}{|c|}{$(n=22)$} & \multicolumn{2}{|c|}{$(n=76)$} \\
\hline & Mean & $S D$ & Mean & $S D$ & Mean & $S D$ & Mean & $S D$ \\
\hline Academic adjustment & 7.29 & 1.46 & 8.00 & 1.97 & 7.73 & 1.96 & 7.76 & 1.52 \\
\hline Social adjustment & 7.71 & 1.74 & 7.25 & 1.65 & 8.09 & 1.48 & 7.03 & 2.09 \\
\hline Mental well-being & 8.26 & 1.39 & 7.95 & 1.60 & 7.82 & 1.84 & 7.79 & 1.93 \\
\hline Physical health & 8.00 & 1.71 & 7.50 & 1.67 & 8.23 & 1.27 & 7.37 & 1.75 \\
\hline Goal commitment & 9.39 & 1.14 & 9.75 & 0.44 & 9.32 & 1.29 & 8.75 & 1.99 \\
\hline General self-efficacy & 54.55 & 7.91 & 55.10 & 10.18 & 61.00 & 7.78 & 57.41 & 8.67 \\
\hline Task coping & 58.10 & 8.83 & 58.85 & 8.71 & 59.18 & 10.15 & 56.67 & 8.84 \\
\hline Emotion coping & 43.94 & 10.25 & 41.95 & 11.18 & 44.50 & 9.43 & 44.24 & 10.19 \\
\hline Avoidance coping & 50.42 & 9.53 & 52.15 & 8.42 & 50.23 & 10.69 & 47.43 & 9.91 \\
\hline Total perceived social & 103.65 & 16.88 & 92.75 & 27.08 & 101.09 & 20.10 & 99.61 & 22.57 \\
\hline suppor & & & & & & & & \\
\hline
\end{tabular}


Table 3

Descriptive statistics of dependent variables for samples included in subanalysis

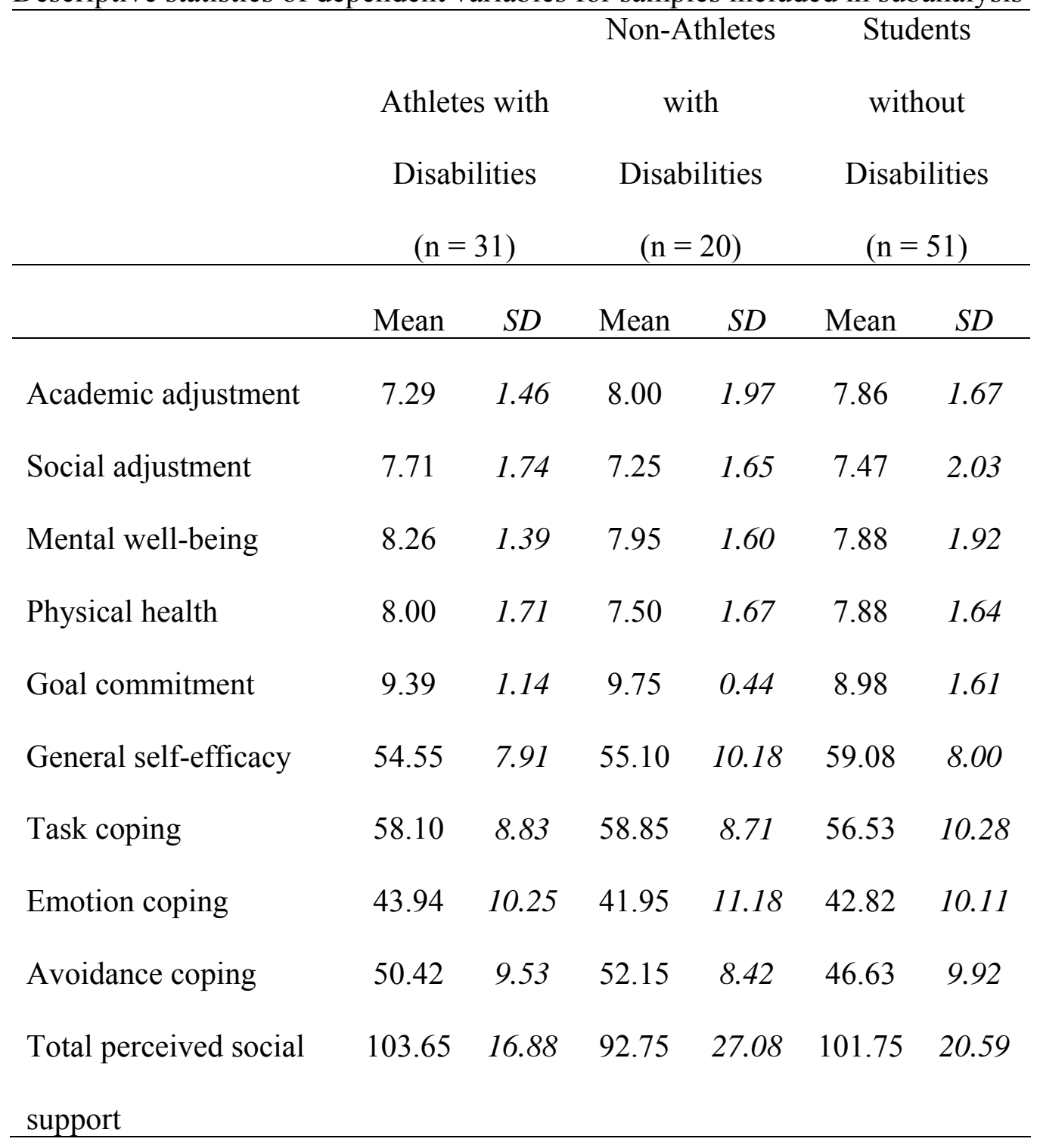


Table 4

Correlation Matrix of Study Variables

\begin{tabular}{llllllllll}
1 & 2 & 3 & 4 & 5 & 6 & 7 & 8 & 9 & 10 \\
\hline
\end{tabular}

1. Level of academic adjustment .112

2. Level of social adjustment $.273 * * \quad .470^{* *} \quad-$

3. Level of mental well-being

$.281 * * \quad .329 * * \quad .401 * *$

4. Level of physical health

$\begin{array}{llll}.006 & .404 * * & .280 * * & -.013\end{array}$

5. Level of goal commitment

$\begin{array}{lllll}.408 * * & .353 * * & .525 * * & .353 * * & .069\end{array}$

6. General self-efficacy

$.283^{* *} \quad .14$

$.312 * * \quad .228$

7. CISS - Task coping

$\begin{array}{lllllll}-.124 & -.278 * * & -.455^{* *} & -.314 * * & -.066 & -.429 * * & .010\end{array}$

8. CISS - Emotional Coping

.069

102

9. CISS - Avoidance

.098

$.330 * * \quad .257 * * \quad .174$

$-.022$

$-.081$

.123

.064

$-.135 \quad-.013$

10. ISEL - Total social support 
Table 5

Demographic Characteristic of Interview Sample

Student Athletes with Disabilities

$\begin{array}{lll}\text { SAD1 } & \text { Male } & \text { Graduate Student } \\ \text { SAD2 } & \text { Male } & \text { Freshmen } \\ \text { SAD3 } & \text { Male } & \text { Freshmen } \\ \text { SAD4 } & \text { Male } & \text { Freshmen } \\ \text { SAD5 } & \text { Female } & \text { Senior }\end{array}$

Student Non-athletes with Disabilities

$\begin{array}{lll}\text { SD1 } & \text { Male } & \text { Freshmen } \\ \text { SD2 } & \text { Male } & \text { Sophomore } \\ \text { SD3 } & \text { Male } & \text { Senior } \\ \text { SD4 } & \text { Female } & \text { Freshmen } \\ \text { SD5 } & \text { Female } & \text { Junior }\end{array}$

Students without Disabilities

\begin{tabular}{lll} 
SND1 & Female & Freshmen \\
SND2 & Male & Senior \\
SND3 & Female & Senior \\
SND4 & Female & Sophomore \\
\hline
\end{tabular}




\section{Table 6}

Comparison of Emergent Themes Related to Reported Typical Weekly Activities

\begin{tabular}{|c|c|c|c|c|c|}
\hline \multicolumn{2}{|c|}{$\begin{array}{l}\text { Student Athletes with Disabilities }(N=5) \\
\text { Students } \\
\text { Reporting } \quad \text { Raw Data Themes }\end{array}$} & \multicolumn{2}{|c|}{$\begin{array}{l}\text { Student Non-Athletes with Disabilities (5) } \\
\text { Students }\end{array}$} & $\begin{array}{l}\text { Students } \\
\text { Reporting }\end{array}$ & $\begin{array}{l}\text { udent Without Disabilities (4) } \\
\text { Raw Data Themes }\end{array}$ \\
\hline 5 & $\begin{array}{l}\text { Activities that surrounding } \\
\text { classes/homework ( } 7)\end{array}$ & 5 & $\begin{array}{l}\text { Activities that surrounding } \\
\text { classes/homework (6) }\end{array}$ & 4 & $\begin{array}{l}\text { Activities that surrounding } \\
\text { classes/homework (6) }\end{array}$ \\
\hline 5 & $\begin{array}{l}\text { Socializing activities with } \\
\text { friends }(6)\end{array}$ & 2 & $\begin{array}{l}\text { Socializing activities with } \\
\text { friends }(2)\end{array}$ & 3 & Socializing activities with friends (5) \\
\hline 2 & $\begin{array}{l}\text { Social activities that involve drinking } \\
\text { alcohol (2) }\end{array}$ & & & 2 & $\begin{array}{l}\text { Social activities that involve drinking } \\
\text { alcohol (2) }\end{array}$ \\
\hline 4 & Activities related to eating (4) & 2 & Activities related to eating (2) & 2 & Activities related to eating (2) \\
\hline & & 2 & Activities related to work/job (2) & 3 & Activities related to work/job (4) \\
\hline & & 1 & Participation in an internship (1) & 1 & Participation in an internship (1) \\
\hline 5 & Organized sport activities (10) & & & 1 & Organized sport activities (2) \\
\hline & & 1 & Physical activity (1) & 1 & Physical activity (1) \\
\hline 1 & Sleep (1) & 2 & Sleep (2) & & \\
\hline 3 & $\begin{array}{l}\text { Activities such as watching TV or } \\
\text { playing video games that students } \\
\text { uses as distraction (3) }\end{array}$ & & & 1 & $\begin{array}{l}\text { Activities such as watching TV or } \\
\text { playing video games that students } \\
\text { uses as distraction (1) }\end{array}$ \\
\hline & & 5 & Campus organizations (13) & 2 & Campus organizations (5) \\
\hline & & 4 & $\begin{array}{l}\text { Activities related to leadership } \\
\text { positions in campus organization ( } 8)\end{array}$ & 1 & $\begin{array}{l}\text { Activities related to leadership } \\
\text { positions in campus organization (2) }\end{array}$ \\
\hline & & 1 & Physical therapy (1) & 1 & Personal activity not school related (1) \\
\hline
\end{tabular}


Table 7

Comparison of Emergent Themes Related to Perceived Challenges Within a Typical Week

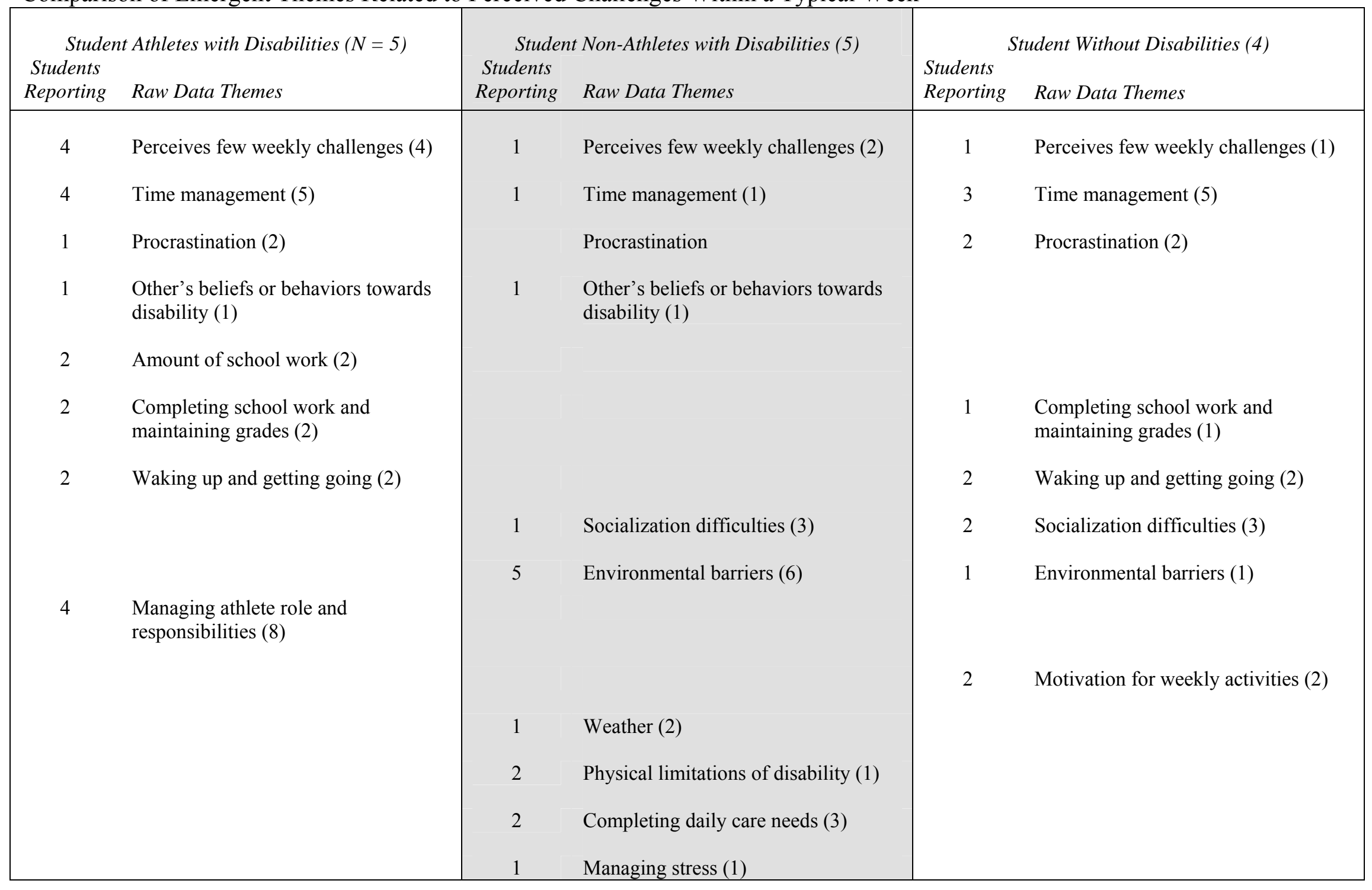


Table 8

Comparison of Emergent Themes Related to Perceived Resources for Managing Weekly Challenges

\begin{tabular}{|c|c|c|c|c|c|}
\hline \multicolumn{2}{|c|}{$\begin{array}{l}\quad \text { Student Athletes with Disabilities }(N=5) \\
\text { Students }\end{array}$} & \multicolumn{2}{|c|}{$\begin{array}{l}\text { Student Non-Athletes with Disabilities (5) } \\
\text { Students }\end{array}$} & $\begin{array}{l}\text { Students } \\
\text { Reporting }\end{array}$ & $\begin{array}{l}\text { Udent Without Disabilities (4) } \\
\text { Raw Data Themes }\end{array}$ \\
\hline 2 & Family (2) & 2 & Family (4) & 2 & Family (2) \\
\hline 1 & Friends (1) & 3 & Friends (5) & 4 & Friends (4) \\
\hline & & 1 & Significant other (1) & 1 & Significant other (1) \\
\hline 5 & Teammates $(5)$ & & & & \\
\hline 4 & Coaches (4) & & & & \\
\hline & & & & 2 & Professors (3) \\
\hline 2 & $\begin{array}{l}\text { Utilization of time management } \\
\text { techniques (i.e. planner, alarms) (2) }\end{array}$ & & & 2 & $\begin{array}{l}\text { Utilization of time management } \\
\text { techniques (i.e. planner, alarms) (2) }\end{array}$ \\
\hline & & 1 & Personal Qualities (1) & 1 & Personal Qualities (3) \\
\hline & & 2 & $\begin{array}{l}\text { On-campus resources (i.e. career } \\
\text { services, library) (2) }\end{array}$ & 1 & $\begin{array}{l}\text { On-campus resources (i.e. career } \\
\text { services, library) (1) }\end{array}$ \\
\hline 1 & Disability Services (2) & 4 & Disability Services (7) & & \\
\hline & & 3 & Personal Care Assistants (4) & & \\
\hline & & 3 & Transportation Services (3) & & \\
\hline & & 2 & Community resources off campus (2) & & \\
\hline
\end{tabular}


Table 9

Comparison of Emergent Themes Related to Factors Perceived to Create Stress

\begin{tabular}{|c|c|c|c|c|c|}
\hline \multicolumn{2}{|c|}{$\begin{array}{l}\text { Student Athletes with Disabilities }(N=5) \\
\text { Students }\end{array}$} & \multicolumn{2}{|c|}{$\begin{array}{l}\text { Student Non-Athletes with Disabilities (5) } \\
\text { Students }\end{array}$} & $\begin{array}{l}\text { Students } \\
\text { Reporting }\end{array}$ & $\begin{array}{l}\text { udent Without Disabilities (4) } \\
\text { Raw Data Themes }\end{array}$ \\
\hline & Internal Factors (5) & 1 & $\begin{array}{l}\text { Internal Factors (6) } \\
\text { Worrying (1) }\end{array}$ & 1 & $\begin{array}{l}\text { Internal Factors (10) } \\
\text { Worrying (1) }\end{array}$ \\
\hline 2 & Management of different life roles (2) & & & 1 & Management of different life roles (1) \\
\hline & & 1 & $\begin{array}{l}\text { Lack of confidence for managing } \\
\text { stress (1) }\end{array}$ & 1 & $\begin{array}{l}\text { Lack of confidence for managing } \\
\text { stress (1) }\end{array}$ \\
\hline 1 & $\begin{array}{l}\text { Holding self to a higher perceived } \\
\text { standard or setting high goals (1) }\end{array}$ & & & 1 & $\begin{array}{l}\text { Holding self to a higher perceived } \\
\text { standard or setting high goals (1) }\end{array}$ \\
\hline & & 2 & Perfectionism (2) & 2 & Perfectionism (2) \\
\hline 1 & $\begin{array}{l}\text { Fear or anxiety over not knowing } \\
\text { what to expect (1) }\end{array}$ & 1 & Slacking off (1) & 3 & Lack of ability to manage stress (3) \\
\hline 1 & Self-criticalness (1) & 1 & Procrastination (1) & 1 & $\begin{array}{l}\text { Perceived lack of time to complete } \\
\text { things (1) }\end{array}$ \\
\hline 3 & $\begin{array}{l}\text { External Factors (7) } \\
\text { Course work and homework (3) }\end{array}$ & 5 & $\begin{array}{l}\text { External Factors (20) } \\
\text { Course work and homework (5) }\end{array}$ & 3 & $\begin{array}{l}\text { External Factors (13) } \\
\text { Course work and homework (3) }\end{array}$ \\
\hline 1 & $\begin{array}{l}\text { Transitioning into new college } \\
\text { environment (1) }\end{array}$ & 1 & $\begin{array}{l}\text { Transitioning into new college } \\
\text { environment (1) }\end{array}$ & & \\
\hline 3 & Participation in sport (3) & 1 & Other people (1) & 2 & Other people (2) \\
\hline & & 1 & Campus Involvement (1) & 1 & Campus Involvement (1) \\
\hline & & 2 & $\begin{array}{l}\text { Environmental barriers/Accessibility } \\
\text { (4) }\end{array}$ & 1 & $\begin{array}{l}\text { Environmental barriers/Accessibility } \\
\text { (1) }\end{array}$ \\
\hline
\end{tabular}




\begin{tabular}{|l|c|l|l|l}
1 & Work (1) & \multicolumn{1}{l}{ Work (1) } \\
2 & Negative socialization experiences (5) \\
1 & $\begin{array}{l}\text { Physical limitation due to disability } \\
1\end{array}$ & Pending transition out of college (1) \\
1 & Loss of old support network (2) \\
1 & Evaluation of professors (1)
\end{tabular} \mid


Table 10

Comparison of Emergent Themes Related to Factors Perceived to Aid in Managing Stress

\begin{tabular}{|c|c|c|c|c|c|}
\hline \multicolumn{2}{|c|}{$\begin{array}{l}\text { Student Athletes with Disabilities }(N=5) \\
\text { Students } \\
\text { Reporting Raw Data Themes }\end{array}$} & \multicolumn{2}{|c|}{$\begin{array}{l}\text { Student Non-Athletes with Disabilities (5) } \\
\text { Students }\end{array}$} & $\begin{array}{l}\text { Students } \\
\text { Reporting } \\
\end{array}$ & $\begin{array}{l}\text { udent Without Disabilities (4) } \\
\text { Raw Data Themes }\end{array}$ \\
\hline $\begin{array}{l}2 \\
2\end{array}$ & $\begin{array}{l}\text { Internal Factors (10) } \\
\text { Takes a positive perspective (3) } \\
\text { Pro-active personality (3) }\end{array}$ & 1 & $\begin{array}{l}\text { Internal Factors (4) } \\
\text { Pro-active personality (1) }\end{array}$ & 1 & $\begin{array}{l}\text { Internal Factors (4) } \\
\text { Takes a positive perspective (1) }\end{array}$ \\
\hline 1 & Laid back attitude (1) & 1 & Laid back attitude (1) & & \\
\hline 1 & Prayer (1) & 1 & Perfectionist (1) & 1 & $\begin{array}{l}\text { Good time management techniques } \\
\text { (2) }\end{array}$ \\
\hline 1 & Balances work with play (1) & 1 & Physical activity (1) & 1 & Self-responsibility (1) \\
\hline 1 & $\begin{array}{l}\text { Enjoys engaging in new experiences } \\
\text { (1) }\end{array}$ & & & & \\
\hline 4 & $\begin{array}{l}\text { External Factors (6) } \\
\text { Other people (4) }\end{array}$ & 3 & $\begin{array}{l}\text { External Factors (4) } \\
\text { Other people (3) }\end{array}$ & 2 & $\begin{array}{l}\text { External Factors (4) } \\
\text { Other people (2) }\end{array}$ \\
\hline 2 & Participation in sport (2) & 1 & Being able to drive (1) & 1 & $\begin{array}{l}\text { Campus location (1) } \\
\text { Parents' Expectation (1) }\end{array}$ \\
\hline
\end{tabular}


Table 11

Comparison of Emergent Themes Related to Perceived Social Support

\begin{tabular}{|c|c|c|c|c|c|}
\hline \multicolumn{2}{|c|}{$\begin{array}{l}\text { Student Athletes with Disabilities }(N=5) \\
\text { Students }\end{array}$} & \multicolumn{2}{|c|}{$\begin{array}{l}\text { Student Non-Athletes with Disabilities (5) } \\
\text { Students }\end{array}$} & \multicolumn{2}{|c|}{ Student Without Disabilities (4) } \\
\hline 5 & $\begin{array}{l}\text { Parent(s) } \\
\text { Tangible support (7) } \\
\text { Emotional support (1) } \\
\text { Listening (2) } \\
\text { Esteem support (1) } \\
\text { Belonging support (2) }\end{array}$ & 4 & $\begin{array}{l}\text { Parent(s) } \\
\text { Tangible support (3) } \\
\text { Emotional support (2) } \\
\text { Listening (2) } \\
\text { Esteem support (1) } \\
\text { Appraisal/advice support (3) } \\
\text { Belonging support (3) } \\
\text { Challenge (3) }\end{array}$ & 4 & $\begin{array}{l}\text { Parent(s) } \\
\text { Tangible support (2) } \\
\text { Emotional support (1) } \\
\text { Listening (1) } \\
\text { Esteem support (1) } \\
\text { Shared social reality support (1) } \\
\text { Belonging support (3) } \\
\text { Provides distraction/fun (2) }\end{array}$ \\
\hline 2 & $\begin{array}{l}\text { Friends } \\
\text { Emotional support (3) } \\
\text { Listening (2) } \\
\text { Appraisal/advice support (1) } \\
\text { Belong support (3) } \\
\text { Provides distraction/fun (2) }\end{array}$ & 4 & $\begin{array}{l}\text { Friends } \\
\text { Tangible support (2) } \\
\text { Emotional support (1) } \\
\text { Listening (3) } \\
\text { Esteem support (4) } \\
\text { Appraisal/advice support (1) } \\
\text { Shared social reality support (3) } \\
\text { Belonging support (5) } \\
\text { Provides distraction/fun (4) } \\
\text { Challenge (1) }\end{array}$ & 4 & $\begin{array}{l}\text { Friends } \\
\text { Emotional support (1) } \\
\text { Listening (2) } \\
\text { Esteem support (1) } \\
\text { Appraisal/advice support (5) } \\
\text { Shared social reality support (2) } \\
\text { Belonging support (5) } \\
\text { Provides distraction/fun (6) }\end{array}$ \\
\hline 2 & $\begin{array}{l}\text { Siblings } \\
\text { Appraisal/advice support (3) } \\
\text { Shared social reality support (1) } \\
\text { Belonging support (1) } \\
\text { Provides distraction/fun (1) }\end{array}$ & 1 & $\begin{array}{l}\text { Siblings } \\
\text { Emotional support (1) } \\
\text { Esteem support (1) } \\
\text { Belonging support (1) }\end{array}$ & & \\
\hline 1 & $\begin{array}{l}\text { Campus supports } \\
\text { Appraisal/advice support (2) }\end{array}$ & 2 & $\begin{array}{l}\text { Campus supports } \\
\text { Appraisal/advice support (1) } \\
\text { Challenge (2) }\end{array}$ & & \\
\hline & & 1 & $\begin{array}{l}\text { Significant other } \\
\text { Emotional support (1) }\end{array}$ & 1 & $\begin{array}{l}\text { Significant other } \\
\text { Esteem support (1) }\end{array}$ \\
\hline
\end{tabular}


Disability, Athletics, \& Adjustment

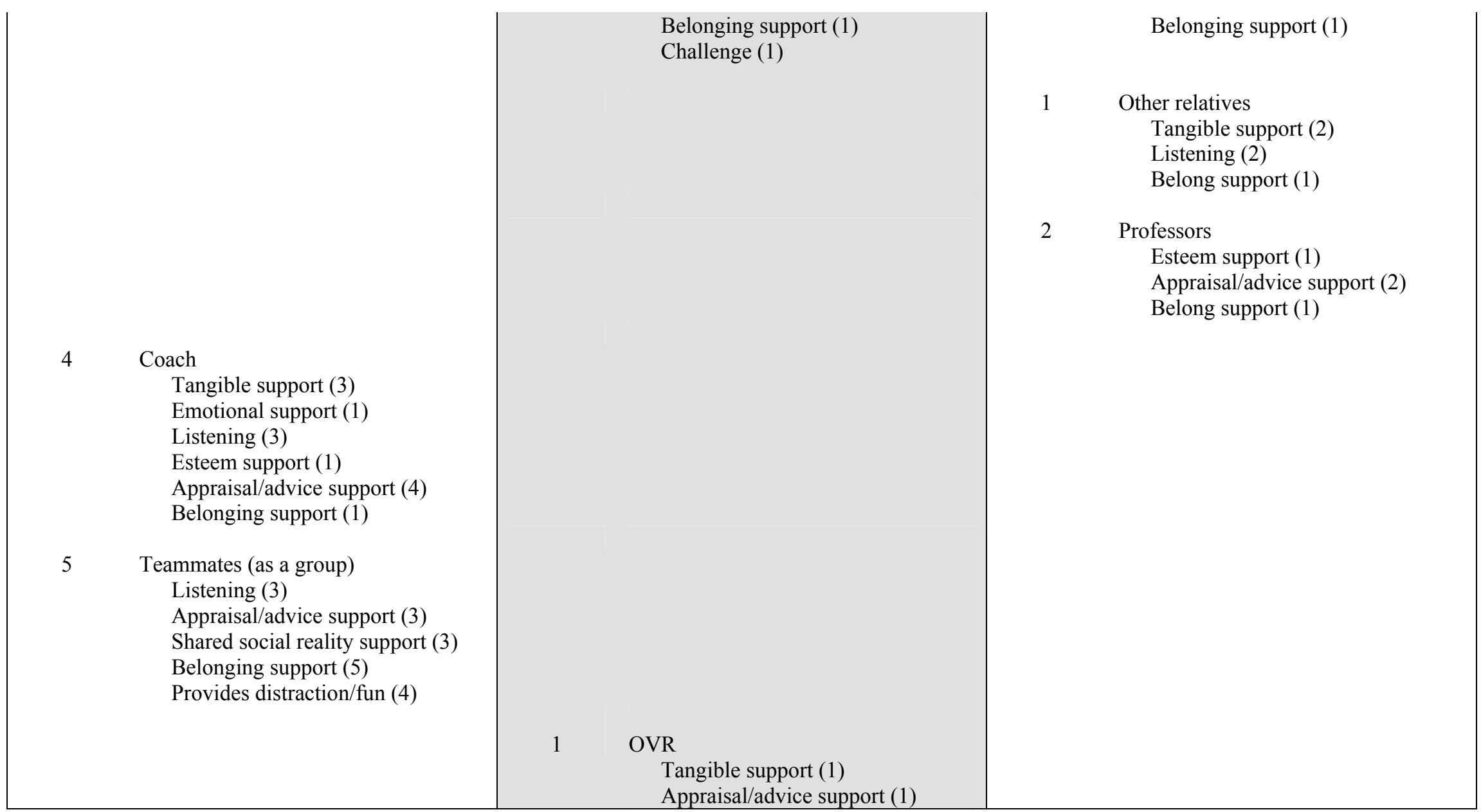


Table 12

Comparison of Emergent Themes Related to Coping Style for Managing Academic Stress

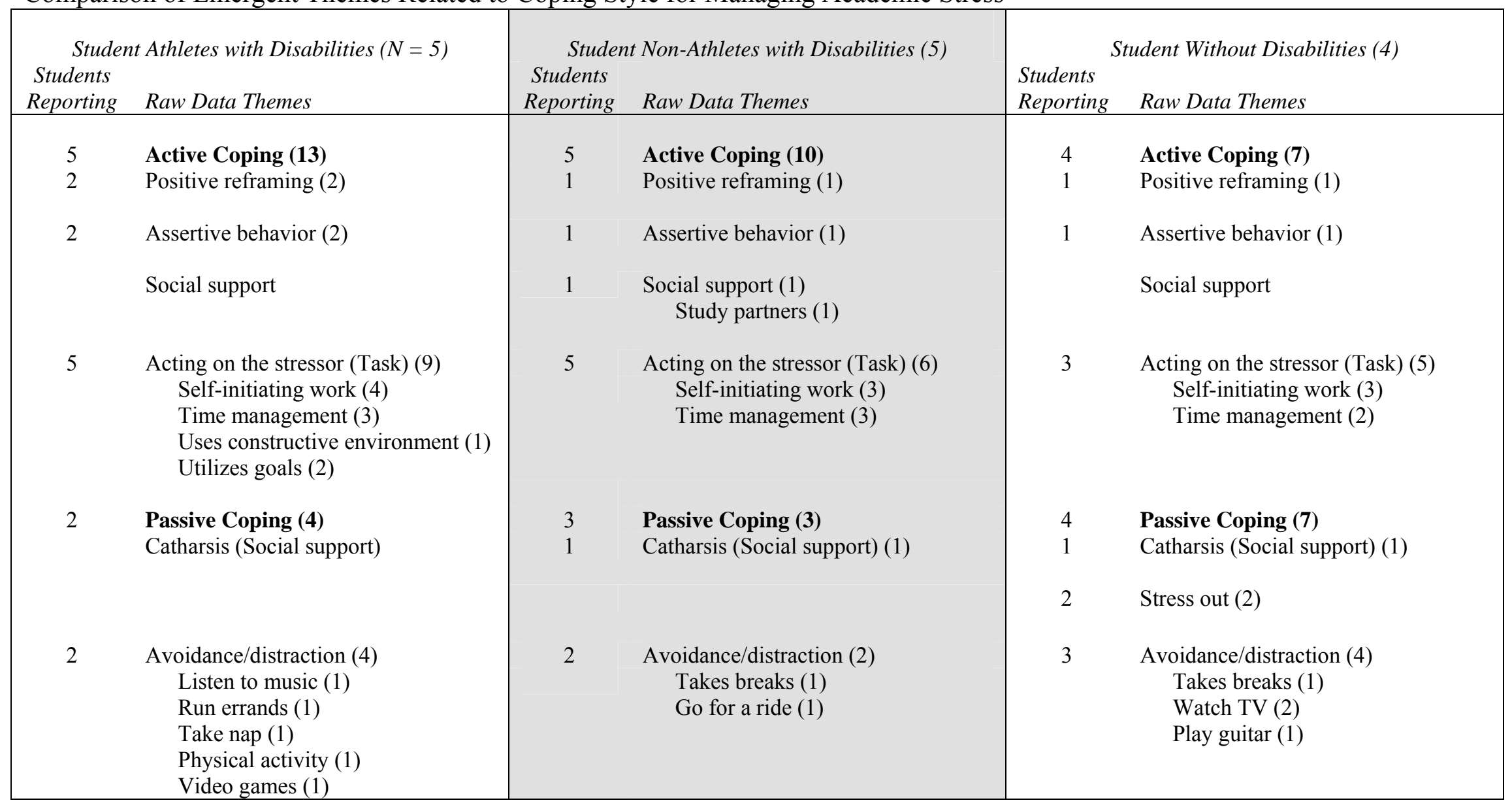


Table 13

Comparison of Emergent Themes Related to Coping Style for Managing Relationship Stress

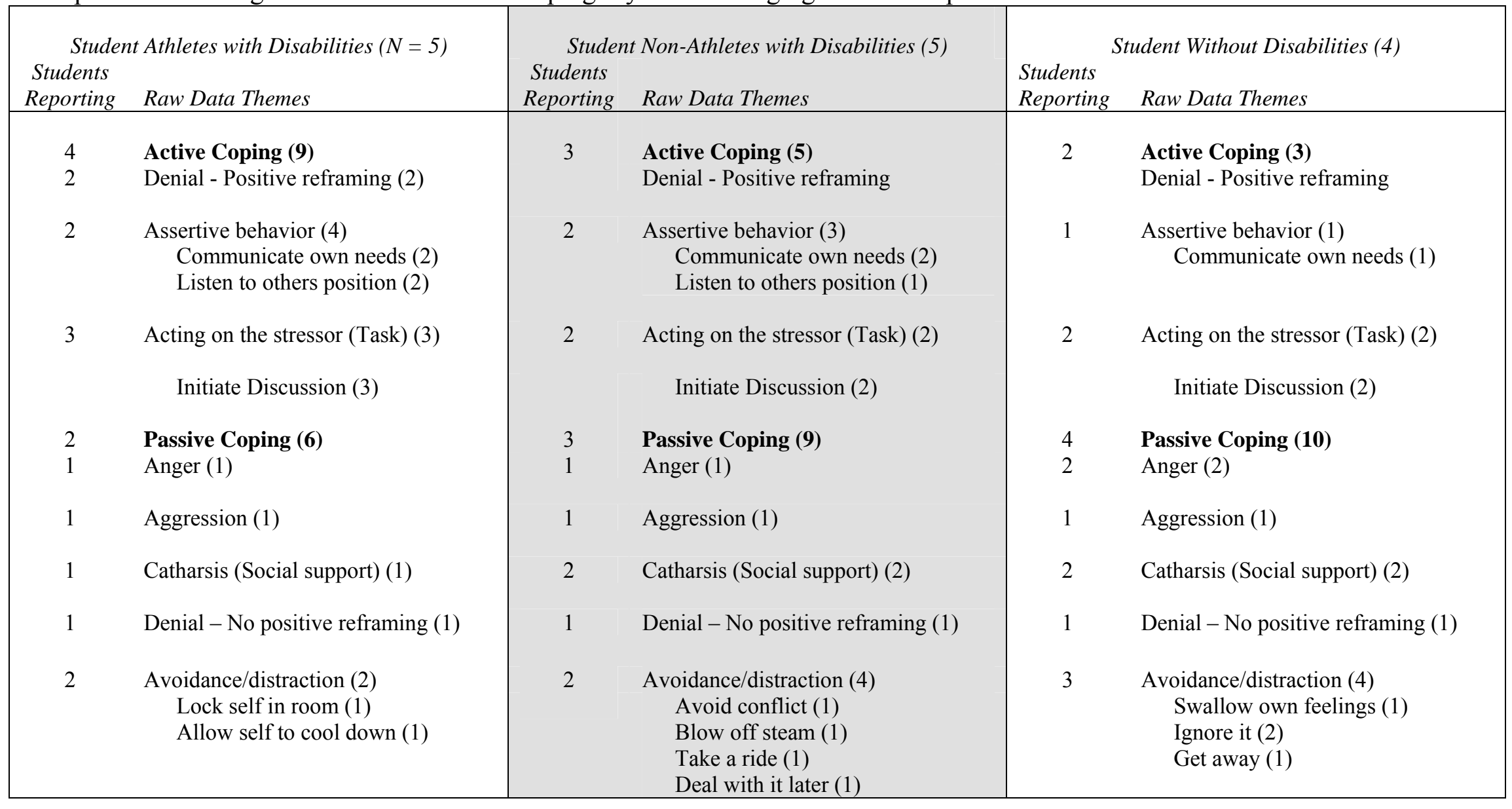


Table 14

Comparison of Emergent Themes Related to Coping Style for Managing a Life Event Where Participant Felt Like Quitting

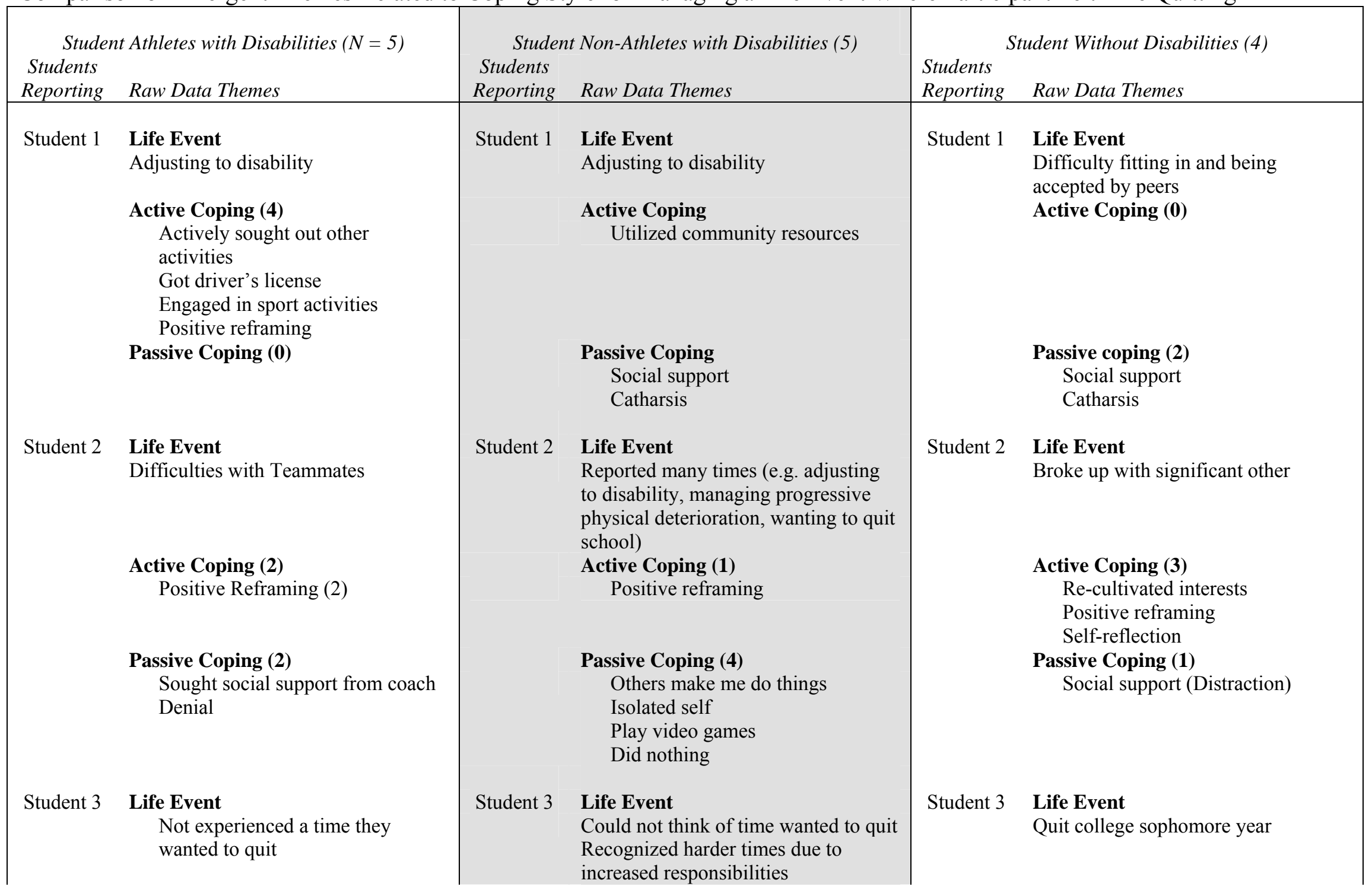




\begin{tabular}{|c|c|c|c|c|c|}
\hline & & & $\begin{array}{l}\text { Active Coping (3) } \\
\text { Positive attitude } \\
\text { Positive reframing } \\
\text { Perceived social support } \\
\text { Passive Coping (0) }\end{array}$ & & $\begin{array}{l}\text { Active Coping (2) } \\
\text { Self-reflection } \\
\text { Explored other options } \\
\text { Passive Coping (3) } \\
\text { Social support from family } \\
\text { Avoidance } \\
\text { Catharsis }\end{array}$ \\
\hline Student 4 & $\begin{array}{l}\text { Life Event } \\
\text { Does not identity with word quit } \\
\text { Has struggled with math } \\
\text { Active Coping (2) } \\
\text { Thought control } \\
\text { Preparation } \\
\text { Passive Coping (0) }\end{array}$ & Student 4 & $\begin{array}{l}\text { Life Event } \\
\text { Managing advanced placement classes } \\
\text { in high school } \\
\text { Active Coping (1) } \\
\quad \text { Studied with friends } \\
\text { Passive Coping (1) } \\
\quad \text { Catharsis with friends/family }\end{array}$ & Student 4 & $\begin{array}{l}\text { Life Event } \\
\text { Wanted to quit school sophomore year } \\
\text { Active Coping (1) } \\
\text { Sought social support from } \\
\text { professors } \\
\text { Passive Coping (3) } \\
\text { Sought social support from family } \\
\text { Catharsis } \\
\text { Avoidance }\end{array}$ \\
\hline Student 5 & $\begin{array}{l}\text { Life Event } \\
\text { Struggled with Math } \\
\text { Active Coping (1) } \\
\quad \text { Sought out tutoring } \\
\\
\text { Passive Coping (2) } \\
\quad \text { Drink for stress relief } \\
\text { Shared social reality support }\end{array}$ & Student 5 & $\begin{array}{l}\text { Life Events } \\
\text { Other tell her she can't do something } \\
\text { Active Coping (3) } \\
\text { Positive Reframing } \\
\text { Positive attitude } \\
\text { Self-efficacy } \\
\text { Passive Coping (0) }\end{array}$ & & \\
\hline
\end{tabular}


Table 15

Comparison of Emergent Themes Related to Expectations for College and Adjustment Difficulties

\begin{tabular}{|c|c|c|c|c|c|}
\hline \multicolumn{2}{|c|}{$\begin{array}{l}\text { Student Athletes with Disabilities }(N=5) \\
\text { Students }\end{array}$} & \multicolumn{2}{|c|}{$\begin{array}{l}\text { Student Non-Athletes with Disabilities (5) } \\
\text { Students }\end{array}$} & $\begin{array}{l}\text { Students } \\
\text { Reporting }\end{array}$ & $\begin{array}{l}\text { Udent Without Disabilities (4) } \\
\text { Raw Data Themes }\end{array}$ \\
\hline 4 & $\begin{array}{l}\text { Expectations for College } \\
\text { Expectations were meet (4) }\end{array}$ & 2 & $\begin{array}{l}\text { Expectations for College } \\
\text { Expectations were meet (2) }\end{array}$ & 1 & $\begin{array}{l}\text { Expectations for College } \\
\text { Expectations were meet (1) }\end{array}$ \\
\hline 1 & Some met, some not met (1) & 2 & Some met, some not met (2) & 1 & Some met, some not met (1) \\
\hline & $\begin{array}{l}\text { Expectations were not met } \\
\text { Adjustment Difficulties (2) } \\
\text { Difficulty adjusting to academic work } \\
\text { of college }\end{array}$ & 1 & $\begin{array}{l}\text { Expectations were not met (1) } \\
\text { Adjustment Difficulties (9) } \\
\text { Difficulty adjusting to academic work } \\
\text { of college (3) }\end{array}$ & 2 & $\begin{array}{l}\text { Expectations were not met (2) } \\
\text { Adjustment Difficulties (12) } \\
\text { Difficulty adjusting to academic work } \\
\text { of college }\end{array}$ \\
\hline & $\begin{array}{l}\text { Lack of integration into a group on } \\
\text { campus }\end{array}$ & 2 & $\begin{array}{l}\text { Lack of integration into a group on } \\
\text { campus (2) }\end{array}$ & 3 & $\begin{array}{l}\text { Lack of integration into a group on } \\
\text { campus (3) }\end{array}$ \\
\hline & $\begin{array}{l}\text { Lack of divestment in old roles and } \\
\text { relationships at home }\end{array}$ & & $\begin{array}{l}\text { Lack of divestment in old roles and } \\
\text { relationships at home }\end{array}$ & 2 & $\begin{array}{l}\text { Lack of divestment in old roles and } \\
\text { relationships at home (2) }\end{array}$ \\
\hline 1 & $\begin{array}{l}\text { Social difficulty with peers on campus } \\
\text { (1) }\end{array}$ & 2 & $\begin{array}{l}\text { Social difficulty with peers on campus } \\
\text { (2) }\end{array}$ & 2 & $\begin{array}{l}\text { Social difficulty with peers on campus } \\
\text { (2) }\end{array}$ \\
\hline 1 & $\begin{array}{l}\text { Experienced negative affect related to } \\
\text { college experience (1) }\end{array}$ & 2 & $\begin{array}{l}\text { Experienced negative affect related to } \\
\text { college experience (2) } \\
\text { Depression (1) } \\
\text { Overwhelmed (1) }\end{array}$ & 2 & $\begin{array}{l}\text { Experienced negative affect related to } \\
\text { college experience (5) } \\
\text { Loneliness (3) } \\
\text { Depression (1) } \\
\text { Anxiety (1) }\end{array}$ \\
\hline
\end{tabular}




\section{Appendix A: Review of Literature}

This chapter will discuss the following constructs addressed in this study: (1) adjustment, (2) coping style, (3) self-efficacy, (4) perceived social support, (5) self-advocacy, and (6) athletic participation. Each section will contain a discussion of the relevant theoretical basis for the construct, a review of research with the general population (except athletic participation), and then a review of research focusing on persons with disabilities. This chapter will be concluded with a discussion of future research recommendations.

\section{Adjustment to College Theory}

The determinants of success in postsecondary education have consumed psychological and educational researchers for decades (Robbins et al., 2004). Pascarella and Terenzini (1991) suggested that the development of theoretical frameworks that synthesize and focus investigation into the college student change process (i.e. adjustment) might have been the single most important evolution in student development literature from the 1970's to the 1990's. Tinto's student integration theory was one of these theoretical frameworks.

\section{Tinto's Student Integration Theory}

Tinto began his inquiry within the social anthropology literature, specifically Van Gennep's (1960) study of rites of membership in tribal societies. Van Gennep's (1960) work on the transition of individuals from membership in one group to membership in another, especially as this movement occurs for individuals transitioning from youth to adult status in society, was most pertinent to understanding the process of college student adjustment. Van Gennep identified three distinct phases that assisted in moving an individual from youthful participation to full membership in adult society: seperation, transition, and incorporation. Tinto (1988) has applied these three stages to the longitudinal process of persistence in college students. 
Separation. The first stage of the college career requires students to separate themselves, to varying degrees, from past communities, such as high school, family, or past places of residence. The difficulty of this separation will greatly depend on the established norms surrounding the worth of a college education in the previous communities. For example, if a student's family strongly believes in obtaining a college education, the college transition may be easier than for a student whose family does not strongly believe in the value of college. All separations, however, entail some form of parting from past habits and patterns of affiliation (Tinto, 1988). A student must invariably change to adopt the behaviors and norms appropriate for the new college environment. For some students, this can be a stressful and disorienting process. Students must disassociate themselves physically and socially from their past communities to fully integrate into their new college community. However, this process may differ for those individuals who stay at home while attending college.

Transition. The second stage of the college career is that of transition. Students must transition between the old and new, between associations of the past and anticipated associations with communities of the present (Tinto, 1988). Already having begun the process of separation, students must discover what the accepted norms and patterns of behavior are for their new college environment. Since students have yet to establish the personal bonds necessary for community membership, they enter a type of limbo. They are neither firmly bound to the past, nor firmly tied to their future. Understandably, students can experience stress and a sense of loss and bewilderment as a result of the social and environmental ambiguity. A student's ability to cope with the problems of adjusting to the social and intellectual life of college will affect persistence. Differences in individual coping skills and in educational goals and commitments have much to do with individual responses to the stresses of separation and transition (Tinto, 
1988). An inability to withstand and cope with the stresses of transition is more responsible for student withdrawal in the early academic year than is an inability to become integrated with the social and academic communities of the college (Cutrona, 1982). However, Tinto (1988) states that the stressors associated with separation and transition do not in themselves cause student attrition; the student's response to these stresses is what ultimately determines leaving or staying (Klien \& Rennie, 1985).

Incorporation. Having separated from old norms and behavior patterns of past associations, the student now faces the problem of finding and adopting norms appropriate to the new college setting and establishing competent membership in the social and intellectual communities of college life (Tinto, 1988). A significant factor involved in this process is the student's ability to establish relationships with students and faculty to avoid isolation and promote integration. Failure to do so may lead to departure from the institution. The unfortunate aspect about integrating into a college environment, as opposed to a traditional society, is the lack of formal rituals and ceremonies where such social contacts are ensured (Tinto). Some institutions utilize freshmen orientation classes, fraternities, sororities, athletics, or extracurricular activities as various formal avenues in which students can connect with others. Not all students are able to make such integrative contacts on their own. They are unable to establish competent social and intellectual membership in the college community and must learn the appropriate social and academic norms and behavior patterns of college on their own (Tinto).

The impetus for Tinto's work and much of the research conducted within the domain of college adjustment focuses on the initial transition into the college environment during the freshmen year. This focus is logical considering that attrition rates are highest during the freshmen year. However, longer term retention and eventual matriculation involves much more 
than one year. A student's need to adjust to changing and progressing roles and responsibilities continues throughout his or her tenure in college. The theoretical work of Medalie (1981) addresses a more developmentally comprehensive framework for the concept of student adjustment that can extend and compliment Tinto's work.

Medalie's Mini-Life Cycles of the College Years

Medalie (1981) suggests the structure of college life imposes certain life tasks upon students that are best addressed in a regular sequence. The environmental demands of college continually confront students with decisions and changes. Medalie proposes that some of the maladaptive behavior of college students, which could lead to attrition, may result from a failure to adequately address the psychosocial tasks of each phase of the college life cycle.

Similar to Tinto's theory, Medalie considers the two most important concepts of the freshmen year: divestment from the past and investment in a new life. One part of this process is mourning. For a student to optimally adjust, he or she must mourn the losses involved in the process of growing up. A student must also make attachments by reaching out for new relationships and must select and participate in suitable interests and activities that are available in his or her new environment. Freshmen must also cope with new academic challenges, like selecting courses, even though personal interests and career direction is vague and unformulated. The student must also perform to new levels of expectations and standards of achievement with vastly decreased guidance and supervision.

Medalie suggests that sophomore and junior years are less discrete, but still identifiable units. The overall task during these years is to increase mastery of work by differentiating interests and forming some commitments to future goals. Students in their sophomore year need to start formulating their intended majors by the end of the year. Those students who made 
premature decisions in selecting majors are forced to assess whether the choice is realistic in terms of their ability to achieve the goal. The junior year heralds another increase in expectations for the level of work; personal relationships and other decisions take on a new seriousness because students can start to envision an end to college and are making some bridges to the adult world. The major developmental task of the senior year is to anticipate and make realistic plans for the future while permitting oneself to experience the sadness associated with the disengagement from the now familiar and secure college world (Medalie, 1981).

There are two important implications of Medalie's theory in regard to the concept of adjustment to college. First, "adjustment to college" may actually ebb and flow through out the student's entire postsecondary education. Each developmental phase, as outlined by Medalie, holds its own set of challenges and stresses that must be adapted to by the student. Second, the model suggests the importance of looking beyond freshmen year adjustment, since some maladaptive behaviors can disguise adjustment problems beyond the first year. For example, Medalie points out that some students hit the "sophomore slump" after what appears a very successful freshman year. The cause for this slump is generally related to inadequate divestment and incomplete investment. In essence, the student will be continuing to tackle the "adjustment" to college within his or her sophomore year. Therefore, considering adjustment as a dynamic process that extends beyond the first year might be a reasonable consideration for student development researchers.

Overall, it seems clear based on the theoretical frameworks of both Tinto (1988) and Medalie (1981) that a student's ability to adjust and integrate into the social and academic culture of college will influence his or her ability to persist and eventually matriculate. For this reason, factors that contribute to adjustment and adaptation within college warrant exploration. 


\section{Research on College Adjustment}

Early studies focused on academic ability as a predictor of retention, but the broader concept of adjustment involves more than academic performance (Gerdes \& Mallinckrodt, 1994). Following the examination of academic ability, goal and institutional commitment variables were explored. Research supported that students who had made relatively early decisions to identify clear, purposeful educational goals tended to persist as compared to those who delayed their academic planning (Wessell, Engle, \& Smidchens, 1978). Having a firm resolve to complete a college degree has also been associated with academic adjustment (Baker \& Siryk, 1984a). Pascarella and Chapman (1983) found that institutional commitment (indicating the importance of graduating from a particular college) and goal commitment (indicating the importance of graduating from college) have a strong effect on persistence. Demographic variables such as age, gender, or socioeconomic status, tended to have more indirect effects that interacted with social and academic integration or institutional commitment to predict persistence.

A growing body of literature suggests psychosocial predictors have a significant influence on college outcomes. In fact, recent meta-analytic research of 109 different studies on college outcomes suggested psychosocial variables were better predictors of retention than strictly academic factors (Robbins et al., 2004). The researchers utilized academic goals, institutional commitment, social support, social involvement, and academic self-efficacy as psychosocial variables and ACT/SAT scores and high school GPA as traditional academic achievement variables. The regression model of traditional factors could account for $9 \%$ of the variance in the retention criterion, whereas the model involving the psychosocial factors accounted for $13 \%$ of the variance in retention. Even more interesting, the researchers utilized a 
procedure developed by Hunter and Schmidt (1990) that enabled the authors to correct for distortions in the observed correlations due to measurement and statistical artifacts in the predictor variables. This procedure provides a more accurate estimate of the construct-level relationship between predictor and criterion variables. The model containing the "constructs" underlying the psychosocial variables accounted for $21.3 \%$ of the total variance in retention. Academic self-efficacy and institutional commitment (measured by the SACQ) were the two strongest predictors of retention (.196 and .154 at measurement level, respectively; .461 and .217 at construct level, respectively). Social support was a weaker predictor of retention in the regression model and was moderately correlated with retention.

Gerdes and Mallinckrodt (1994) conducted a longitudinal study involving 112 men and women that investigated the influence of adjustment constructs on long-term retention. One month prior to entrance into college, students were given the Anticipated Student Adaptation to College Questionnaire that measures expectations for adjustment before enrollment in college. Seven weeks into the first fall semester, the Student Adaptation to College Questionnaire was distributed to the participants via mail survey. A six-year follow-up was conducted by examining the students' transcripts to determine enrollment, graduation, and academic status. Results of the study suggested that the adjustment construct of personal adjustment and integration into the social fabric of campus life played as important of a role as academic factors in student retention. Martin, Swartz-Kulstad, and Madson (1999) completed two studies utilizing the same protocol to examine psychosocial factors that predicted adjustment in first-year undergraduate students. The SACQ was utilized in conjunction with a demographic survey that gathered information on academic variables, personal variables, campus variables, and hours spent in employment. In addition, participants were asked to rate their perceptions of peer, faculty, and 
parental support during their academic studies, how well they liked the university, and their perception of the social life at the institution.

For the first sample of sixty male and female undergraduates, academic self-confidence, positive attitude toward the university, and faculty support predicted $62 \%$ of the variance $(\mathrm{R}=$ $.802, \mathrm{~F}(3,56)=33.66, \mathrm{p}<.001)$ in the total score for the SACQ (Martin, Swartz-Kulstad, \& Madson, 1999). The second study conducted by the authors sampled a larger population of 119 (62 women, 57 men) utilizing the same protocol as the first study. This time four variables (positive attitude toward the university, friends' support, academic self-confidence, and personal difficulties) accounted for $45 \%$ of the variance $(\mathrm{R}=.669, \mathrm{~F}(4,107)=21.711, \mathrm{p}<.001)$ in total score of the SACQ. The two universities observed in this study were different in size, geographic location and student population, which may account for the differing results found between the two studies. However, academic self-confidence and positive attitude toward the university still accounted for a significant portion of the variance in total adjustment suggesting psychosocial variables are important when considering retention.

\section{Adjustment to College of Students with Disabilities}

Little research has been conducted on the adjustment to college of students with disabilities. The 1970's, following the passage of Section 504 of the Rehabilitation Act of 1973, saw the first notable admission of students with disabilities to college campuses. Thirty years later, little research has been conducted to examine this population's adjustment to the college environment. Despite the considerable research examining individual and socio-environmental correlates of adjustment during college, relatively little attention has been given to this issue among students with disabilities. 
One study, a doctoral thesis, provided an excellent step forward in examining psychosocial issues related to students' with disabilities adjustment to the college environment (Collins, 1995). Collin's literature review of research surrounding college adjustment and students with disabilities consisted of a mere two studies. One study conducted in 1978 was a nation-wide survey of college students with disabilities and primarily descriptive in nature (Lawrence, 1982, as cited in Collins, 1995). A second study conducted by Burbach and Babbitt (1988) utilized questionnaires and interviews to examine the lives of students with disabilities on a small college campus. No information was provided on the nature of the questions or the interview questions and provided no generalizable information to understand adjustment for this student population.

Collins's (1995) did provide useful information in conceptualizing some aspects of college adjustment for students with disabilities. Utilizing a sample of 188 students with physical disabilities ranging from freshmen to second year graduate students (mean age $=23$ years), Collins examined four constructs: (1) social academic interaction, (2) perceived social support, (3) psychological distress, and (4) institutional/goal commitment. Subscales from both the Student Adaptation to College Questionnaire (Baker \& Siryk, 1984) and the Interpersonal Support Evaluation List (ISEL) (Cohen \& Hoberman, 1983) were utilized for this study. Surveys were mailed to participants who were identified through the campus Rehabilitation Education Center as having a physical disability.

Collins performed correlation analyses between all the variables in her study. Both the appraisal and belonging scales of the ISEL were significantly positively correlated at the $p<.001$ level with the three subscales of the SACQ that were utilized for the study. In addition, study results supported a significant negative relationship between perceived social support and 
psychological distress. The SACQ personal emotional adjustment scale was one measure utilized to capture psychological distress. In addition, perceived social support was also found to have a significant positive relationship with Institutional/goal commitment. Collins's hypothesis that Social/academic interaction would affect institutional/goal commitment indirectly through social support was not supported by the data. Perceived social support was highly correlated with both constructs, but did not mediate the relationship between the two variables.

One consideration in interpreting the results of Collins' study was the range of students utilized including freshmen to graduate students. The SACQ has typically been utilized in freshmen populations. The measure has not been normed on other student groups as it treats adjustment as a freshmen issue. The questions within the SACQ are geared toward freshmen and may not translate well to students further along in their academic progression, especially graduate students. For this reason, Collins' results must be interpreted with caution.

A second study investigated the influence of problem-solving skills, stressful situations, social support, resource use, and satisfaction with Access Office services on adjustment to college (Sanders \& DuBois, 1996). Zero order correlations were used to explore the relationships between the variables. First, negative daily life events were moderately negatively correlated with personal/emotional adjustment $(r=-.58, \mathrm{p}<.01)$ and with total adjustment $(r=-.39, \mathrm{p}<$ .05). Satisfaction with Access Services was also moderately correlated with personal/emotional adjustment $(r=.54, \mathrm{p}<.01)$. The strongest relationship suggested by this research was the strong positive correlation between social support from campus organizations and total adjustment to college $(r=.78, \mathrm{p}<.001)$. In addition, academic adjustment $(r=.60, \mathrm{p}<.001)$, social adjustment $(r=.60, \mathrm{p}<.001)$, and institutional attachment $(r=.65, \mathrm{p}<.001)$ were showed moderate correlations with social support from campus organizations. The authors' findings suggest that 
support received as a result of contacts with formal campus organizations may facilitate the adjustment of students with disabilities in both academic and psychosocial domains. Significant correlations were also found between measures of social support, stressful life events, and problem-solving skills.

Like with the Collins' study, the Sanders and DuBois study suffered from sampling issues. The authors had a very small sample of only 29 students, which ranged in age from 18 to 50. The study was unclear if the students were all first year students or not. The types of disability the students reported were generally split between wheelchair users and learning disabilities. Though still useful, results of the study should be considered with caution, because, once again, the SACQ is not intended nor has been normed on students older than 25 years old. This does pose a dilemma for researchers wishing to explore adjustment issues in the disability student population, as the average age tends to be older than that of the non-disabled population. When the gold standard measurement for college adjustment is not functional, other options must be considered.

\section{Summary of Adjustment Literature}

Research concerning both students with and without disabilities suggests that psychosocial variables are efficacious to explore along with academic performance predictors in relation to adjustment and retention of college students. However, the theoretical literature related to adjustment does not propose through what mechanism these factors may influence the adjustment process. Therefore, it is difficult to determine which psychosocial variables should be considered. However, an answer may be found within the stress and coping literature for linking potential psychosocial factors to behavior changes such as adjustment to college. 


\section{The Transactional Model of Stress}

The transition to college is marked by complex challenges in emotional, social, and academic adjustment (Chickering, 1969; Medalie, 1981). Students with lower levels of adjustment tend not to perform as well academically in college and have a substantially higher rate of withdrawal (Baker \& Schultz, 1992). As discussed earlier, adjustment involves a process of discontinuing old roles or behaviors and establishing new ones. Central to effective transition and adjustment is the management of the stress and uncertainty inherent in learning new roles and behaviors (Schlossberg, Waters, \& Goodman, 1995). The Transactional Model of Stress (TMS), developed by Lazarus and Folkman (1984), can provide an operational framework for understanding how personal, emotional, and social factors contribute to the adjustment process.

The concept of coping as a process, represented within the Transactional Model of Stress (TMS), was developed as an alterative to the strictly behavioral approaches to coping. In this model, coping is defined as "constantly changing cognitive and behavioral efforts to manage specific external and/or internal demands that are appraised as taxing or exceeding the resources of a person.” (Lazarus \& Folkman, 1984, p. 141).

The appraisal process is initially stimulated by a potentially stressful event, such as a life transition. The primary appraisal occurs first, in which students determine if the life transition is in fact a threat or a challenge. Simultaneously, a secondary appraisal transpires in which students evaluate their options and ability to deal with the potential stress. The resulting feedback will determine if the situation is perceived as threatening and if the stressful situation exceeds perceived resources to cope or if the life transition can be managed (Lazarus \& Folkman, 1984). Since the appraisal process is the central mechanism behind whether situational demands are 
viewed as stressful or manageable it is important to understand what factor influence this process.

The primary and secondary appraisals are influenced by both personal and environmental variables. Personal variables would include: (1) personality traits, (2) values and beliefs, (3) existing coping and life skills, and (4) coping style. Environmental variables include: (1) timing, (2) predictability, (3) duration of the stressors, (4) options, and (5) social support. No matter the source, any shift in the person-environment relationship will lead to a reevaluation of what is happening, its significance, and what can be done. The reappraisal process will then influence future coping efforts (Lazarus \& Folkman, 1984) by influencing either the perception of threat or ability to cope.

By combining the theoretical models of adjustment (Medalie, 1981; Tinto, 1988) and the functional framework of the Transactional Model of Stress (Lazarus \& Folkman, 1984), several potential psychosocial variables appear worth exploring when considering retention of college students. These variables would include: coping style, self-efficacy, perceived social support, self-advocacy skills, and athletic participation. An explanation and review of relevant literature for each variable follows. Both research within the general college student population and that conducted within disability populations will be examined.

\section{Coping Style}

There are two basic theoretical approaches to examining coping: the transactional approach and the structural approach. In the transactional approach coping skills or strategies are thought to be situation specific behaviors that are enacted to manage the perceived demands of a certain situation (Lazarus \& Folkeman, 1984). The cognitive appraisal process will determine what skills will be enacted in each situation. 
The structural approach suggests that coping is a function of coping styles or methods of coping that characterize an individual's reactions to stress either across different situations or over time within a given situation (Compas, 1987, p. 394). Since coping styles may be related to personal values, beliefs, and goals, they may partly reflect what the individual prefers. This does not necessarily constitute a relationship with underlying personality variables that predispose an individual to respond in particular ways to stress. Instead, coping styles may reflect the proclivity to respond in a particular way when confronted with a specific set of circumstances (Compas, 1987).

The results of some studies confirm the possibility of regarding coping in both ways, as preferred styles and as situation-specific coping behaviors. Individuals actively and consciously select and engage in particular coping behaviors (Lazarus \& Folkman, 1984). However, individuals' choices fall in a limited range of behaviors and tend to reflect preferences even across different situations (Endler \& Parker, 1989; Fleischman, 1984; Miller, Brody, \& Summerton, 1988). In addition, an increasing amount of psychology literature has supported coping style as a predictor of an individual's use of selected coping techniques (Carver, Scheier, \& Weintraub, 1989; Endler \& Parker, 1990).

Research by Hudek-Knezevic and Kardun (2000) investigated the role of dispositional coping, situational coping, perceived social support, and cognitive appraisals on the satisfaction and perceived efficacy of coping efforts. Utilizing a sample of 116 adult women, the researchers administered the Coping Orientation to Problems Experienced (measuring coping style), a situational coping inventory, a stressful situations measure, cognitive appraisal form, and the Social Support Appraisal Scale. Using linear structural equation modeling, the authors tested two theoretical models of the relationships between the above variables. In general, results of the 
study supported Lazarus and Folkman's (1984) concept of the cognitive appraisal (i.e. primary appraisal of the threat of a situation and secondary appraisal of one's resources to manage the situation) as a direct influential factor on coping outcomes. In both of the tested models, cognitive appraisals showed the most statistically significant effects on perceived efficacy and satisfaction with coping (Hudek-Knezevic \& Kardun, 2000). These results support the Transactional Model of Stress and the role of the primary and secondary cognitive appraisal in the coping process. Hudek-Knezevic \& Kardun's study also supported past research (McCrae \& Costa, 1986) that indicates the influence of coping style on perceived satisfaction and efficacy of coping as mediated through the cognitive appraisal process. However, the hypothesized mediating role of situational coping strategies (coping skills) between cognitive appraisals and immediate coping outcome was not confirmed.

In addition, perceived social support had a significant positive effect on the outcomes of coping (perceived efficacy and satisfaction with coping efforts) when mediated through the secondary appraisal of controllability. The secondary appraisal is the point at which an individual tries to determine if he or she has the resources to manage a potentially stressful situation (Lazarus \& Folkman, 1984). The perception that others are with you in your struggles may increase an individual's perception of available resources to manage potentially stressful situations. Hudek-Knezevic and Kardun's (2000) work supports the importance of coping style and perceived social support as mediating variables in the adaptation to stressful events. In addition, the previous results suggest coping style maybe more efficacious to explore versus coping skills when investigating a more multifaceted concept like adjustment that involves more than one specific situation. 
Leong and Bonz (1997) conducted research that specifically investigated the effect that coping style had on adjustment to college in a sample of 161 college freshmen. The SACQ was utilized to explore adjustment to college and the COPE questionnaire captured student's coping styles. The coping measure served as a predictor for the adjustment measure. A step-wise multiple regression was conducted for each of the four subscales of the SACQ. Preliminary analyses to test for gender differences were conducted first before the regression analyses. Leong and Bonz (1997) did not find any significant differences between males and females on the adjustment scales of the SACQ. However, statistically significant gender differences were found on some of the subscales of the COPE measure.

Results of the study indicated that coping style predicted two of the four subscales of the adjustment measure (Leong \& Bonz, 1997). Active coping and suppression of competing activities accounted for $5 \%$ of the variance and successfully predicted $(p<.01)$ academic adjustment. Active coping, which is focusing on doing something positive to solve a problem, predicted academic adjustment. Suppression of competing activities, which consists of attending to one problem at a time at the exclusion of others, was negatively predictive of academic adjustment. Overall, active coping was a more important predictor than suppression of competing activities, but both were weak overall in predicting academic adjustment.

Focus on and venting of emotions and active coping were the most significant predictors $(p<.01)$ of personal emotional adjustment, accounting for $7 \%$ of the variance in adjustment scores (Leong \& Bonz, 1997). Focus on and venting of emotion, basically emotional catharsis, was negatively predictive of personal emotional adjustment, whereas active coping was positively predictive. Social and Attachment/goal commitment subscales of the SACQ were not significantly predicted by any of the coping style variables. 
There are a few possible explanations for the very small relationships found in this study between coping style and adjustment. First, psychometric problems with the COPE may have influenced the results. The COPE Inventory is a 60 item inventory which is divided into 12 different subscales. Five of the 12 scales have questionable alpha coefficients less than .70 and the confirmatory factor analysis provided marginal support the 12 proposed factors of the COPE. Second, four separate stepwise MANOVAS were utilized to predict the four adjustment scales utilizing the 12 COPE scales as independent variables. The 161 student sample was not of sufficient size to run this type of regression with 12 independent variables. This would results in a significant reduction in power and may of accounted for the small predictive results of coping style. With a sufficient sample size or had the authors chose to perform univariate statistical analyses they may of found more significant results.

\section{Coping Style and Disability}

One exploratory investigation utilizing college students with disabilities suggested that coping strategies added significantly to the variance in both disability-specific psychosocial adjustment and life satisfaction, after controlling for the contribution of disability-related factors (Livneh \& Wilson, 2003). Groomes and Leahy (2002) conducted a study examining the relationships between the stress appraisal process, coping disposition (i.e. coping style), and level of acceptance of disability. The study utilized a convenient sample of 151 individuals with either a physical or emotional disability drawn from a public rehabilitation service, an independent living center, and a disability services office on a local college campus. The Coping Inventory for Stressful Situations (CISS) was utilized to measure coping style, along with the Stress Appraisal Inventory for Life Situations, and an Acceptance of Disability Scale. 
Statistical analysis of the relationship between stress appraisals and coping disposition determined that individuals with a task-focused coping orientation or an emotion-focused coping orientation rated situations as more harmful and threatening than did participants with avoidancefocused coping orientations (Grommes \& Leahy, 2002). This result would suggest that an avoidance coping style was more productive in reducing the perception of stress for the hypothetical situations suggested by the Stress Appraisal Inventory for Life Situations measure. In contrast, when examining results between coping disposition and acceptance of disability, individuals with task-focused coping orientations had a higher level of acceptance of disability as compared to individuals with an emotion or avoidance focused disposition (Grommes \& Leahy, 2002).

A review of literature by Cairns and Baker (1993) regarding coping style and adjustment to spinal cord injury generally suggested that more active coping styles were associated with lower depression and better adjustment to spinal cord injury. In addition, the review suggested that individual's perceptual beliefs also contributed to the behavioral outcomes of coping. Selfefficacy is one such perceptual belief that could impact the behavioral aspects of the coping process. Self-Efficacy Theory

Tinto and Medalie suggest the importance of behavioral change in the effective adjustment to college. Self-efficacy has been suggested as one of the strongest predictors of behavioral change, because it is the impetus to perform behavior and motivation to persist in the face of adversity (Bandura, 1977). The core principle of self-efficacy theory is that cognitive processes can mediate behavioral change but that cognitive events are induced and altered most readily by the experience of mastery arising from effective performance (Strauser, 1995). 
Interventions that focus strictly on increasing knowledge and awareness of skills necessary for a particular behavioral change will remain inert unless the individual believes he or she can execute the behavior effectively. For instance, students with disabilities can be taught the skills and knowledge needed to advocate for themselves, but ultimately if they do not believe in their ability to utilize these skills, they're likely not to self-advocate. This is the role of self-efficacy expectations.

Self-efficacy expectations are defined as an individual's conviction that he or she can successfully execute the behaviors required to produce a desired outcome (Bandura, 1977). Bandura suggested that expectations of personal efficacy are based on four major sources of information: (1) performance accomplishments, (2) vicarious experiences, (3) verbal persuasion, and (4) emotional arousal. An instance where an individual has engaged in a behavior encompasses performance accomplishments and is the most influential source of efficacy information. Successful experiences will increase efficacy while failure will likely decrease efficacy. Vicarious experiences involve the individual observing others engaging in the behavior without adverse consequences. Verbal persuasion suggests that individuals are able to cope successfully with a situation that has previously been overwhelming. Vicarious experience and verbal persuasion may underlie the effectiveness of mentoring programs. Lastly, emotional arousal is the result of stressful and taxing situations. Information gathered from these experiences may have informative value concerning personal competency (Bandura, 1977). Bandura originally conceptualized self-efficacy as context or situation specific. Several psychological measures have been developed that explore self-efficacy within very specific contexts. However its generative and predictive power on performance across different behavioral domains has been substantially documented (Choi, 2003). According to Sherer et al. 
(1982), “an individual's past experiences with success and failure in a variety of situations should result in a general set of expectations that the individual carries into new situations. These generalized expectancies should influence the individual's expectations of mastery in the new situations" (p.664). Some authors suggest that general self-efficacy may explain some individual differences when a person faces a new and less clearly defined task, whereas specific selfefficacy may explain individual differences better when a person faces narrowly and clearly defined tasks (Shelton, 1990; Tipton \& Worthington, 1984). Adjustment to college is multidimensional encompassing several behavioral domains. Therefore, measuring general selfefficacy would seem more prudent if one was examining self-efficacy in relation to adjustment to college.

\section{Self-Efficacy, Disability, and Adjustment to College}

Several of the research studies examining the influence of self-efficacy and adjustment to college in the general student population were discussed previously. This section will focus on literature relating the interaction of self-efficacy and disability.

Despite many years of investigation on self-efficacy, there is little research dealing with this construct among college students with disabilities (Blake, 2002).

Blake (2002) examined the relationship between self-efficacy and self-esteem in a sample of 44 undergraduate and 4 graduate students with disabilities. The researcher collected data on self-esteem and self-efficacy via survey instruments, including the Self-Efficacy Scale, and then compared the results to previous normed data of the instruments. Blake found that the mean scores for the students with disabilities were not significantly different from the norms. The author also attempted to conduct a stepwise multiple regression utilizing the self-esteem, selfefficacy, and various demographic variables to predict college grade point average. Only two 
demographic variables matriculation classification and socioeconomic status significantly entered into the equation.

While Blake's research does provide some support that students' with disabilities selfefficacy does not differ from that of the general student population, the following considerations must be taken into account. First, Blake had a very small sample size. Performing a stepwise multiple regression with only 48 subjects and numerous independent variables is inappropriate. Any conclusion that self-efficacy does not factor into grade point average would not be reasonable to assume. Second, Blake's recruitment method for his research was to leave survey packets in the Office of Disability Services to complete. Students had to self-initiate to complete the surveys. This may be an important consideration as self-efficacy is related to the likelihood to initiate behavior. Data collection method may have biased the sample to those students who had higher self-efficacy. Volunteerism may be a potential limiting factor in examining a construct like self-efficacy and adjustment too.

A third study examining self-esteem, self-efficacy, and adjustment to college compared these constructs in a total sample of sixty-five students with and without learning disabilities (Saracoglu, Minden, \& Wilchesky, 1989). Authors attempted to match the samples on sex, age, and year of study. Sherer et al.'s (1982) Self Efficacy Scale and the SACQ were two of the utilized measures. Mulitvariate analysis of variance with two between factors (group and sex) and one covariate (social desirability) was conducted in the measures of adjustment, selfefficacy, and self-esteem. No differences were shown between the two groups on the selfefficacy measure. However, further analysis did support that self-efficacy was positively correlated with academic adjustment, personal-emotional adjustment, and social adjustment. One caution in interpreting the results of this study is to bear in mind that the disability population 
utilized was learning disabilities. These results may or may not translate to other disability groups.

Finally, Hampton (2004) conducted a study with 127 men and women with spinal cord injuries investigating the joint contributions of demographic variables, perceived health, selfefficacy beliefs, and perceived social support to subject well-being. The General Self-Efficacy

Scale was again utilized. Zero order correlations showed both general self-efficacy and perceived social support were moderately correlated with subjective well-being $(r=.43, p<.01$ and $r=$ $.44, p<.01$, respectively). Hierarchical multiple regression analysis revealed that age at injury, perceived health, self-efficacy, and perceived social support accounted for $36 \%$ of the variance in subjective well-being. In addition, the joint contribution of self-efficacy and perceived social support accounted for additional and unique variance in subjective well being apart from perceived health and age at injury reflective in their beta weights $(\beta=-.23$ and $\beta=-.25$, respectively). Hampton's (2004) results support previous research that identified the importance of self-efficacy in relation to depression (Shnek et al., 1997) and quality of life (Hampton, 2000) for individuals with spinal cord injuries. In conclusion, self-efficacy may directly influence or moderate adjustment and retention, thus ultimately influencing matriculation.

\section{Social Support Theory}

Hampton's research, as well as other previously cited studies (e.g. Collins, 1995; HudekKnezevic \& Kardun's, 2000), also suggests perceived social support as an important factor to consider. The theoretical framework utilized for this study to understand the relationship between social support and stress is the buffering hypothesis (Cohen and Willis, 1985). According to Cohen and Willis, social support is differentiated into three major categories (i.e. 
tangible, appraisal, and emotional) encompassing four different types of support: (1) tangible support, (2) appraisal support, (3) self-esteem support, and (4) belonging support.

Tangible Support. Any type of material aid would be classified under tangible support (Cohen \& Hoberman, 1983). For example, a college student's scholarship, room and board, clothes, food, transportation, or needed equipment would be considered tangible support if provided by others. The effectiveness of tangible support as a buffer for stress is fairly straightforward. When providers supply necessary material resources to people under stress, it is reasonable to conclude that the provided support may reduce feelings of stress. Though virtually anyone can provide tangible support, this support is probably more effective when the receiver views what is provided as appropriate.

Another important point to consider when examining tangible support is the possible psychological support implication associated with the receipt of material aid. Provision of tangible support could by interpreted by the receiver as evidence of the love and esteem of the giver (Cohen \& McKay, 1984). In fact, psychometric testing of the Interpersonal Support Evaluation List (Cohen \& Hoberman, 1983), the assessment of perceived social support based on Cohen and Willis's theory, revealed a moderate correlation between the tangible support and belonging support subscales. Therefore, even provision of tangible support may contain some psychological support components that buffer stress.

Appraisal support. Support classified under the appraisal category is anything that contributes to an individual's knowledge or beliefs (Cohen \& Hoberman, 1983). The interpersonal relationships that would be classified as appraisal support are generally those that assist people to problem solve and evaluate their circumstances (Cohen \& McKay, 1984). For example, discussing a problem with a friend or talking to a mentor about how to apply for a job 
are forms of appraisal support. The information gained from these interpersonal interactions will influence an individual's assessment of their situation as stressful. Appraisal support provided by others may enter the analysis by altering either one's assessment of threat or one's assessment of their ability to cope (Cohen \& McKay, 1984). For instance, a doctoral student might sit down and discuss with a peer her anxiety and frustration about writing her dissertation. That peer may provide information that suggests these experiences are normal to the process. This support might aid the student in assessing the writing of her dissertation as less stressful since others have experienced similar feelings and still succeeded. Alternatively, the doctoral student could share these same feelings with her advisor who may proceed to provide more guidance and direction in the dissertation process. This newfound knowledge may allow the student to assess the dissertation writing as less stressful, because with the new knowledge she feels greater ability to tackle the challenge.

Emotional support. There are two types of support interactions that are classified under emotional support: self-esteem support and belonging support. Self-esteem support is anything that allows an individual to see herself positively in comparison to others (Cohen \& Hoberman, 1983). Self-esteem support is most beneficial when an individual chooses to respond to a stressor with self-deprecation. Theoretically, this type of support would contradict a person's perceive helplessness to manage the situation when they attribute their inability to cope to their own incompetence. For example, a student may appraise their ability to go out and meet new people as highly stressful because he does not think people generally like talking to him. Support interactions that enhanced the student's perception of himself as interesting or worthwhile to talk to may influence his perception. Cobb (1976) has argued that esteem support might encourage a person to go out and master a problem or confront a challenge. In this case, the support is serving 
to increase the individual's feelings of self-efficacy or self-worth. Though the perceived threat of a situation may not change, self-esteem support may assist a student in appraising their ability to cope as higher.

Belonging support is the perceived availability of other people to do things with (Cohen \& Hoberman, 1983). If a stressor is compromising an individual's perception that he or she belongs and is loved by others, belonging support can facilitate coping. For example, if a freshman knows of people she can go ask to lunch, this creates a feeling of belonging. Alternatively, if another student does not feel that she has anyone to ask to lunch, she may perceive school as more lonely and threatening as she feels isolated. A next-door neighbor telling her she would be happy to go to lunch anytime would be an example of belonging support. A connection has potentially been created that could assist the student as feeling a part of her social environment even if it is not utilized. Another example is the wearing of team uniforms in sports. Since each player looks similar it creates a sense of solidarity and belonging to a common cause in the team members. The most effective form of support in cases where a stressor deprives one of feelings of belonging would be relatively intimate interpersonal relationships.

\section{Buffering Effect vs. Main Effect Models}

There are two possible ways that the stress buffering mechanism of social support may work. First, social support may intervene between the stressful event, or the expectation of that event, and a stress reaction by attenuating or preventing a stress appraisal response (Cohen \& Hoberman, 1983). Perceiving that others can and are willing to provide support may influence the primary and secondary appraisal processes of the coping process. A stressful reaction could be averted because the stressor is ultimately not seen as a threat or the person feels they have adequate resources to manage the stressor. Second, social support may intervene between the 
experience of stress and the onset of pathological outcomes, such as experiencing depression or reduced health outcomes, by eliminating the stress reaction or by directly influencing physiological processes (Cohen \& Hoberman, 1983). Resources provided by members of a support network could reduce the stress response by providing a solution to a problem, reducing the perceived importance of a problem, providing medication for the physiological response, or by promoting healthy stress management behaviors.

The main effect model of social support suggests that the efficacy of support occurs through large social networks that provide regular positive experiences and a set of stable, socially rewarding roles within the community (Cohen, Sherrod, \& Clark, 1986). Recognition of self-worth, stability in one's life situation, predictability, and positive affect could be responsible for the overall well-being social support can provide. Cohen and Willis (1985) provided research that provides support for both models. The main-effects and buffering-effects models both represent a viable conceptualization of social support; each just represents a different process through which the support may affect well being (Cohen, 1988).

\section{Perceived Social Support and Adjustment to College}

Brissette, Scheier, and Carver (2002) examined the role of optimism in social network development, coping, and psychological adjustment to college for first-year residential students. Eighty-nine students, both men and women, completed survey assessments three weeks into the fall semester and then 12 to 16 weeks following the initial assessment. Optimism, self-esteem, coping (as measured by a modified version of the COPE), perceived social support (as measured by the ISEL), friendship network size, depression, and perceived stress were explored in the study. Relevant results to the present study were as follows. First, greater increases in perceived social support were a reflection of changes in perceived support on campus as opposed to off- 
campus support. These results may stress the importance of integration into the social community of a university. Students who have difficulty finding satisfying peer groups on campus may be at risk for maladjustment. Second, social support and coping behaviors represented distinct, but related resources that influenced adaptation to life stress, (i.e. adjustment to college). Finally, the authors concluded that their data suggested changes in perceived social support over the course of the semester was critical in explaining why greater optimism was related to superior adjustment to college (Brissette, Scheier, and Carver, 2002).

Lakey and Cassidy (1990) conducted two research studies to explore the hypothesis that perceived social support operated much like a personality self-schema that guides memory for and interpretation of actual supportive behaviors. The first study included 101 college juniors completing the ISEL, the Index of Socially Supportive Behaviors, measures of three cognitive personality variables (self-esteem, dysfunctional attitudes, and control beliefs), and the Beck Depression inventory. The second study involved 101 intorductory psychology students completing the Social Support Evaluation and Recall Task (SSERT). The SSERT was specially designed for the study and involved evaluation of eight hypothetical supportive behaviors presented for six different hypothetical situations. The SSERT was again related to the cognitive personality variables and a different measure of perceived social support, which was not specific to the college population.

Four major findings emerged from the data. First, perceived support demonstrated a pattern of correlations more similar to cognitive personality variables than to enacted support. Second, low perceived support was associated with a bias toward perceiving supportive attempts as unhelpful. Third, low perceived support was associated with a bias toward recalling fewer 
instances of helpful supportive behavior. Lastly, perceived support was associated with psychological distress, but enacted support (i.e. received support) was not.

In contrast, Brissette, Scheier, and Carver (2002) found students' mean levels of social support were greater at the end of the semester than in the beginning. However, perceptions at the beginning were still highly correlated with end of the semester perceptions of support. The high correlation, but obvious change in perception between the beginning of the semester and semester's end lead these authors to assume that the ISEL was able to capture both the stable differences and fluctuations in perceived social support. Brissette and colleagues explored adjustment in first-year students in their first semester. First semester of the freshmen year, according to Tinto (1988), is characterized by a transition between old roles and relationships and new roles and relationships. This process certainly initiate small changes in even more stable personality variables. Therefore, some difference in perceived social support scores seems reasonable during this initial adjustment period.

Mcgown (1984) examined the influence of perceived social support, received social support and social loss life events on positive and negative psychological functioning. A sample of 97 college students was administered four measures of psychological functioning (e.g Beck Depression Inventory, Quality of Life Scale), the Interpersonal Support Evaluation Model (measure of perceived support), and the Inventory of Socially Supportive Behavior (measure of received social support), and the College Student Life Event Scale. These instruments were given twice over an eight-week period. Perceived social support (ISEL) displayed a significant main effect $(p<.001)$ on psychological status both cross-sectionally and prospectively. Univariate analysis revealed ISEL score was positively correlated with scores on the Quality of Life Scale, Positive Affective Balance Scale, Langner Psychiatric Screening Inventory, and 
negatively correlated with the Beck Depression Inventory. More importantly, ISEL score was found to significantly predict changes in psychological status, independent of the influence of negative life events, social loss events, or initial psychological status (McGown, 1984).

This data provides support for the main effects model of social support as opposed to the buffering effect model discussed earlier. Received social support, in contrast to perceived social support, had extremely limited predicative power on psychological functioning. The limited predictive power of received support would suggest that when examining variables that are influenced by psychological functioning, exploring perceived social support is more advantageous then examining received support constructs. Self-Advocacy

Social support has repeatedly demonstrated a moderating effect upon the deleterious effects of stressful situations for many people (Elliott \& Gramling, 1990). Some interpersonal factors have been identified that influence the provision of social support. One such factor is personal assertiveness. Elliott \& Gramling (1990) conducted research with college students that examined the relationships between social support, stress, and personal assertiveness. Results suggested that in times of stress, individuals who are more assertive are able to gain more benefit from relationships with people who share their values and interests than persons who are not assertive. These research finding reveal an interesting connection with another construct that has been identified within the disability literature as important to postsecondary success.

Self-advocacy has become a hot topic in the area of education and disability. In their 2003 position paper "People with Disabilities and Postsecondary Education", the National Council on Disability cited self-advocacy as one of the critical components to postsecondary access for students with disabilities. Assertiveness or assertive communication is one of several 
components of self-advocacy. Broadly defined, self-advocacy is knowing what you want, what you are entitled to, and how you can go about getting it. Review of the literature revealed three major components of self-advocacy: (1) knowledge, (2) assertiveness, and (3) communication skills.

Knowledge. The component of knowledge can potentially be broken down into three subcomponents: (1) policy or legal knowledge, (2) resource knowledge, and (3) self knowledge. Policy legal knowledge refers to the students understanding of his or her legal rights and working knowledge of the policies that govern their educational environment. For all students this would entitle understanding the policies contain within the institution's student handbook. For students with disabilities it further implies their knowledge of disability legislation (e.g. ADA) and how it affects access and accommodation issues. Resource knowledge refers to the student's awareness and knowledge of individuals, organizations, and services that can assist them in achieving what they want. For example, a student's ability to utilize the library or knowing where he or she can find tutoring services would be considered research knowledge. Self knowledge is the students awareness of his or her own personal strengths, limitations, aptitudes, and abilities. For students with disabilities, self knowledge is further extended to include knowledge of their disability and how it affects their daily life and educational pursuits.

Assertiveness. Assertiveness is the second major component of self-advocacy. This construct has been defined as the effective communication of personal thoughts and feelings in interpersonal encounters in a fashion that respects and regards the thoughts and feelings of others (Wolpe, 1958; Wolpe \& Lazarus, 1966). Assertive communication is differentiated from nonassertive and aggressive communication in the following way: non-assertive communication disrespects the rights of oneself and aggressive communication disrespects the rights of others. 
College students who are lower in assertiveness report more loneliness than do assertive students (Gambrill, Florian, \& Splaver, 1986).

Communication skills. Finally, communication skills represent the behavioral aspect of assertiveness and self-advocacy. Communication skills are what allow students to transmit their thoughts and feelings to others as well as develop open lines of communication. Not only would communication skills encompass verbal skills, but also nonverbal skills such as tone of voice and body language. Students need to be able to express themselves clearly and concisely to others when trying to self-advocate. For example, when a student is attempting to meet with a professor about arranging accommodations, the student should be able to specifically explain the problem and provide whatever examples are needed in a clear and confident manner.

Dale (1995) evaluated a program for first-year students at Purdue University that taught a combination of advocacy and life skills. Though it would be impossible to separate out the influence of self-advocacy training, the program significantly increased the long-term retention rate of the students who participated in the program. Longitudinal data showed an $85 \%$ retention rate for the intervention group over a five-year period versus $47 \%$ for the control group.

Self-advocacy has also been related to self-concept for students with disabilities (Appleby, 1994) and learning self-advocacy skills can increase assertive behaviors (Starke, 1987). In addition, qualitative research by Lehmann, Davies, and Laurin (2000) reported that students with disabilities themselves identified their need to develop the skills associated with self-advocacy. All and all, the last twenty years has seen efforts to teach students with disabilities self-advocacy skills and then evaluate the efforts based on "expert" interpretation. However, Brinckerhoff (1994) and Izzo (2001) both suggest efforts should be based on providing students 
with disabilities real, authentic opportunities to make decisions and accept consequences. Such opportunities might be found in athletic participation.

Athletics, Disability, and Adjustment to College

There is little research examining the influence of athletic participation on adaptation to college, coping variables, self-efficacy or perceived social support for students with disabilities. There is even less research comparing athletes to non-athletes on these variables. A comprehensive search of literature conducted covering the years of 1986 to 1996 elicited 436 articles, over half of which were review articles (Reid \& Prupas, 1998). Of the 204 data-based articles, 87 examined differences/similarities of athletes with disabilities. A majority did not actually involve direct comparisons of disabled and non-disabled populations and primarily centered on athletic injuries and physiological profiles, not psychosocial concepts (Reid \& Prupas). However, some psychosocial literature does exist examining social support mechanisms of athletes with disabilities (Martin \& Mushett, 1996), the meaning of sport for athletes with disabilities (Wheeler, Malone, Van Vlack, Nelson \& Steadward, 1996), and transition out of disability sport (Martin, 1999a; Wheeler, Steadward, Legg, Hutzler, Campbell, \& Johnson, 1999). All in all, the psychosocial research conducted within disability sport suggests that it has considerable incentives, is associated with enhanced self-esteem, and is a perceived option for transcending impairment by some athletes (Wheeler et al., 1999).

Social support mechanisms for athletes with disabilities were explored through the Support Functions Questionnaire (SFQ) (Martin \& Mushett, 1996); Rosenfeld, Richman, \& Hardy, 1989). The SFQ asks individual to rate the importance of six different kinds of social support and then identify the individuals who supply that support. Thus, the instrument captures factors related to social network components. Two additional measures, one for self-efficacy and 
one for athletic satisfaction, were included in the survey administration. Seventy elite male and female swimmers with physical disabilities, ranging in age from 12 to 44 completed the survey packets. Results of the athletes with disabilities were compared retrospectively with a similar study conducted by Hardy, Richmond, and Rosenfeld (1991), utilizing the SFQ, in a population of non-disabled intercollegiate athletes. Martin and Mushett (1996) found an average of 3 to 4 people who provided each type of social support for the athlete with disabilities. The athletes without disabilities in the Hardy et al. study had approximately two people providing each type of support. Thus, the athletes with disabilities generally had larger support networks than the athletes in Hardy's study. In addition, for athletes with disabilities, the same people (generally parents) tended to provide support across all the support types. The results of this study suggest a potential difficulty as it may apply to students with disabilities transition into the college environment. If the majority of support provided to individuals with disabilities comes from the family, particularly the parents, for those moving away from home to attend college distance may limit this very important support resource.

Students with disabilities have generally displayed lower scores on developmental skills related to interpersonal relationships (Beneshoff and Fried, 1990), which suggests a lower capacity for developing and maintaining important social relationships. If social integration into the university community through increased on campus as opposed to off-campus support is important to student well being and adjustment (Brissette, Scheier, and Carver, 2002), students with disabilities may be at risk for lower adjustment.

A qualitative study examining themes related to retirement for athletes with disabilities suggested that sport served as a vital opportunity to experience and develop personal competence (Wheeler et al., 1996). In addition, involvement in sport appeared to serve as a way of combating 
marginalization and provided an outlet that aided in social integration. The themes important to this project that emerged included: (1) facilitation of self-confidence and a strong belief in self, (2) increased awareness of one's potential, (3) increased perceptions of independence and control over one's life, (4) an increased sense of accomplishment and feeling of self-actualization, (5) active encouragement to set and pursue goals, (6) strengthening of determination to attain set goals, (7) the competitiveness fostering a more assertive approach to achieving goals through competition (8) providing opportunities to connect and bond with others, increase social skills, and broaden social experiences, and finally (9) facilitating societal inclusiveness (Blinde \& Taub, 1999).

Even though students with disabilities may be at an increased risk for maladjustment, due to reduced developmental skills related to interpersonal relationships and less extensive social support networks, participation in sport may "fill in the gap". As discussed previously, Sanders and Dubois (1996) provided support for a strong correlation between social support provided by campus organizations and total adjustment. Athletic teams are one campus organization that could provide this type of support to students. For the participants in the Blinde and Taub (1999) study sport was an opportunity to connect and bond with others, increase social skills, broaden social experiences, and facilitating societal inclusiveness. The result of the opportunities provided by sport participation may supply the needed stimulus to develop better skills related to interpersonal relationships and higher perceived social support. This would potentially allow a student to developed the needed on-campus support that fosters social integration and adjustment to the college environment. 


\section{Recommendations for Future Research}

Based on this review of literature, the primary recommendation for future research is for research to actually involve students with disabilities. There is a dearth of well-designed studies examining variables that possibly influence adjustment and eventual matriculation for students with disabilities. There is little evidence on whether present theoretical frameworks can apply to this minority group. Research should be conducted to investigate what differences occur between disability and non-disability student populations that might account for the lower college outcomes reported (NCD, 2003). In addition, research investigating what factors positively or negatively influence students with disabilities should be expanded to include psychosocial variables. Most research to date has focused on environmental and policy variables and how they influence access for students with disabilities. While these efforts continue, research also needs to be conducted that will allow educators and counselors to assist students with disabilities to develop strategies and skills that contribute to positive college outcomes. By identifying areas of strength and weakness within the disability student population as a whole, interventions can be created and tailored to address the general and specific needs of this student population. 
Appendix B: Additional Methods Section

\section{Research Design}

As discussed previously, gender and year in school were matching variables for the sample populations. Disability status will serve as an independent variable within the larger sample, while athletic status will serve as an independent variable within the disability subgroup. Perceived social support, coping style, self-efficacy, and self-advocacy skills will be the dependent variables.

This study employed a QUAN + qual (Morse, 2003) mixed methods utilizing a concurrent triangulation design. Concurrent triangulation designs are utilized when a researcher is attempting to confirm, cross-validate, or corroborate findings within a single study (Morgan, 1998). Separate quantitative and qualitative methods are generally used to offset the weaknesses inherent within one method with the strengths of the other method (Creswell, Plano Clark, Gutmann, \& Hanson, 2003). With this type of design, equal priority can be given to one or both methodological approaches. This study gave priority to the quantitative methods to drive the study. Integration of the data occurred in the interpretation stage of the research. This means that data collected from the two methods were analyzed separately and then compared utilizing a “comparing results" analytic procedure that supports statistical trends with qualitative themes.

There are several strengths of this research design. First, concurrent triangulation design can result in well-validated and substantiated findings (Creswell et al., 2003). Second, collecting the quantitative and qualitative data concurrently allows for a shorter data collection period as opposed to sequential designs. Third, by matching the samples of students with and without disabilities it increases the likelihood that differences found between the two groups are a result of the independent variables. Limitations of this research design are lower external validity. By 
utilizing convenient sampling, generalizability is compromised and results will have to be considered within the context of the study. In addition, utilizing mixed methods requires greater efforts and expertise to adequately study a phenomenon and it can be difficult and unclear to a researcher how to resolve discrepancies that arise between the two analyses of the different data forms (Creswell et al.).

Translating the Surveys to Web Format. To facilitate data collection the consent form and survey instrument packet were translated into an online web page format. One of the benefits of online research is that it allows for automation as a human experimenter does not need to give instructions, introduce the experiment, and/or supervise data collection (Kraut et al., 2004). Web surveys are both flexible and less error prone as results can be transferred right into an existing database. Challenges and concerns do exist with conducting surveys online, however with reasonable safeguards these concerns can be reduced.

Online data collection reduces the control over the environment in which the research is conducted. Therefore, Kraut and colleagues (2004) encourage researchers to pre-test instructions, and data collection instruments thoroughly prior to the start of the research project. Pre-testing of the online data collection system for this project occurred through pilot research discussed in the next section. Another additional concern with conducting web-based research is the anonymous nature of the Internet allows for frivolous or malicious activity to disrupt the integrity of the research. One way to control such activity, such as multiple submissions by one person, is to invite known individuals to participate.

Protection of human subjects is also a concern with web-based research that must be monitored and planned for in the set-up of the project. In general, online research poses no more risk to human subjects than comparable research conducted through other means (Kraut et al., 
2004). To maintain the anonymity of participants' responses, particular attention was given to how information was collected and stored within the website. Recording personal identifiers separately from the research data served to decrease risks to confidentiality.

\section{Pilot Research}

First, the survey packet was piloted to a convenient sample of undergraduate students in a sport psychology seminar class to determine the average time required for completing the paper and pencil surveys. The average time to completion of the survey packet was 25 minutes.

Next, a second sample of graduate students was chosen to pilot the online data collection system. Each participant received an email from the researcher that contained instructions on how to access and use the survey website. Testing entailed participants utilizing the emailed link to navigate to the website. Students then completed the data collection procedure to include: reading the instructions, fulfilling the consent process, completing the surveys themselves, and then completing the optional interview interest form and entry form for the prize drawing. Participants were asked to identify any misspellings or errors within the question format and provide general feedback on the ease of use and experience. Feedback was returned to the researcher via email. Small modifications were made passed on the feedback provided.

Lastly, the researcher utilized six students as part of a class project to pilot the interview protocol. Piloting allowed for the researcher to practice the specific interview script prior to data collection. The researcher's skill to attend to both the content and process is essential to obtaining worthwhile information; therefore, practice was necessary. Piloting the script was also crucial for determining if questions were eliciting the appropriate and expected information.

Six students, five females and one male, participated in the piloting of the interview script. Three participants were fourth year students, two were second year students, and one was 
completing her first year. Two of the students were currently participating in an intercollegiate sport. Two had participated during their freshmen year and then quit. One student participated in club sports and one student did not participate in a sport. However, all students reported being physically active in some way. In addition, all students were currently pursuing the same major.

Participants completed one interview session with the researcher. Interviews were conducted in a private room that allowed for uninterrupted conversation and ease of listening. Prior to the start of each interview students provided informed consent, were allowed to read through the interview script and the researcher answered any questions. Each interview was recorded utilizing a standard microcassette recorder. The researcher conducted the interview with each student following the same script, utilizing standard probes to follow up and elicit more information. Following the completion of the interview, the researcher turned off the recorder and debriefed with the participant. Each participant was asked if there were any questions that they did not understand. Information was also solicited about any questions that were unclear or ambiguous to the student. In addition, the researcher asked participants to comment on their comfortableness in the interview and interaction with the researcher. Lastly, students were asked to provide recommendations for ways the protocol could be improved based on their experience. The researcher noted feedback during the debriefing.

Following completion of the interviews, the tapes were transcribed verbatim and then reviewed for accuracy. Responses were examined to confirm the content that each question was eliciting from the participants. A meeting was held with the researcher's committee member most experienced in qualitative research to re-examine the question strategy based on participant feedback and data collected from the interviews. Changes to the interview script were made and justified based on the information collected during the pilot. 
Changes to Interview Script. There were four major changes made to the interview script based on the piloting process. First, the original script had contained a question that simply asked: "Could you tell me what it means to self-advocate?" This item was designed to explore the student's understanding and perception of the term self-advocacy. The question was the only item that participants indicated was confusing and interrupted the flow of conversation.

The way the item was originally phrased it was presented as a knowledge question right after the participants had been asked to be reflective on their past experience with a difficult situation. To fix the problem of flow and provide a better lead into discussion of the term self-advocacy a change in the presentation and timing of the question was made. The researcher decided that recognition of behaviors that maybe associated with self-advocacy were more enlightening than knowing a specific definition. Therefore the question was changed in the following manner: "Reflecting back on the experiences we just discussed, explain as best you can how you think you did or could have advocated for yourself in those situations?

a. So based on your perspective and experiences, what may be a possible definition for self-advocacy?"

Second, when asking students about the supportive relationships in their life, most did a good job in listing people and what relationship they had with them. However, the original questioning strategy was providing limited information about what type of support each person provided. Therefore, the researcher added a prompt to go back though the list of people that are mentioned and confirm what types of support they were providing to the student. In addition, the section on social support was ended with the following two questions:

How do you perceive the availability of support if you needed it?

In general, how have you felt about the support you have received? 
Based on the data gathered from the pilot interviews, the researcher found that these items were not eliciting any new or novel information. Therefore, these two questions were dropped. The researcher then added a question to end the discussion of social support that was more likely to reveal different and enlightening information about the students' satisfaction with their social support. The following question was added to the end of the social support section:

"In terms of adjusting and managing life in college, is there any type of support you wish you had that would make your time at college better?"

A third change that was made to the interview questions was the addition of a question regarding the student's expectations for college. The addition of this question was suggested by one of the students interviewed. The question is consistent with the transition theory of Schlossberg, Waters, and Goodman (1995) that stresses that adjustment will be influence by how closely expectations for a transition match up with the reality of the situation. Hence a question was added to the beginning of the adjustment section that asks the student to reflect on the expectations they had and if they differed from the experience.

"During your first semester, did any of the expectations you had about going to college differ from what you experienced once you got here? [What and How]" This question then leads into discussing the student's first semester experiences. The questions guiding the student's reflection on their first semester did not change. However, changes were made to the question strategy to gain a more longitudinal perspective on the student's adjustment process. The original follow up questioning was replaced in the following manner:

Original Follow up Questioning
How would you say that you are currently managing within college?

Academic

Social

Emotional

Working toward career goals 
New Follow-up

Questioning
How did things change, if at all, in your Sophomore Year? Junior Year? Senior Year?

How would you say you are currently managing within college?

Working toward your career goals?

The researcher felt that the new questioning would obtain information that would be more effective in supporting or contrasting Medalie's (1984) transition theory. Additional support for this alternation was provided by at least one participant who experienced adjustment concerns in her sophomore year as opposed to her freshmen year. The researcher felt the change would assist in expanding and enriching the data, especially when interviews were conducted with seniors or graduate students.

\section{Instrumentation}

Demographic Questionnaire. A demographic questionnaire (see Appendix A) was utilized to capture information on each participant. The questionnaire captured information on gender, age, year in school, disability characteristics, and intercollegiate athletic participation. The demographics questionnaire also contained a series of five questions that attempted to tap the students' perception of their current level of college adjustment. The five questions presented represent the four major areas of adjustment (i.e. Academic, Social, Personal/Emotional, and Institutional/Goal Achievement), discussed previously, however, the questions have been written generally, so as to apply to any level of student, not just freshmen. For example, "How would you rate your current level of academic achievement?" Each student's scores on the five adjustment questions were to be totaled to produce an overall adjustment score. 
Internal consistency was calculated for the total adjustment scale for both the disability and non disability populations ( 0.59 and 0.62 , respectfully). Since neither of the internal reliability measures reached a 0.70 level, the researcher determined that the created items did not reliably hold together as a total scale. Therefore, analysis was completed utilizing each individual question.

Perceived Social Support Measure. The Interpersonal Support Evaluation List - College Version (ISEL) (Cohen \& Hoberman, 1983) (see Appendix B) is a 48-item self-report survey that measures an individual's perceived availability of potential social resources. Items were developed on theoretical grounds to cover the domain of socially-supportive elements of relationships which college students might be expected to experience. In addition to providing an overall support measure, the ISEL measures four separate functions of social support: tangible support, appraisal support, self-esteem support, and belonging support. The tangible support subscale measures the perceived availability of material aid. The appraisal support subscale measures the perceived availability of someone with whom to discuss issues of personal importance. The self-esteem subscale captures the presence of others with whom the individual feels he or she compares favorably. Finally, belonging support measures the perception that there is a group with which one can identify and socialize. Each subscale consists of twelve questions, six positively phrased and six negatively phrased.

The internal reliability (Cronbach alpha) for the total scale is .86. Cronbach alphas for the subscales were: tangible subscale $=.71$, belonging scale $=.75$, self-esteem subscale $=.68$, and the appraisal subscale $=.77$. Items were found to correlate more highly with their assigned subscale than with any other subscale. Intersubscale correlations were not significant with two exceptions. The belonging subscale was moderately correlated with both the tangible and 
appraisal subscales. The authors rationalized that it is possible that feelings of belonging are necessary in order to approach someone for either tangible or appraisal support. Therefore, it may not be possible to create a belonging scale that is totally independent (Cohen \& Hoberman, 1983).

Brookings and Bolton (1988) provided construct validity for the ISEL by performing a confirmatory factor analysis study. The four-factor model was supported by the confirmatory factor analysis. This research supported the ISEL as a valid measurement of general perceived social support construct. However, the authors suggested that analyzing the ISEL solely as a unidemensional measure might result in the loss of unique information carried within the four subscales. In addition, in Cohen and Hoberman's (1983) original study the ISEL was positively correlated $(.46, p<.001)$ with scores on the Inventory of Socially Supported Behaviors (Barrera, 1981; Barrera, Sandler, \& Ramsay, 1980). This evidence provides support for the concurrent validity of the measure. Overall, the ISEL-CF appears to have reasonable psychometric properties and has been used with college student populations (Lakey \& Cassady, 1990).

Internal reliability was calculated for the disability and non-disability populations within the present study. Total scale reliability was 0.97 for the disability population and 0.95 for the non-disability population. Subscale internal consistencies ranged between 0.71 and 0.95 for both sample groups and generally showed greater internal consistency than the previously mentioned studies.

Coping Style Measure. The Coping Inventory for Stressful Situations (CISS) (see Appendix C) is a 48-item self-report instrument utilized for measuring multidimensional coping (Endler \& Parker, 1999). Three coping dimensions are evaluated with the CISS: Task, Emotion and Avoidance. The avoidance scale also has two additional sub-scales, Distraction, and Social 
Diversion. Respondents are asked to rate their level of engagement in each of the 48-items on a Likert-type rating scale ranging from (1) "Not at all" to (5) "Very much."

The CISS scales were derived from both theoretical and empirical bases, and have been used in a variety of research and applied settings. An original 70-item inventory was administered to 559 undergraduate males and females. The 70 items were analyzed using principal-components analysis with varimax rotation, and three factors emerged which were labeled Task-Oriented, Emotion-Oriented, and Avoidance-Oriented coping (Endler \& Parker, 1990). The factor structures were almost identical for males and females when separate analyses were conducted. In a second study, a sample of 394 college students and 284 adults were given a revised 66-item inventory and again principle-components factor analysis with varimax rotation was completed (Endler \& Parker, 1990). After eliminating items that loaded .35 or above on two or more factors or items that did not load .35 or above on any one of the three factors, the current 48-item instrument was created. Again the factor structures of the adult and college populations were compared using congruence coefficients and the structures were found to be virtually identical.

The internal reliability coefficients ranged between .85 and .95 for each of the three scales. Six week test re-test reliabilities were reported at .51 to .74 (Endler \& Parker, 1990). In addition, the CISS has demonstrated good concurrent and construct validity and has been normed on both college undergraduate and disability populations (Endler \& Parker, 1994).

Internal consistency values were calculated within the disability and non-disability samples for the Task Coping scale, Emotion Coping scale, and Distraction Coping scale. Within the disability sample the Task Coping scale was 0.83 , the Emotion coping scale was 0.90 , and the Distraction Coping scale was 0.79 . For the non-disability population the Task Coping scale 
was 0.86 , the Emotion Coping scale was 0.89 , and the Distraction Coping scale was 0.82 . These internal consistency values show slightly lower internal consistency than previous research (Endler \& Parker, 1990), yet still acceptable.

Self-Efficacy Measure. The Self-Efficacy Scale (Sherer et al., 1982) (see Appendix D) is a 23-item instrument consisting of 2 subscales, general self-efficacy and social self-efficacy. The development of this instrument provided a measure of self-efficacy that is not tied to specific situations or behavior (Sherer et al., 1982). Sherer and colleagues established both reliability and validity for the Self-Efficacy Scale. Utilizing a sample of 376 undergraduate students, factor analysis was conducted on an original 36-item pool. Results of the analysis confirmed a twofactor solution and thirteen items that did not load at a .40 level or higher were discarded. Cronbach alpha coefficients of .86 and .71 were obtained for the General Self-efficacy subscale and Social Self-efficacy subscale, respectively. In 2003, Choi conducted a further examination of the factorial validity of the Self-Efficacy Scale using a sample of 651 male and female undergraduate students. The principal component analysis with an orthogonal rotation produced a two-factor model remarkably similar to Sherer et al. (1982) earlier work, providing further evidence for the factorial validity of the Self-Efficacy Scale.

Construct validity was established by running correlations with several other measures of personality characteristics related to personal efficacy (e.g. Rotter's Internal-External Control Scale, Ego Strength Scale, Interpersonal Competency Scale, and Rosenberg's Self-Esteem Scale). Results indicated that the Self-efficacy Scale was moderately correlated with each item in the expected direction. However, none of the correlations were of sufficient magnitude to indicate that any of the scales were measuring the same underlying construct (Sherer et al., 1982). Sherer and Adams (1983) demonstrated further construct validity by utilizing a sample of 
101 undergraduate males and females who completed the Self-efficacy Scale, the MMPI, and the Rathus Assertiveness Scale. Higher scores on the general self-efficacy sub-scale were moderately correlated with better adjustment as measured by the $D, P t$, and Si scales of the MMPI (Sherer \& Adams, 1983).

Internal consistency values were determined for the Self-Efficacy total scale and general and social subscales. Results indicated less than optimal internal consistency within the sample groups. The Cronbach Alpha value within the disability sample for the total scale was only 0.68 and 0.61 within the non-disability sample. The low alphas were a result of significantly lower internal consistency values for the social subscale in both the disability and non-disability samples (0.49 and 0.38 respectively) than found in previous research (Sherer et al., 1982). Internal consistency for the general subscale reached 0.76 in the disability sample and 0.73 in the non-disability sample. Therefore, the decision was made to utilize only the general subscale as the measure for self-efficacy instead of the total score of the Self-Efficacy Scale.

Interview Script. Potential questions for the interview script were generated based on a review of the relevant literature to query self-advocacy, coping with stress, social support, and adjustment. Questions were then reviewed for wording and sequencing based on recommendations made by Patton (2002) in his discussion of qualitative interviewing. A preliminary script was presented to two faculty experts, both with experience in qualitative interviewing, for suggestions and feedback. The script was then piloted as discussed previously. Alternations to the interview script were made based on the data gathered from the pilot research. 
Appendix C: Complete Reference List

Appleby, E. (1994). The relationship between self-advocacy and self-concept among college students with disabilities (Doctoral dissertation, New York University, 1994). Dissertation Abstracts International, 54, 4588.

Baker, R. \& Schultz, K. (1992). Measuring expectations about college adjustment. NACADA Journal, 12, 23-32.

Baker, R. \& Siryk, B. (1984). Measuring adjustment to college. Journal of Counseling Psychology, 31, 179-189.

Barrera, M. (1981). Social Support in the adjustment of pregnant adolescents: Assessment issues. In B. Gottlieb (Ed.), Social networks and social support. Beverly Hills: Sage Publications.

Bandura, A. (1977). Self-efficacy: Toward a unified theory of behavior change. Psychological Review, 94, 191-215.

Barrera, M., Sandler, I., \& Ramsay, T. (1980). Preliminary development of a scale of social support: Studies on college students. American Journal of Community Psychology, 9, 435-447.

Benshoff, J. \& Fried, J. (1990). Developmental skill attainment among college students with disabilities. Rehabilitation counseling Bulletin, 34, 44-53.

Beyers, W., \& Goossens, L. (2003). Psychological separation and adjustment to university: Moderating effects of gender, age, and perceived parenting style. Journal of Adolescent Research, 18, 363-382.

Bianco, T., \& Eklund, R. (2001). Conceptual considerations for social support research in sport and exercise settings. Journal of Sport and Exercise Psychology, 23, 85-108. 
Blake, T. (2002). Self-esteem and self-efficacy of college students with disabilities. College Student Journal, 36, 214-221.

Blinde, E. \& Taub, D. (1999). Personal empowerment through sport and physical fitness activity: Perspectives from male college students with physical and sensory disabilities. Journal of Sport Behavior, 22, 181-203.

Brinckerhoff, L. (1994). Developing effective self-advocacy skills in college-bound students with learning disabilities. Intervention in School and Clinic, 29, 229-237.

Brissette, I., Scheier, M., \& Carver, C. (2002). The role of optimism in social network development, coping, and psychological adjustment to life transition. Journal of Personality and Social Psychology, 82, 102-111.

Brookings, J. \& Bolton, B. (1988). Confirmatory factor analysis of the Interpersonal Support Evaluation List. American Journal of Community Psychology, 16, 137-147.

Burbach, H. \& Babbitt, C. (1988). Physically disabled students on the college campus. RASE: Remedial and Special Education, 9, 12-19.

Cairns, D. \& Baker, J. (1993). Adjustment to spinal cord injury: A review of coping styles contributing to the process. Journal of Rehabilitation, 30- 33.

Carver, C., Scheier, M., \& Weintraub, J. (1989). Assessing coping strategies: A theoretically based approach. Journal of Perosnality and Social Psychology, 56, 267-283.

Chickering, A. (1969). Education and identity. San Francisco: Jossey-Bass.

Choi, N. (2003). Further examination of the Self-Efficacy Scale. Psychological Reports, 92, 473480.

Cobb, S. (1976). Social support as a moderator of life stress. Psychosomatic Medicine, 38, 300314. 
Cohen, S. (1988). Psychosocial models of the role of social support in the etiology of physical disease. Health Psychology, 7, 269-297.

Cohen, S., \& Hoberman, H. (1983). Positive events and social supports as buffers of life change stress. Journal of Applied Social Psychology, 13, 99-125.

Cohen, S., Kamarck, T., \& Mermelstein, R. (1985). A global measure of perceived stress. Journal of Health and Social Behavior, 24, 385-396.

Cohen, S. \& McKay, C. (1984). Social support, stress and the buffering hypothesis: A theoretical analysis. In A Baum, J.E. Singer, \& S. Taylor (Eds.), Handbook of Psychology and Health (Vol. IV). Hillsdale, NJ: Erlbaum.

Cohen, S., Sherrod, D., \& Clark, M. (1986). Social skills and the Stress-Protective role of social support. Journal of Personality and Social Psychology, 50, 963-973.

Cohen, S. \& Willis, T. (1985). Stress, social support, and the buffering hypothesis. Psychological Bulletin, 98, 310-357.

Collins, K. (1995). A model of college adjustment for students with physical disabilities. Unpublished doctoral dissertation, University of Illinois at Urbana-Champaign.

Compas, B. (1987). Stress and coping during childhood and adolescence. Psychological Bulletin, 101, 393-403.

Creswell, J., Plano Clark, V., Gutmann, M., \& Hanson, W. (2003). Advanced mixed methods research designs. In A. Tashakkori \& C. Teddlie (Eds.), Handbook of mixed methods in social and behavioral research (pp. 189-208). Thousand Oaks, CA: Sage Publications.

Cutrona, C. (1982). Transition to College: Loneliness and the Process of Social Adjustment. In L. Peplau \& D. Perlman (Eds.), Loneliness: A sourcebook for current research, theory, and therapy. New York: John Wiley \& Sons. 
Dale, P. \& Zych, T. (1996). A successful college retention program. College Student Journal, 30, 354-361.

Day, A. \& Livingstone, H. (2003). Gender differences in perceptions of stressors and utilization of social support among university students. Canadian Journal of Behavioral Science, 35, 73-83.

Durlak, C., Rose, E., \& Bursuck, W. (1994). Preparing high school students with learning disabilities for the transition to postsecondary education: Teaching skills of selfdetermination. Journal of Learning Disabilities, 27, 51-59.

Elliot, T. \& Gramling, S. (1990). Personal assertiveness and the effects of social support among college students. Journal of Counseling Psychology, 37, 427-436.

Elliott, T., Herrick, S., \& Witty, T. (1992). Problem-solving appraisal and the effects of social support among college students and persons with physical disabilities. Journal of Counseling Psychology, 39, 219-226.

Endler, N. \& Parker, J. (1989). Coping with frustrations to self-realization: Stress, anxiety, crises, and adjustment. In E. Krau (Ed.), Self-realization, success, and adjustment (pp. 153-164). New York: Praeger.

Endler, N. \& Parker, J. (1990). Multidemensional assessment of coping: A critical evaluation. Journal of Personality and Social Psychology, 58, 844-854.

Endler, N. \& Parker, J. (1994). Assessment of multidimensional coping: Task, emotional, and avoidance strategies. Psychological Assessment, 6, 50-60.

Endler, N. \& Parker, J. (1999). CISS: Coping Inventory for Stressful Situations manual (2 $2^{\text {nd }}$ ed.). New York: Multi-Health Systems.

Fleischman, J. (1984). Personality characteristics and coping patterns. Journal of Health and 
Social Behavior, 25, 229-244.

Gambrill, E., Florian, V., \& Splaver, G. (1986). Assertion, loneliness, and perceived control among students with and without disabilities. Rehabilitation Counseling Bulletin, 30, 412.

Gerdes, H. \& Mallinckrodt, B. (1994). Emotional, social, and academic adjustment of college students: A longitudinal study of retention. Journal of Counseling \& Development, 72, 281-288.

Groomes, D. \& Leahy, M. (2002). The relationship among the stress appraisal process, coping disposition, and level of acceptance of disability. Rehabilitation Counseling Bulletin, 46, $15-24$.

Hampton, N. (2004). Subject well-being among people with spinal cord injuries: The role of selfefficacy, perceived social support, and perceived health. Rehabilitation Counseling Bulletin, 41, 31-37.

Hardy, C., Richman, J. \& Rosenfeld, L. (1991). The role of social support in the life stress/injury relationship. Sport Psychologist, 5, 128-139.

Harrell, R. \& Strauss, F. (1986). Approaches to increasing assertive behavior and communication skills in blind and visually impaired persons. Journal of Visual Impairment and Blindness, 80, 794-798.

Hays, R. \& Oxley, D. (1986). Social network development and functioning during a life transition. Journal of Personality and Social Psychology, 50, 305-313.

Henderson, C. (2001). 2001 College freshmen with disabilities: A biennial statistical profile (Cooperative Agreement No. H326H980002). Washington. DC: HEATH Center of American Council on Education. 
Hudek-Knezevic, J. \& Kardum, I. (2000). The effects of dispositional and situational coping, perceived social support, and cognitive appraisal on immediate outcome. European Journal of Psychological Assessment, 16, 190-201

Hunter, J. \& Schmidt, F. (1990). Methods of meta-analysis: Correcting error and bias in research findings. Newbury Park, CA: Sage Publications.

Hutchison, C. (1999). Social support: Factors to consider with designing studies that measure social support. Journal of Advance Nursing, 29, 1520-1526.

Izzo, M., Hertzfeld, J., \& Aaron, J. (2001). Raising the bar: Student self-determination + good teaching = success. Journal of Vocational Special Needs Education, 24, 26-36.

Johnson, J. (1997). Commuter college students: What factors determine who will persist and who will drop out? College Student Journal, 31, 323-332.

Klein, H. \& Rennie, S. (1985). Temperament as a factor in initial adjustment to college residence, Journal of College Student Personnel, 26, 58-62.

Kraut, R., Olson, J., Banaji, M., Bruckman, A., Cohen, J, \& Couper, M. (2004). Psychological research online: Report pf board of scientific affairs' advisory group on the conduct of research on the Internet. American Psychologist, 59, 105-117.

Krebs, C. (2002). Self-advocacy skills: A portfolio approach. RE:view, 33, 160-163.

Krotseng, M. (1992). Predicting persistence from the student adaptation to college questionnaire: Early warning or siren song? Research in Higher Education, 33, 99- 111.

Lakey, B., \& Cassady, P. (1990). Cognitive processes in perceived social support. Journal of Personality and Social Psychology, 59, 337-343.

Lazarus, R., \& Folkman, S. (1984). Stress, appraisal, and coping. New York : Springer Pub. Co. Leatherman-Sommers, S. (2000). Attachment and adjustment to college among students with 
physical disabilities. Dissertation Abstracts International, 60 (7-B), 3570.

Lehmann, J., Davies, T., \& Laurin, K. (2000). Listening to student voices about postsecondary education. Teaching Exceptional Children, 32, 60-65.

Livneh, H., \& Wilson, L. (2003). Coping strategies as predictors and mediators of disabilityrelated variables and psychosocial adaptation: An exploratory investigation. Rehabilitation Counseling Bulletin, 46, 194-208.

Leong, F. \& Bonz, M. (1997). Coping styles as predictors of college adjustment among freshmen. Counseling Psychology Quarterly, 10, 211-221.

Lu, L., \& Argyle, M. (1992). Receiving and giving support: Effects on relationship and wellbeing. Counseling Psychology Quarterly, 5, 123-134.

Mallinckrodt, B. (1988). Student retention, social support, and dropout intention: Comparison of black and white students. Journal of College Student Development, 29, 60-64.

Martin, J. (1999). Loss experiences in disability sport. Journal of Personal and Interpersonal Loss, 4, 225-231.

Martin, J., \& Mushett, C. (1996). Social support mechanisms among athletes with disabilities. Adapted Physical Activity Quarterly, 13, 74-84.

Martin, W., Swartxz-Kulstad, J., \& Madson, M. (1999), Psychosocial factors that rpredict the college adjustment of first-year undergraduate students: Implications for college counselors. Journal of College Counseling, 2, 121-133.

McCrae, R. \& Costa, P. (1986). Personality, coping, and coping effectiveness in an adult sample. Journal of Personality, 54, 385-405.

McGowan, J. (1984, August). Social support, social loss and positive and negative psychological functioning. Paper presented at the Annual convention of the American Psychological 
Association, Ontario, Canada.

McKemy, M. (1996). Resilience in college students with physical disabilities. Unpublished dissertation.

Medalie, J. (1981). The college years as a mini-life cycle: Developmental tasks and adaptive options. JACHA, 30, 75-79.

Miller, S., Brody, D., \& Summerton, J. (1988). Styles of Coping with Threat: Implications for Health. Journal of Personality and Social Psychology, 54, 142-148.

Montgomery, R., Haemmerlie, F., \& Ray, D. (2003). Psychological correlates of optimism in college students. Psychological Reports, 92, 545-547.

Morgan, D. (1998). Practical strategies for combining qualitative and quantitative methods: Applications to health research. Qualitative Health Research, 8, 362-367.

Morse, J. (2003). Principles of mixed methods and multimethod research design. In A. Tashakkori \& C. Teddlie (Eds.), Handbook of mixed methods in social and behavioral research (pp. 189-208). Thousand Oaks, CA: Sage Publications.

National Collegiate Athletic Association. (n.d.). Graduation rates of division I student-athletes who entered college in 1996. Retrieved February 10, 2004, from https://www.ncaa.org/grad_rates/2003/d1/d1_aggregate/comparison.html

National Council on Disability. (2003, September). People with disabilities and postsecondary education. Retrieved September 30, 2003 from http://www,ncd.gov/newsroom/pubications/education.html.

Owens, S. (1999). Stress and coping in college seniors: Using a graduation transition workshop to facilitate adaptation to life change. Dissertation Abstracts International, 59 (8-B), 4479. 
Pappas, J. \& Loring, R. (1985). Returning learner. In Lnoel, R Levitz, \& D. Saluri (Eds.), Increasing student retention: Effective programs and practices for reducing the dropout rate (pp. 138-161). San Francisco, CA: Jossey-Bass.

Pascarella, E. \& Chapman, D. (1983). A multiinstitutional, path analytic validation of Tinto's model of college withdraw. American Educational Research Journal, 20, 87-102.

Pascarella, E. \& Terenzini, P. (1991). How college affects students. San Francisco, CA: JosseyBass.

Patton, M. (2002). Qualitative research and evaluation methods ( $3^{\text {rd }}$ ed.). Thousand Oaks, CA: Sage Publications.

Perna, F., Zaichkowsky, L., \& Bocknek, G. (1996). The association of mentoring with psychosocial development among male athletes at termination of college career. Journal of Applied Sport Psychology, 8, 76-88.

Petrie, T \& Russell, R. (1995). Academic and psychosocial antecedents of academic performance for minority and nonminoroty college football players. Journal of Counseling \& Development, 73, 615-620.

Pensgaard, A., Roberts, G., \& Ursin, H. (1999). Motivational factors and coping strategies of Norwegian paralympic and Olympic winter sport athletes. Adapted Physical Activity Quarterly, 16, 238-250.

Powers, L. (1995). An exploratory, randomized study of the impact of mentoring on the selfefficacy and community-based knowledge of adolescents with severe physical challenges. Journal of Rehabilitation, 61, 33-42.

Reid, G., \& Prupas, A. (1998). A documentary analysis of research priorities in disability sport. Adapted Physical Activity Quarterly, 15, 168-179.

Robbins, S., Lauver, K., Le, H., Davis, D., Langley, R., \& Carlstrom, A. (2004). Do psychosocial 
and study skill factors predict college outcomes? A meta-analysis. Psychological Bulletin, $130,261-288$.

Sanders, K. \& DuBois, D. (1996). Individual and socio-environmental predictors of adjustment to college among students with disabilities. Journal of Postsecondary Education and Disability, 12, 28-42.

Saracoglu, B., Minden, H., \& Wilchesky, M. (1989). The adjustment of students with learning disabilities to university and its relationship to self-esteem and self-efficacy. Journal of Learning Disabilities, 22, 590-592.

Schlossberg, N., Waters, E., \& Goodman, J. (1995). Counseling adults in transition: Linking practice with theory ( $2^{\text {nd }}$ ed.). New York: Springer Publishing Co.

Shelton, H. (1990). Developing the construct of general self-efficacy. Psychological Reports, 66, 987-994.

Sherer, M. \& Adams, C. (1983). Construct validation of the Self-Efficacy Scale. Psychological Reports, 53, 899-902.

Sherer, M., Maddux, J., Mercandante, B., Prentice-Dunn, S., Jacobs, B., \& Rogers, R. (1982). The Self-Efficacy Scale: Construction and validation. Psychological Reports, 51, 663671.

Shnek, Z., Foley, F., LaRocca, N., Gordon, W., DeLuca, J., Schwartzman, H., et al. (1997). Helplessness, self-efficacy, cognitive distortions, and depression in multiple sclerosis and spinal cord injury. Annals of Behavioral Medicine, 19, 287-294.

Sievert, A., Cuvo, A., \& Davis, P. (1988). Training self-advocacy skills to adults with mild handicaps. Journal of Applied Behavior Analysis, 21, 299-309.

Smith, J., Ray, R., Wetcher, J., \& Mahail, T. (1998). Levels of fusion, triangulation, and 
adjustment in families of college students with physical and cognitive disabilities. American Journal of Family Therapy, 26, 29-38.

Starke, M. (1987). Enhancing social skills and self-perceptions of physically disabled young adults: Assertiveness training versus discussion groups. Behavior Modification, 11, 3-16.

Strauser, D. (1995). Application of self-efficacy theory in rehabilitation counseling. Journal of Rehabilitation, 61, 7-11.

Thomas, J., Lochbaum, M., Landers, D., \& He, C. (1997). Planning significant and meaningful research in exercise science: Estimating sample size. Research Quarterly for Exercise and Sport, 68, 33-43.

Tinto, V. (1987). Leaving college. Chicago, IL: University of Chicago Press.

Tinto, V. (1988). Stages of student departure: Reflections on the longitudinal character of setudent leaving. The Journal of Higher Education, 59, 438-455.

Tinto, V. (1993). Leaving College: Rethinking the causes and cures of student attrition. Chicago, IL: University of Chicago Press.

Tipton, R. \& Worthington, E. (1984). The measurement of generalized self-efficacy: A study of construct validity. Journal of Personality Assessment, 48, 545-548.

Van Gennep, A. (1960). The Rites of Passage (trans. M. Vizedon and G. Caffee). Chicago: The University of Chicago Press.

Wessell, T., Engel, k., \& Smidchens, V. (1978). Reducing attrition on the college campus, NASPA Journal, 16, 26-32.

Wheeler, G., Malone, L., Van Vlack, S., Nelson, E., \& Steadward, R. (1996). Retirement from disability sport: A pilot study. Adapted Physical Activity Quarterly, 13, 382-399.

Wheeler, G., Steadward, R., Legg, D., Hutzler, Y., Campbell, E., \& Johnson, A. (1999). Personal 
investment in disability sport careers: An international study. Adaptive Physical Activity Quarterly, 16, 219-237.

Wolpe, J. (1958). Psychotherapy by reciprocal inhibition. Stanford, CA: Stanford University Press.

Wolpe, J. \& Lazarus, A. (1966). Behavior therapy techniques. New York: Pargamon Press. 
Appendix D: Interview Codebook

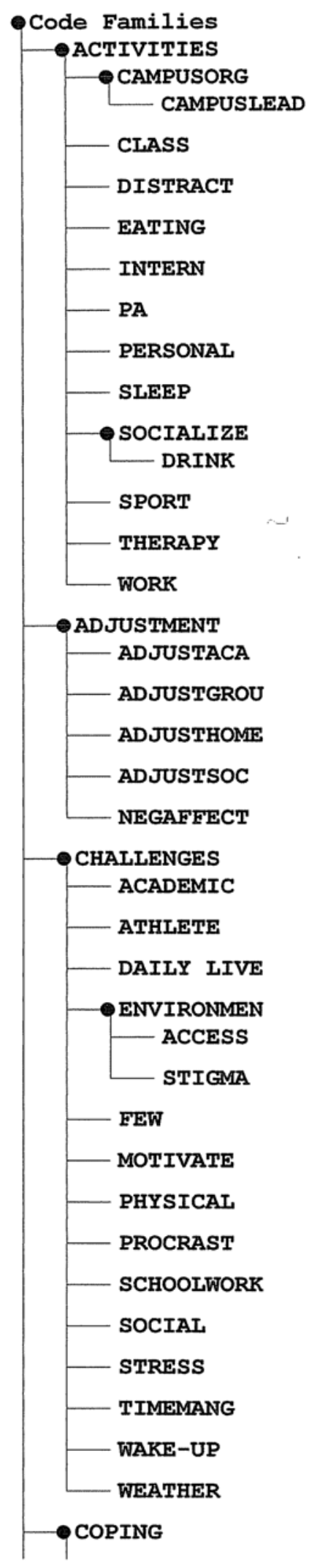




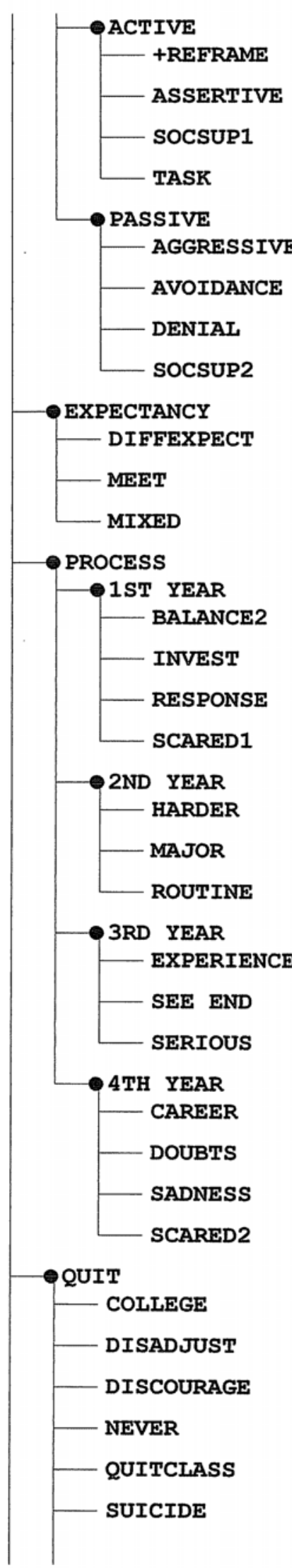




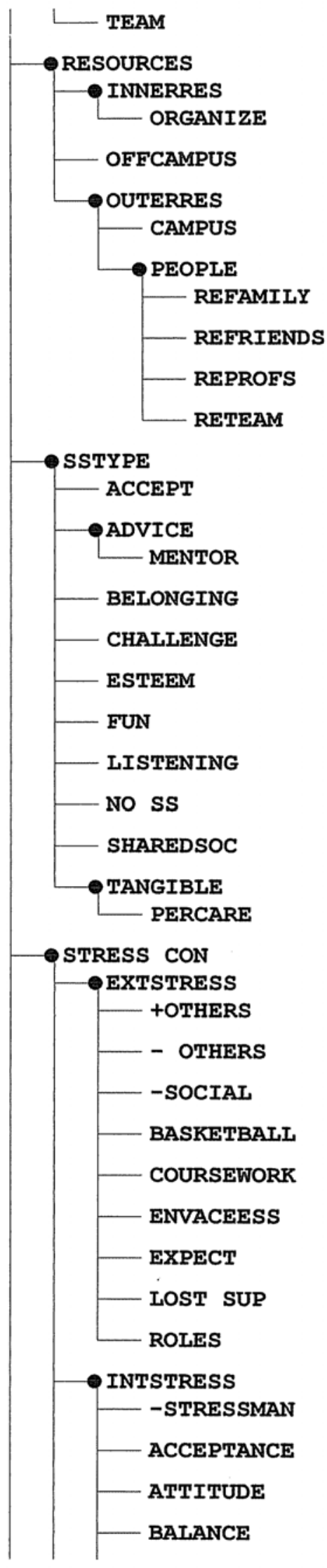




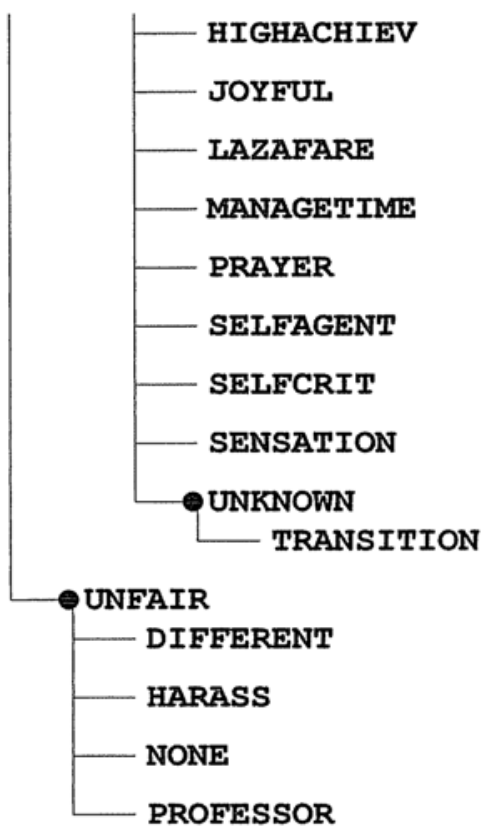




$\begin{array}{clcll}\text { Code Word } & \text { Parent } & \text { Level } & \text { Added } & \text { Modified } \\ \text { +OTHERS } & \text { EXTSTRESS } & 3 & 02 / 26 / 06 & 00 / 00 / 00\end{array}$

Discussed how others help to reduce thier perception of stress

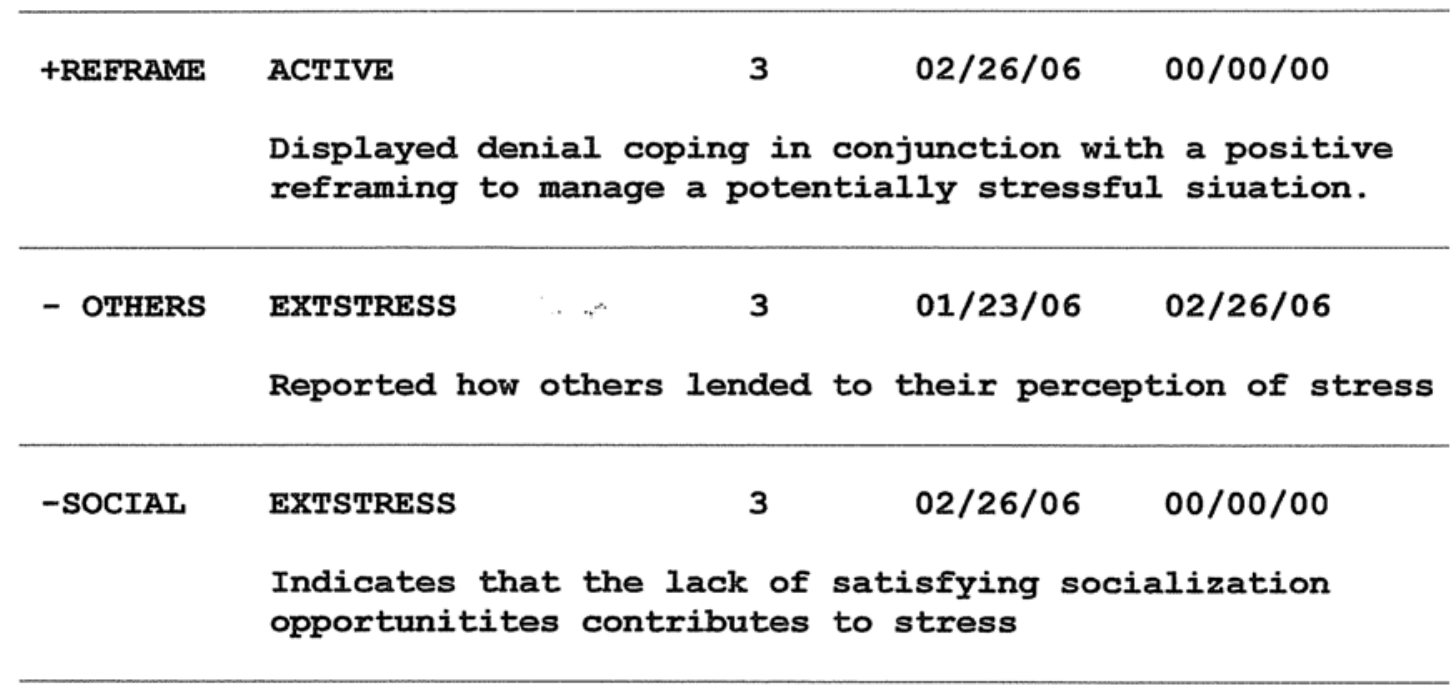
Indicated dissatisfaction with their ability or resources for manage stress levels.

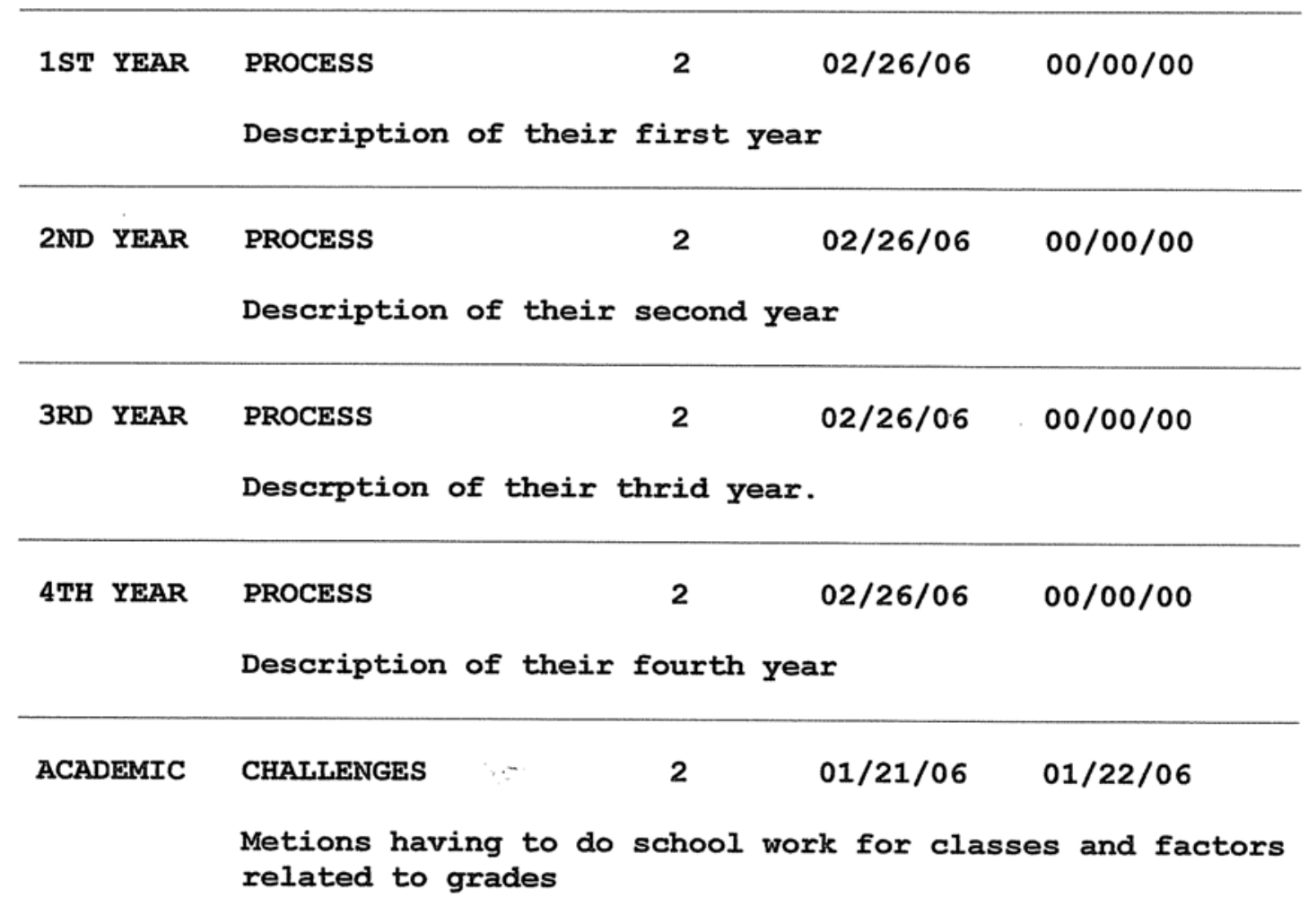




$\begin{array}{cccll}\text { Code Word } & \text { Parent } & \text { Level } & \text { Added } & \text { Modified } \\ \text { ACCEPT } & \text { SSTYPE } & 2 & 02 / 26 / 06 & 00 / 00 / 00\end{array}$

Describes a quality to of support that exemplifies unconditional acceptance. No fear of being judged and they can tell or share anything and it is okay.

ACCEPTANCE INTSTRESS $\quad 3 \quad 01 / 23 / 06 \quad 01 / 23 / 06$

Discusses how they have realized that they can only control so much and discusses an acceptance on only being able to do so much.

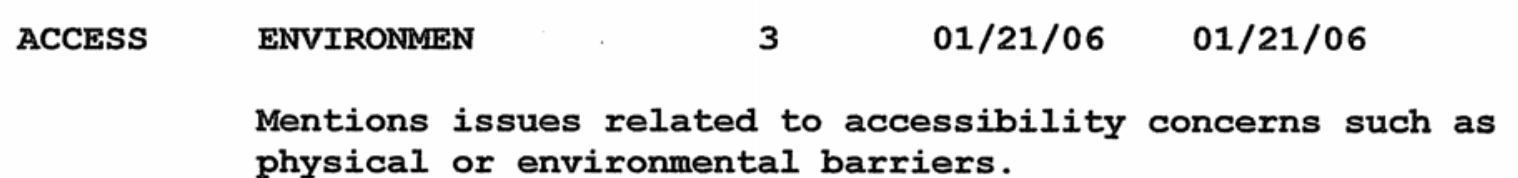

physical or environmental barriers.

\begin{tabular}{llccc}
\hline ACTIVE & COPING & 2 & $02 / 26 / 06$ & $00 / 00 / 00$ \\
& Reported active coping behaviors & \\
\hline
\end{tabular}

ACTIVITIES None

$101 / 22 / 06 \quad 00 / 00 / 00$

Mentioned as a typical weekly activity

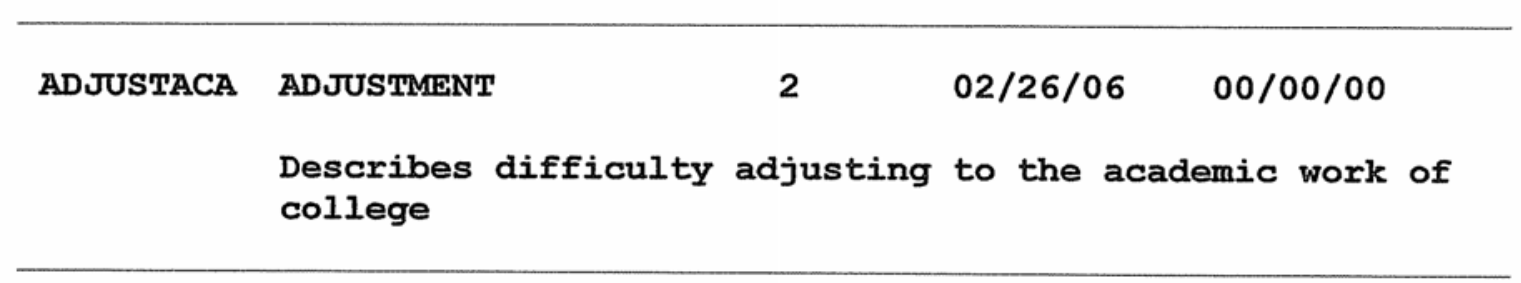
ADJUSTGROU ADJUSTMENT
2
$02 / 26 / 06$
$02 / 26 / 06$

Discribes their lack of integration in a group on campus.

\begin{tabular}{l} 
ADJUSTHOME ADJUSTMENT \\
$\begin{array}{l}\text { Describes a lack of divestment in their old roles and } \\
\text { relationships at home. }\end{array}$ \\
$\begin{array}{l}\text { ADJUSTMENT None } \\
\text { Poor Adjustment Warning Sign }\end{array}$ \\
\hline
\end{tabular}




$\begin{array}{clcll}\text { Code Word } & \text { Parent } & \text { Level } & \text { Added } & \text { Modified } \\ \text { ADJUSTSOC } & \text { ADJUSTMENT } & 2 & 02 / 26 / 06 & 00 / 00 / 00\end{array}$

Discribes difficulty fitting in socially on campus and with others

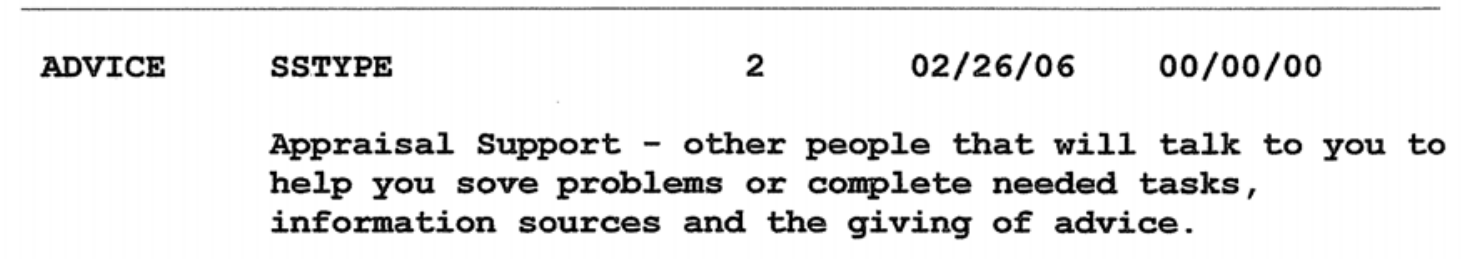

AGGRESSIVE PASSIVE
$\begin{aligned} & \text { Enacted aggressive behaviors, such as yelling, fighting, } \\ & \text { or intimidation, in managing interpersonal conflict. }\end{aligned}$

\begin{tabular}{lllll}
\hline ASSERTIVE ACTIVE & 3 & $01 / 23 / 06$ & $02 / 26 / 06$
\end{tabular}

Demonstrated or discussed the use of an assertive behavior in managing a problem or stressful situation

\begin{tabular}{llccc}
\hline ATHLETE & ChALLENGES & 2 & $01 / 22 / 06$ & $01 / 22 / 06$ \\
& Challenges created by being an athlete & \\
\hline ATtITUDE & INTSTRES & 3 & $01 / 23 / 06$ & $02 / 26 / 06$
\end{tabular}

Descibed their attitude as aiding to the management of stress

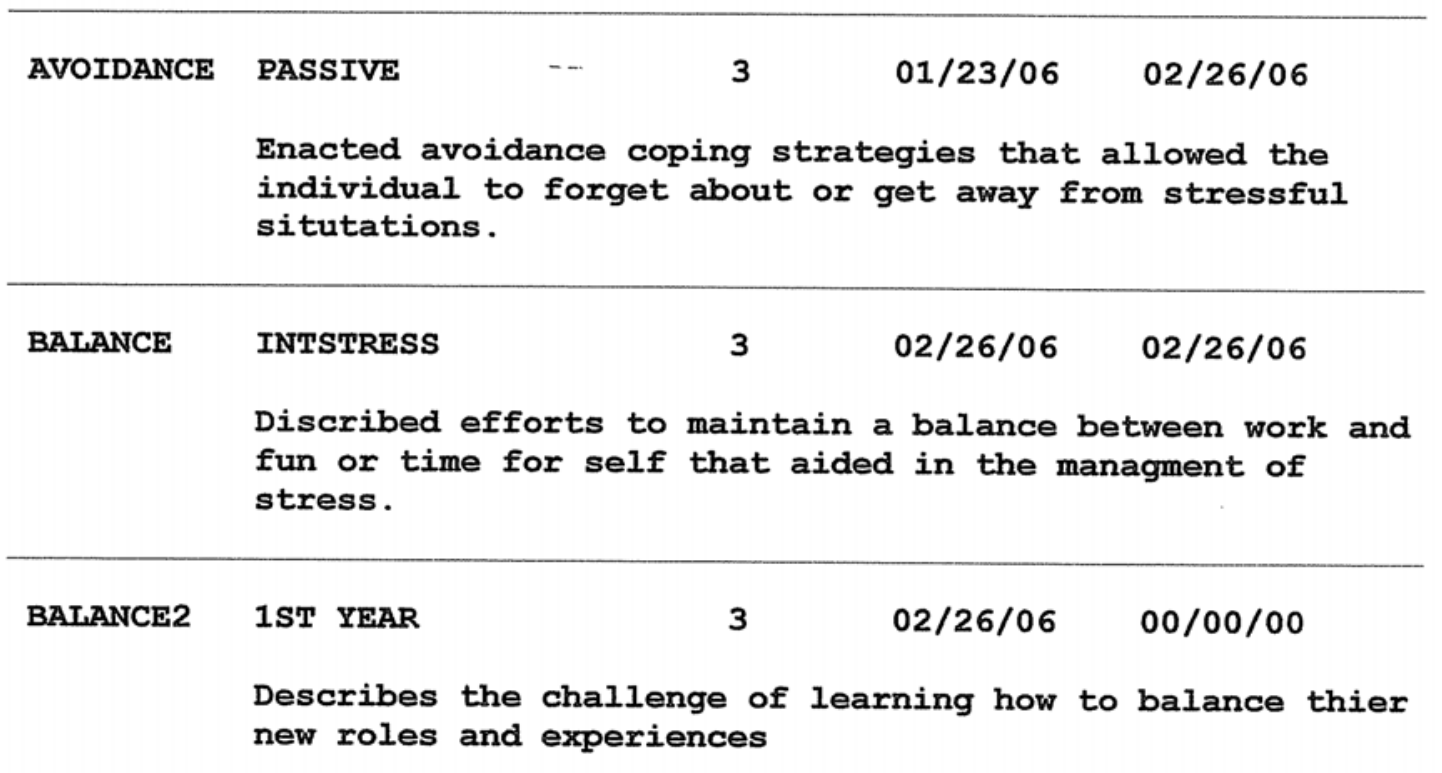


Code Word Parent Level Added Modified

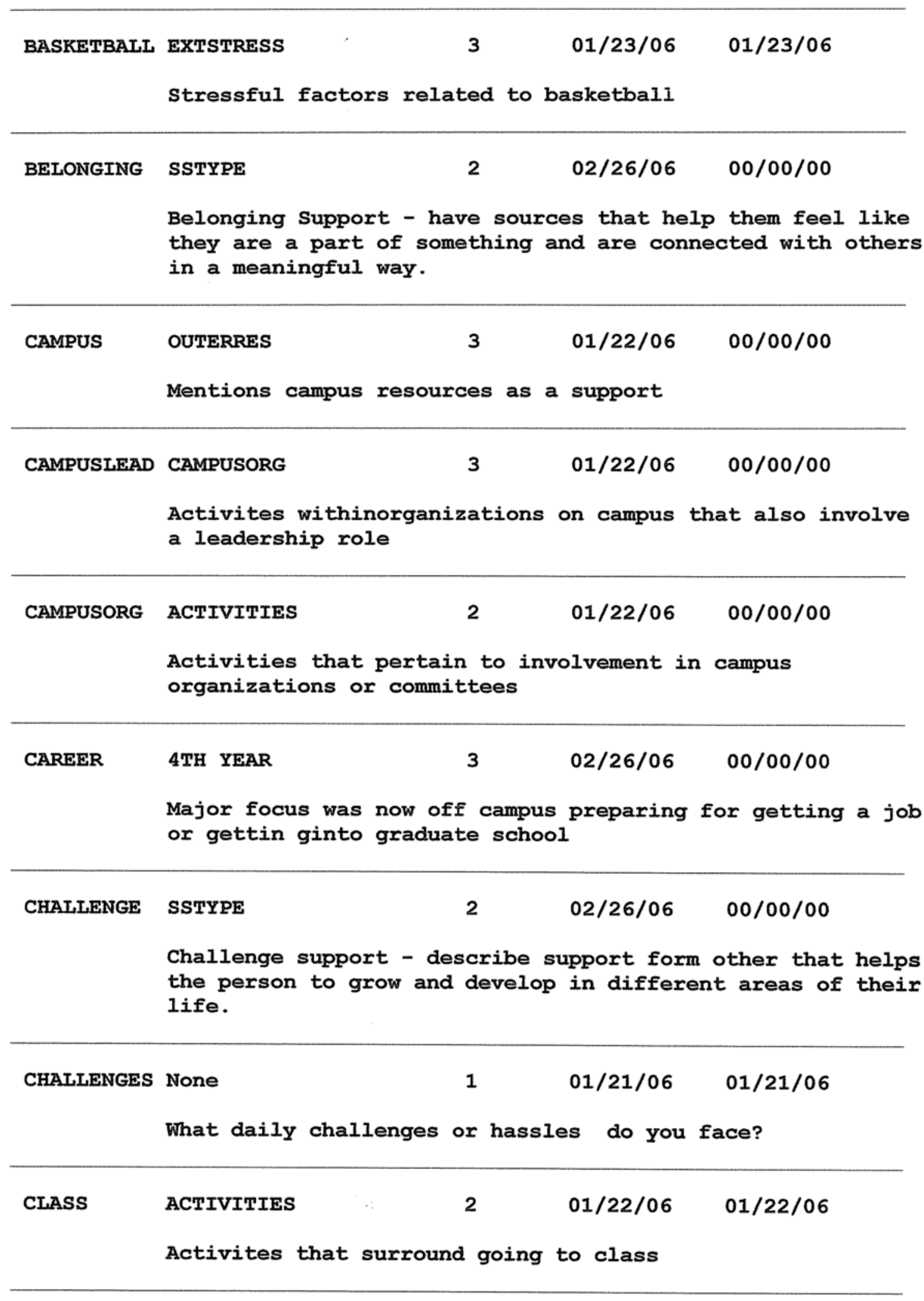




\begin{tabular}{|c|c|c|c|c|}
\hline Code Word & Parent & Level & Added & Modified \\
\hline \multirow[t]{2}{*}{ COLLEGE } & QUIT & 2 & $02 / 26 / 06$ & $00 / 00 / 00$ \\
\hline & $\begin{array}{l}\text { Indicated that } \\
\text { leave college. }\end{array}$ & had the & t about or & did quit anc \\
\hline COPING & None & 1 & $01 / 23 / 06$ & $00 / 00 / 00$ \\
\hline
\end{tabular}

COURSEWORR EXTSTRESS
$\begin{aligned} & \text { Mentions that course work or homework contributes to } \\ & \text { stress level }\end{aligned}$

DAILY LIVE CHALLENGES
$\begin{aligned} & \text { Mentions difficulties } \\ & \text { needs }\end{aligned}$

\begin{tabular}{|c|c|c|c|}
\hline DENIAL & PASSIVE & $02 / 26 / 06$ & $00 / 00 / 00$ \\
\hline & $\begin{array}{l}\text { Enacted or } \\
\text { mention of }\end{array}$ & $\begin{array}{l}\text { discussed the use of denial } \\
\text { a positive reframing of the }\end{array}$ & $\begin{array}{l}\text { coping without } \\
\text { situation. }\end{array}$ \\
\hline
\end{tabular}

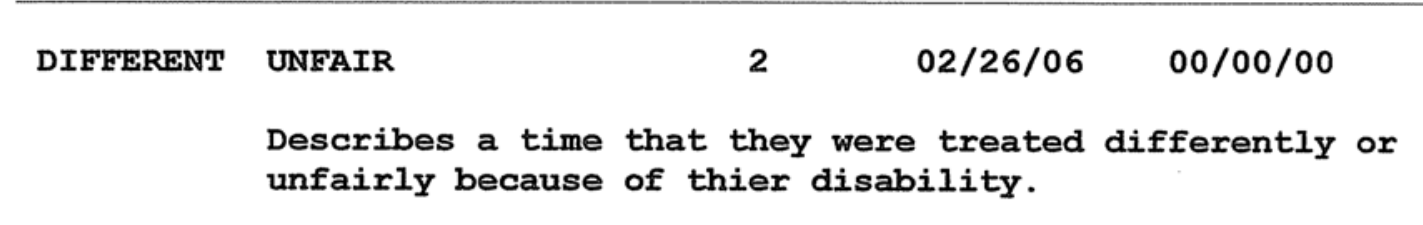

DIFFEXPECT EXPECTANCY
$\begin{aligned} & \text { The student's expectations for college were very different } \\ & \text { from their actual experience. }\end{aligned}$
$\begin{aligned} & \text { DISADJUST } \\ & \text { QUIT }\end{aligned}$
$\begin{aligned} & \text { Reported that their adjustment to their disability was a } \\ & \text { time they thought about giving up or quitting. }\end{aligned}$
$\begin{aligned} & \text { DISCOURAGE } \\ & \text { QUIT } 02 / 26 / 06\end{aligned}$
$\begin{aligned} & \text { When others discourage thier efforts to accomplish their } \\ & \text { goals and dreams. }\end{aligned}$




$\begin{array}{clccll}\text { Code Word } & \text { Parent } & & \text { Level } & \text { Added } & \text { Modified } \\ \text { DISTRACT } & \text { ACTIVITIES } & \cdots & 2 & 01 / 21 / 06 & 01 / 22 / 06\end{array}$

Activites such as watching TV or Playong video games that would be considered distraction coping

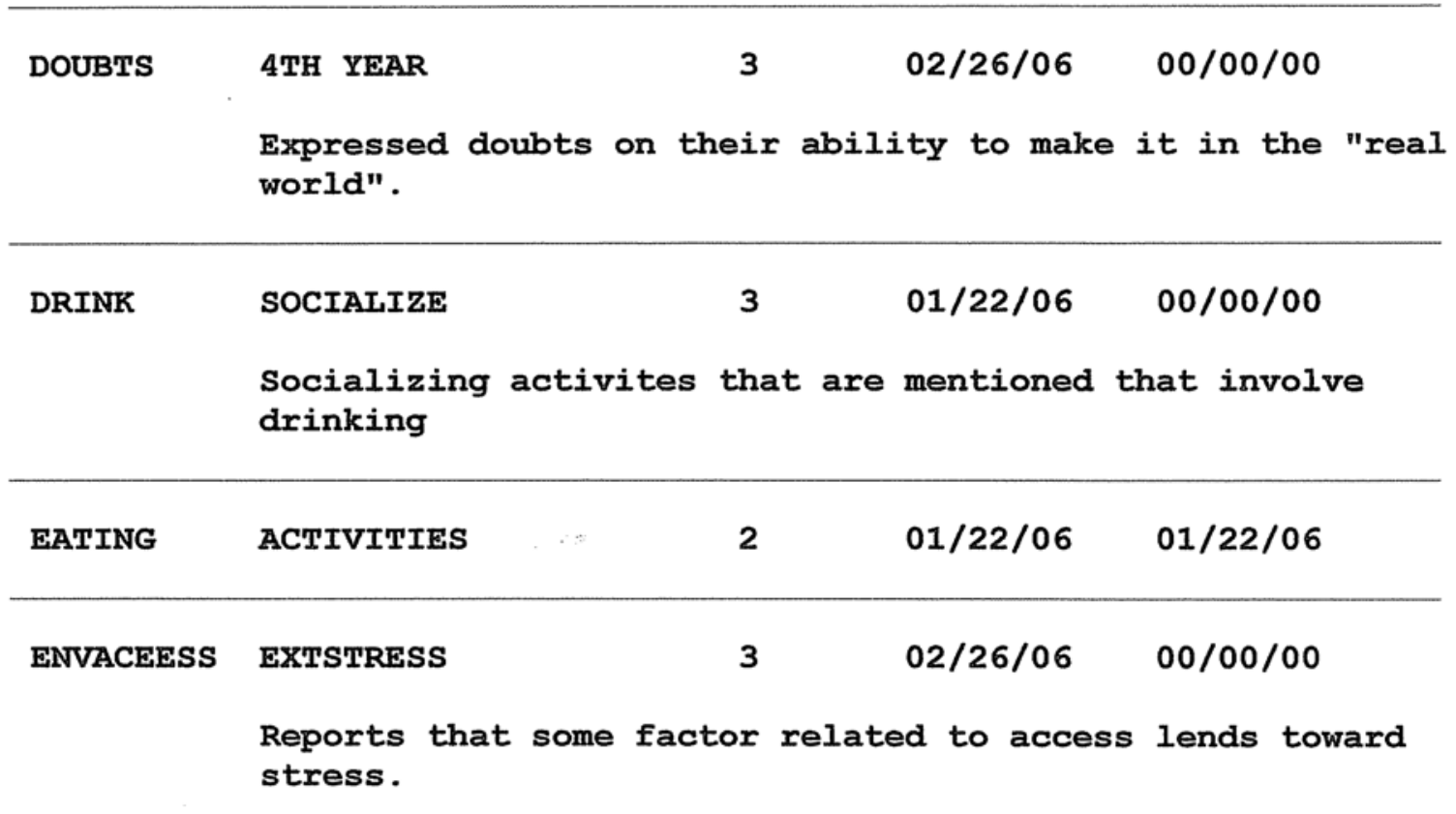

ENVIRONMEN CHALLENGES
$\begin{aligned} & \text { Factors that come form outside the person in their day ato } \\ & \text { day interactions with the physical and social world }\end{aligned}$
day interactions with the physical and social world

\begin{tabular}{|c|c|}
\hline \multirow[t]{2}{*}{ ESTEEM } & $02 / 26 / 06$ \\
\hline & $\begin{array}{l}\text { Esteem Support - have people that help them feel like they } \\
\text { are capable of managing and accomplishing things, that } \\
\text { they are worthy and have value in the world }\end{array}$ \\
\hline \multirow[t]{2}{*}{ EXPECT } & EXTSTRESS \\
\hline & $\begin{array}{l}\text { Discusses the role that the expectations of others plays } \\
\text { in their stress levels }\end{array}$ \\
\hline \multirow[t]{2}{*}{ EXPECTANCY } & $02 / 26 / 06$ \\
\hline & $\begin{array}{l}\text { How did your expectations for college your first semester } \\
\text { compare to reality? }\end{array}$ \\
\hline
\end{tabular}




$\begin{array}{cccll}\text { Code Word } & \text { Parent } & \text { Level } & \text { Added } & \text { Modified } \\ \text { EXPERIENCE } & \text { 3RD YEAR } & 3 & 02 / 26 / 06 & 00 / 00 / 00\end{array}$

Described more work toward professional preparation and focus on a future career or grad school

$\begin{array}{llll}\text { EXTSTRESS STRESS CON } & 2 & 01 / 23 / 06 & 02 / 26 / 06\end{array}$

External factors that contribute to stress

\begin{tabular}{|c|c|}
\hline EEW & CHALLENGES \\
\hline & $\begin{array}{l}\text { Mentions have a hard time thinking of challenges or } \\
\text { perceives them as minor. }\end{array}$ \\
\hline \multirow[t]{2}{*}{ FUN } & $00 / 00 / 00$ \\
\hline & $\begin{array}{l}\text { Distraction Support - describes people that help them to } \\
\text { go out and have fun and get away from their stress and } \\
\text { worries. }\end{array}$ \\
\hline \multirow[t]{2}{*}{ HARASS } & $2 \quad 02 / 26 / 06 \cdot 00 / 00 / 00$ \\
\hline & Describes a time that they were harassed by others \\
\hline \multirow[t]{2}{*}{ HARDER } & 2ND YEAR \\
\hline & $\begin{array}{l}\text { Describes that classes began to get harder once starting } \\
\text { into core classes. }\end{array}$ \\
\hline \multirow[t]{2}{*}{ HIGHACHIEV } & $02 / 26 / 06$ \\
\hline & $\begin{array}{l}\text { Behaviors or attitude that hold a student to a higher } \\
\text { perceived standard that lended to increase perceived } \\
\text { demands. }\end{array}$ \\
\hline \multirow[t]{2}{*}{ INNERRES } & $00 / 00 / 00$ \\
\hline & Resources mentioned that are internal to the person \\
\hline \multirow[t]{2}{*}{ INTERN } & ACTIVITIES \\
\hline & Activities related to one's internship \\
\hline
\end{tabular}




$\begin{array}{rlcll}\text { Code Word } & \text { Parent } & \text { Level } & \text { Added } & \text { Modified } \\ \text { INTSTRESS } & \text { STRESS CON } & 2 & 01 / 23 / 06 & 02 / 26 / 06\end{array}$

Internal factors that contribute to stress

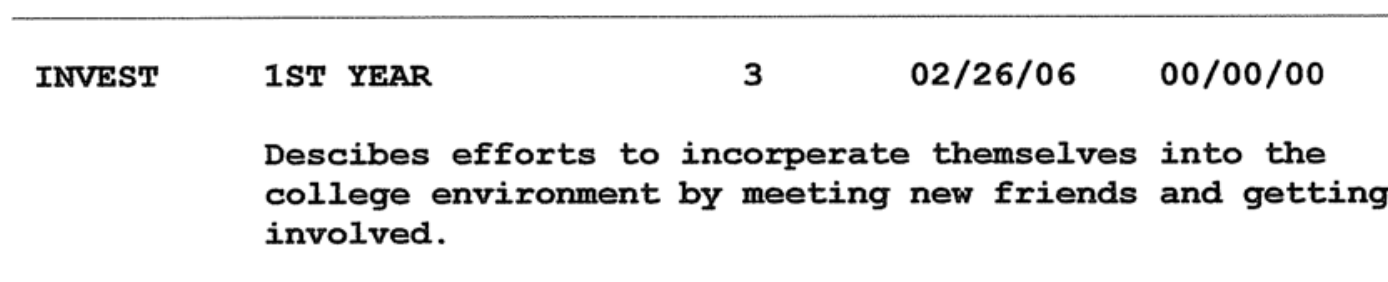

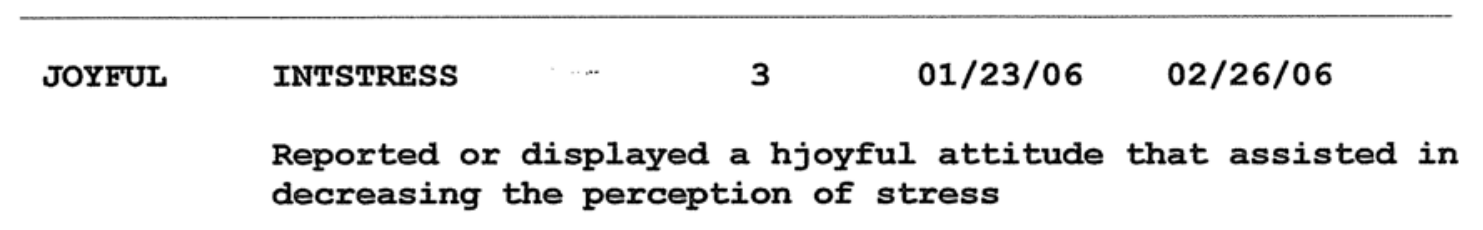

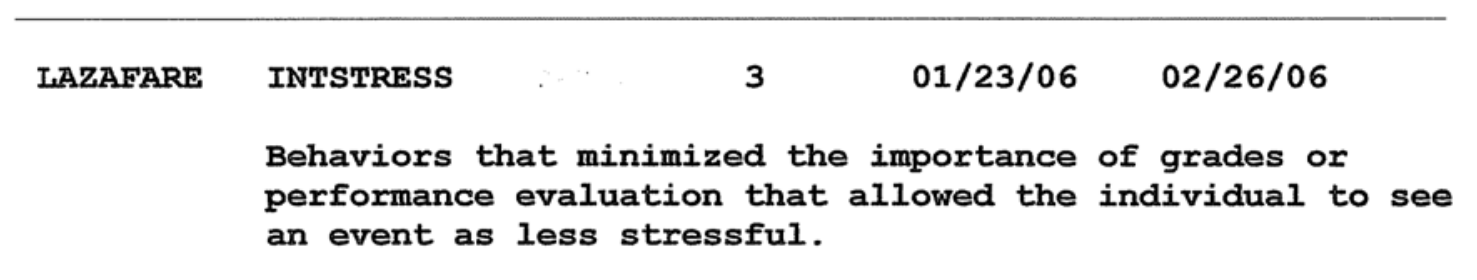

\begin{tabular}{lllll}
\hline LISTENING SSTYPE & 2 & $02 / 26 / 06$ & $00 / 00 / 00$
\end{tabular}

Listening Support - have others that will listen to them and they can talk about how they feeling, not for adivce

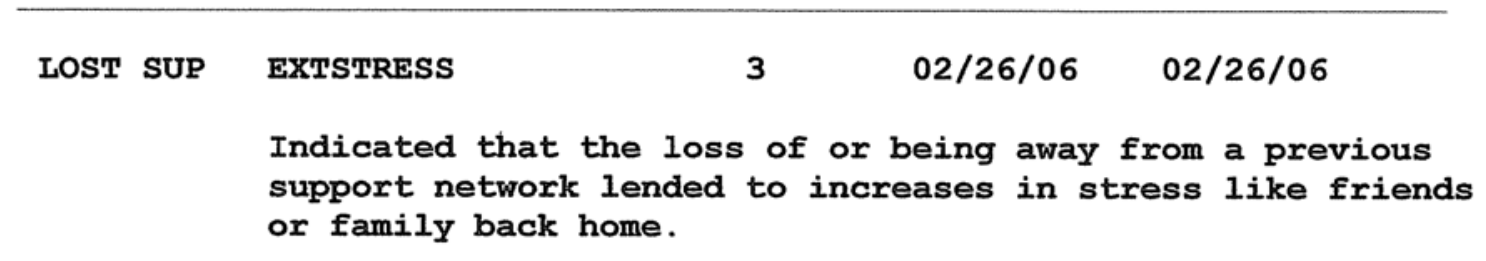

MAJOR 2ND YGAR
$\begin{aligned} & \text { Describes the process of trying to find the right major } \\ & \text { and having to switch. }\end{aligned}$

MANAGETIME INTSTRESS
$\begin{aligned} & \text { Discussed the role their time management skills had in } \\ & \text { helping or hindering their management of stress. }\end{aligned}$
MEET
$\begin{aligned} & \text { EXPECTANCY } \\ & \text { The students expectations for college did not differ from } \\ & \text { thier actual experience. }\end{aligned}$




\section{Code Word Parent Level Added Modified}

\begin{tabular}{|c|c|}
\hline \multirow[t]{2}{*}{ MENTOR } & $02 / 26 / 06$ \\
\hline & $\begin{array}{l}\text { Mentoring support - a special form of appraisal support } \\
\text { that dealt specifically with helping the student better } \\
\text { understand or adjust to an experience like college. }\end{array}$ \\
\hline \multirow[t]{2}{*}{ MIXED } & $2 \quad 02 / 26 / 06 \quad 00 / 00 / 00$ \\
\hline & $\begin{array}{l}\text { Some of the expectations the student had matched reality } \\
\text { and some did not. }\end{array}$ \\
\hline \multirow[t]{2}{*}{ MOTIVATE } & 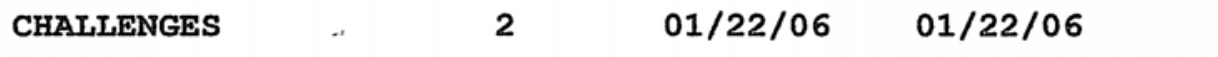 \\
\hline & $\begin{array}{l}\text { Mentions trouble motivating themselves to do their weekly } \\
\text { acitvities }\end{array}$ \\
\hline \multirow[t]{2}{*}{ NEGAFFECT } & $2 \quad 02 / 26 / 06 \quad 00 / 00 / 00$ \\
\hline & $\begin{array}{l}\text { Describes feelings of anxiety, depression, lonilness, } \\
\text { frustration, or other negative affect related to their } \\
\text { college experience. }\end{array}$ \\
\hline \multirow[t]{2}{*}{ NEVER } & $\begin{array}{llll}\text { QUIT } & 2 & 02 / 26 / 06 & 00 / 00 / 00\end{array}$ \\
\hline & $\begin{array}{l}\text { Could not think about a time they ever thought of quitting } \\
\text { or has never wanted to quit. }\end{array}$ \\
\hline \multirow[t]{2}{*}{ NO SS } & $\begin{array}{llll}\text { SSTYPE } & 2 & 02 / 26 / 06 & 00 / 00 / 00\end{array}$ \\
\hline & Does not perceive that they have available support \\
\hline \multirow[t]{2}{*}{ NONE } & UNFAIR \\
\hline & $\begin{array}{l}\text { Indicated that they cold not think of a time they were } \\
\text { treated unfairly. }\end{array}$ \\
\hline \multirow[t]{2}{*}{ OFFCAMPUS } & RESOURCES \\
\hline & $\begin{array}{l}\text { Resources that exist off campus such as community services } \\
\text { or agencies. }\end{array}$ \\
\hline
\end{tabular}




$\begin{array}{clccc}\text { Code Word } & \text { Parent } & \text { Level } & \text { Added } & \text { Modified } \\ \text { ORGANIZE } & \text { INNERRES } & 3 & 01 / 22 / 06 & 01 / 22 / 06 \\ & \text { Mentions using time management strategies for getting } \\ & \text { things done like a planner or alarms, etc. }\end{array}$

\begin{tabular}{lllll}
\hline OUTERRES & RESOURCES & 2 & $01 / 22 / 06$ & $01 / 22 / 06$ \\
& $\begin{array}{l}\text { Resources mentioned that are outside the person, such as } \\
\text { environmental or other people }\end{array}$ \\
\hline PA & ACTIVITIES & 2 & $01 / 23 / 06$ & $01 / 23 / 06$ \\
& Does physical activity & & \\
\hline PASSIVE & COPING & 2 & $02 / 26 / 06$ & $02 / 26 / 06$ \\
& $\begin{array}{l}\text { Enacted or discussed behaviors that sought to manage the } \\
\text { emotions associated with a stressful situation. }\end{array}$
\end{tabular}

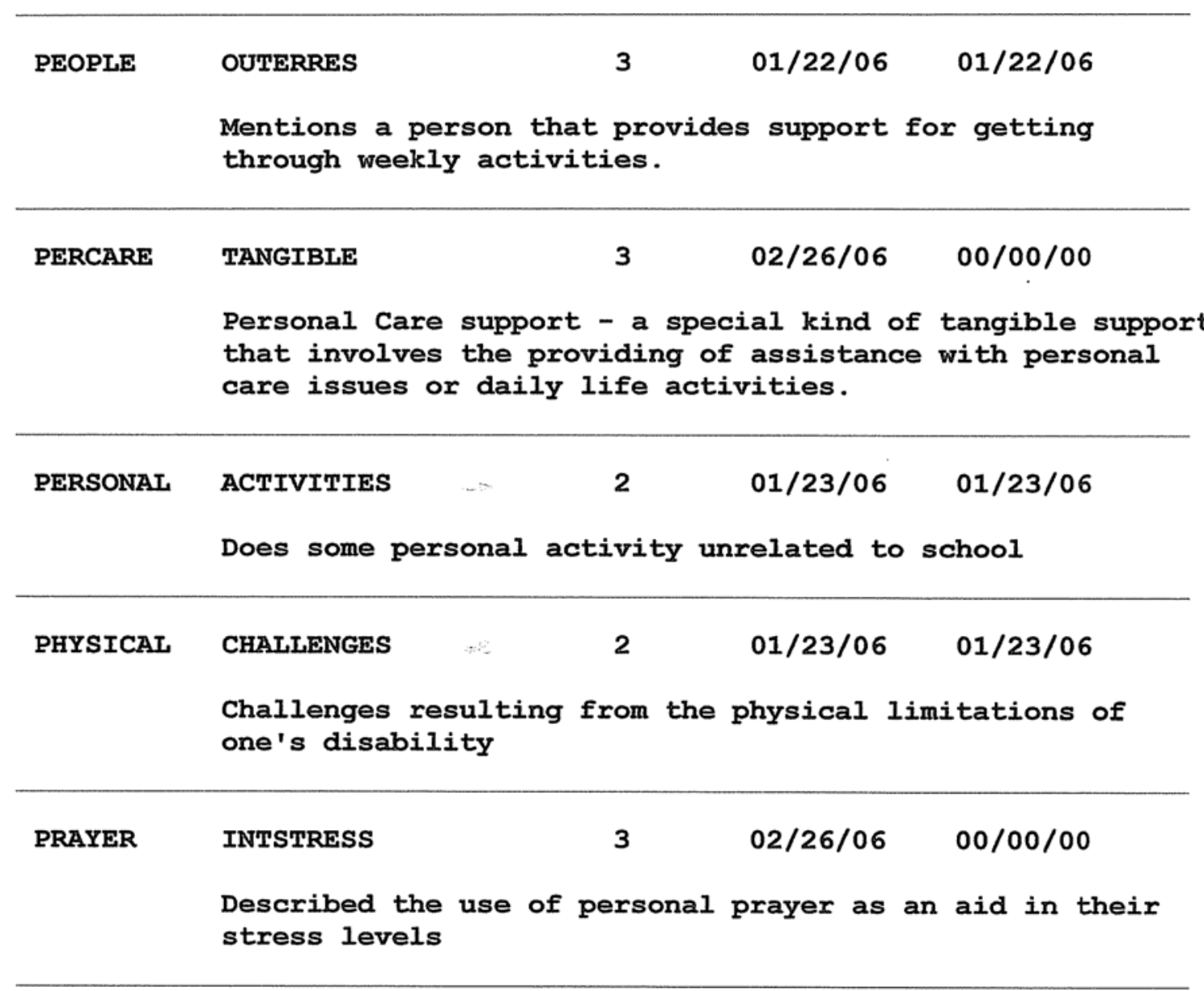




$\begin{array}{clcll}\text { Code Word } & \text { Parent } & \text { Level } & \text { Added } & \text { Modified } \\ \text { PROCESS } & \text { None } & 1 & 02 / 26 / 06 & 00 / 00 / 00\end{array}$

Adjustment Process Questions

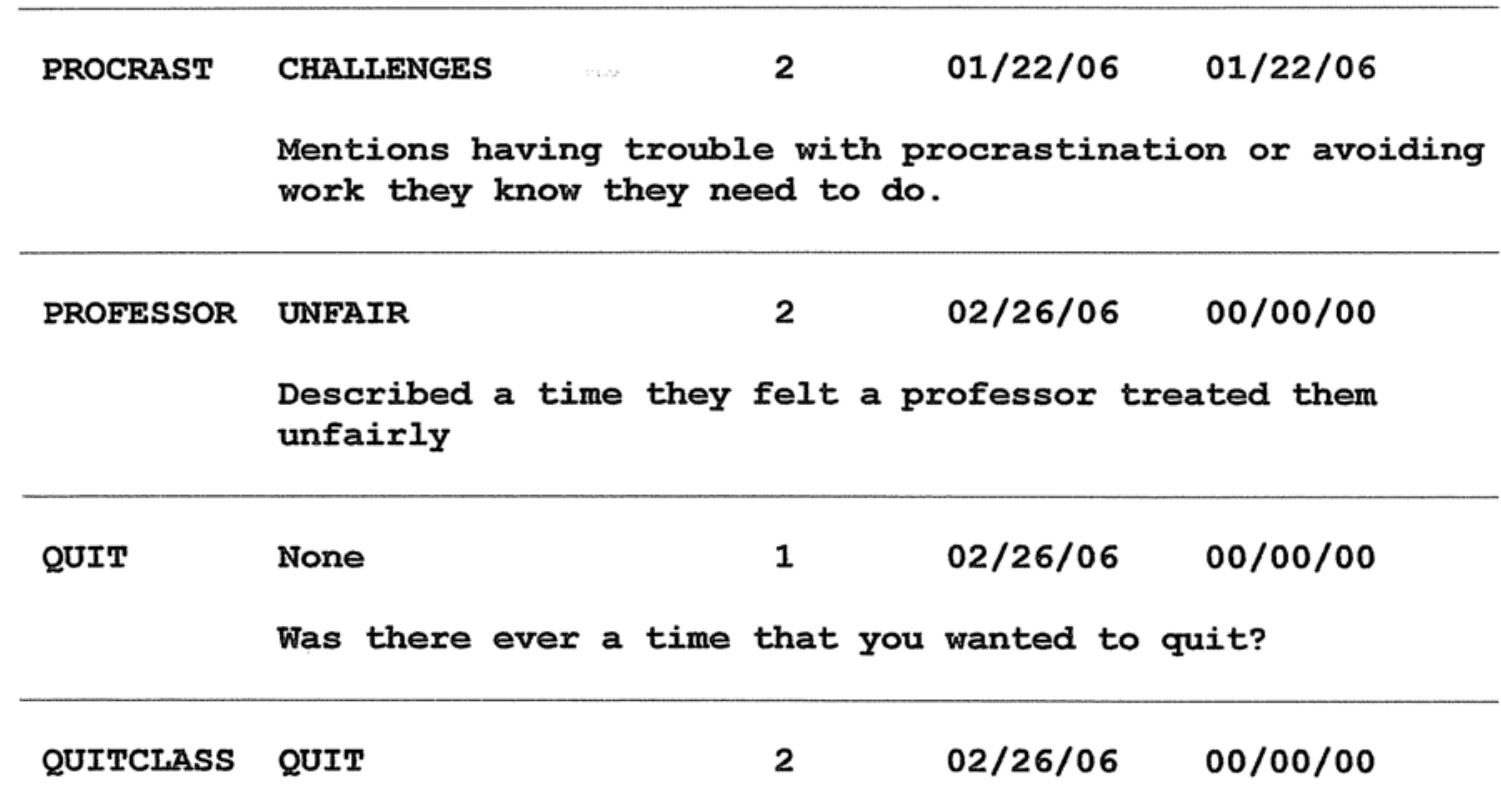

A particular kind of class has stimulated thoughts about quitting. Math was most common.

\begin{tabular}{llccc}
\hline REFAMILY & $\begin{array}{l}\text { PEOPLE } \\
\text { Mentions the family as a resource for managing weekly } \\
\text { activities }\end{array}$ & $01 / 22 / 06$ & $00 / 00 / 00$ \\
\hline REFRIENDS & $\begin{array}{l}\text { PEOPLE } \\
\text { Mentions friends as a resource for managing weekly } \\
\text { activities }\end{array}$ & 4 & $01 / 22 / 06$ & $00 / 00 / 00$ \\
\hline REPROFS & $\begin{array}{l}\text { PEOPLE } \\
\text { Mentions professors as a resource for getting through } \\
\text { weekly activities }\end{array}$ & $01 / 22 / 06$ & $01 / 22 / 06$ \\
\hline RESOURCES & $\begin{array}{l}\text { None } \\
\text { What resources do you have for getting through your weekly } \\
\text { activities }\end{array}$
\end{tabular}




\begin{tabular}{|c|c|c|}
\hline \multirow{3}{*}{$\begin{array}{l}\text { Code Word } \\
\text { RESPONSE }\end{array}$} & \multirow{3}{*}{\multicolumn{2}{|c|}{$\begin{array}{lccc}\text { Parent } & \text { Level } & \text { Added } & \text { Modified } \\
\text { IST YEAR } & 3 & 02 / 26 / 06 & 00 / 00 / 00 \\
\text { Describes having to take over new roles of responsbility } \\
\text { now that they are away form home. }\end{array}$}} \\
\hline & & \\
\hline & & \\
\hline \multirow[t]{2}{*}{ RETEAM } & $01 / 22 / 06$ & $01 / 22 / 06$ \\
\hline & $\begin{array}{l}\text { Mentions teammates or the coach as a resour } \\
\text { through weekly activities }\end{array}$ & rce for getting \\
\hline \multirow[t]{2}{*}{ ROLES } & $\begin{array}{lll}\text { EXTSTRESS } & 3 & 01 / 23 / 06\end{array}$ & $02 / 26 / 06$ \\
\hline & Managing many roles adds to the individuals & s stress \\
\hline \multirow[t]{2}{*}{ ROUTINE } & 2ND YEAR 3 & $00 / 00 / 00$ \\
\hline & Described that they understood the routine & of college now \\
\hline \multirow[t]{2}{*}{ SADNESS } & 4TH YEAR & $02 / 26 / 06$ \\
\hline & $\begin{array}{l}\text { Described sadness over the realization that } \\
\text { coming to an end. }\end{array}$ & t college was \\
\hline \multirow[t]{2}{*}{ SCARED1 } & 1ST YEAR & $00 / 00 / 00$ \\
\hline & $\begin{array}{l}\text { Experienced fear over starting college and } \\
\text { environment. }\end{array}$ & being in a new \\
\hline \multirow[t]{2}{*}{ SCARED2 } & 4TH YEAR & $00 / 00 / 00$ \\
\hline & $\begin{array}{l}\text { described a new fear of leaving a familar e } \\
\text { the unknown of the real world. }\end{array}$ & environment for \\
\hline \multirow[t]{2}{*}{ SCHOOLWORK } & CHALLENGES & $01 / 22 / 06$ \\
\hline & $\begin{array}{l}\text { Mentions challenges with the amount of scho } \\
\text { must complete such as homework and things }\end{array}$ & ool work they \\
\hline \multirow[t]{2}{*}{ SEE END } & 3RD YEAR & $00 / 00 / 00$ \\
\hline & $\begin{array}{l}\text { Recognition that they have one year after } t \\
\text { stimulated more serious thought about the } f\end{array}$ & $\begin{array}{l}\text { this which } \\
\text { future. }\end{array}$ \\
\hline
\end{tabular}




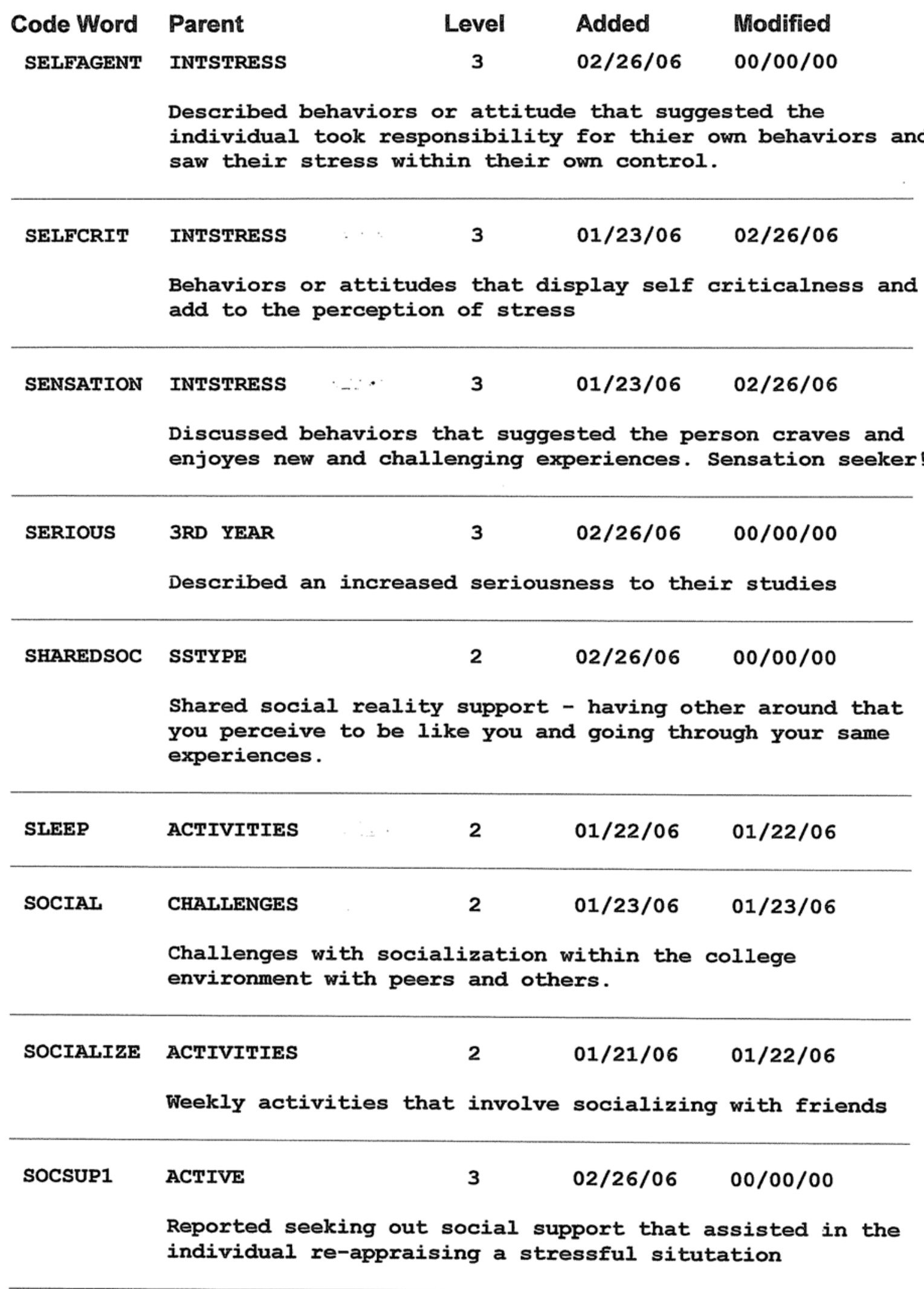




$\begin{array}{clcll}\text { Code Word } & \text { Parent } & \text { Level } & \text { Added } & \text { Modified } \\ \text { socsup2 } & \text { PASsIVE } & 3 & 02 / 26 / 06 & 00 / 00 / 00\end{array}$

Reported seeking out social support which served more as a catharsis and venting of emotions. Did not lend to situtational re-appraisal.

\begin{tabular}{|c|c|}
\hline \multirow[t]{2}{*}{ SPORT } & $01 / 21 / 06 \quad 01 / 22 / 06$ \\
\hline & Activities that are related to playing ones sport \\
\hline \multirow[t]{2}{*}{ SSTYPE } & $02 / 26 / 06$ \\
\hline & What types of support do these people provide? \\
\hline \multirow[t]{2}{*}{ STIGMA } & ENVIRONMEN \\
\hline & $\begin{array}{l}\text { Pressure or difficulty that is placed on the individuals } \\
\text { due to other people's beliefs or behaviors toward } \\
\text { disability. }\end{array}$ \\
\hline \multirow[t]{2}{*}{ STRESS } & CHALLENGES \\
\hline & Mentions managing stress or getting stress out \\
\hline
\end{tabular}

$\begin{array}{llll}\text { STRESS CON None } & 1 & 02 / 26 / 06 & 00 / 00 / 00\end{array}$

Factors that contributed to or aidded in the perception of stress

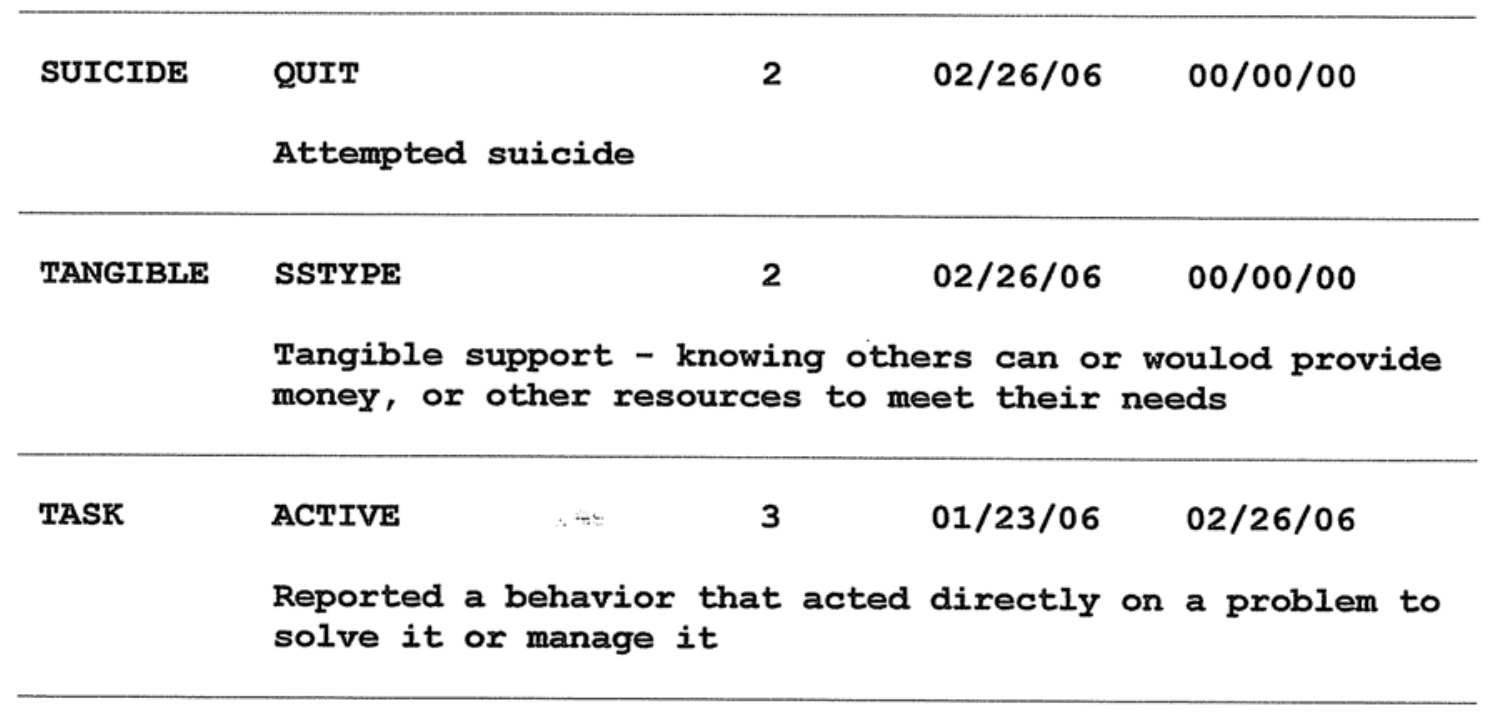




$\begin{array}{clcll}\text { Code Word } & \text { Parent } & \text { Level } & \text { Added } & \text { Modified } \\ \text { TEAM } & \text { QUIT } & 2 & 02 / 26 / 06 & 00 / 00 / 00\end{array}$

Thought about qutting thier team

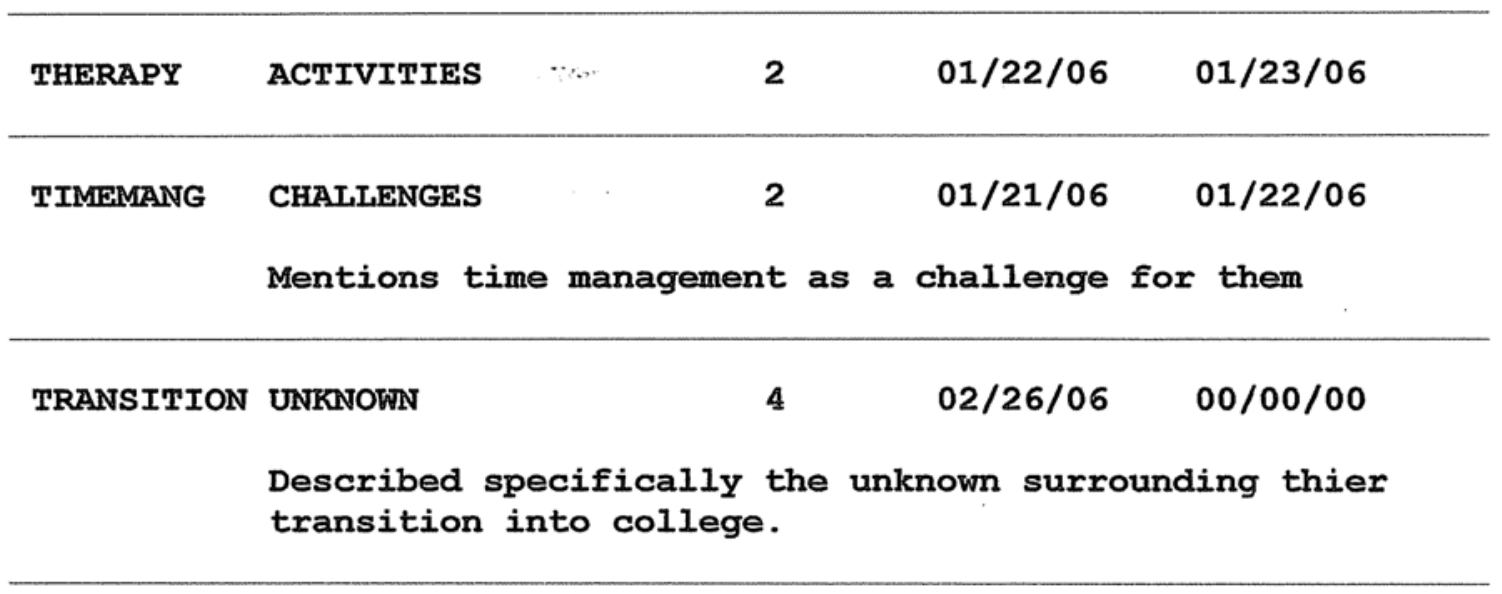

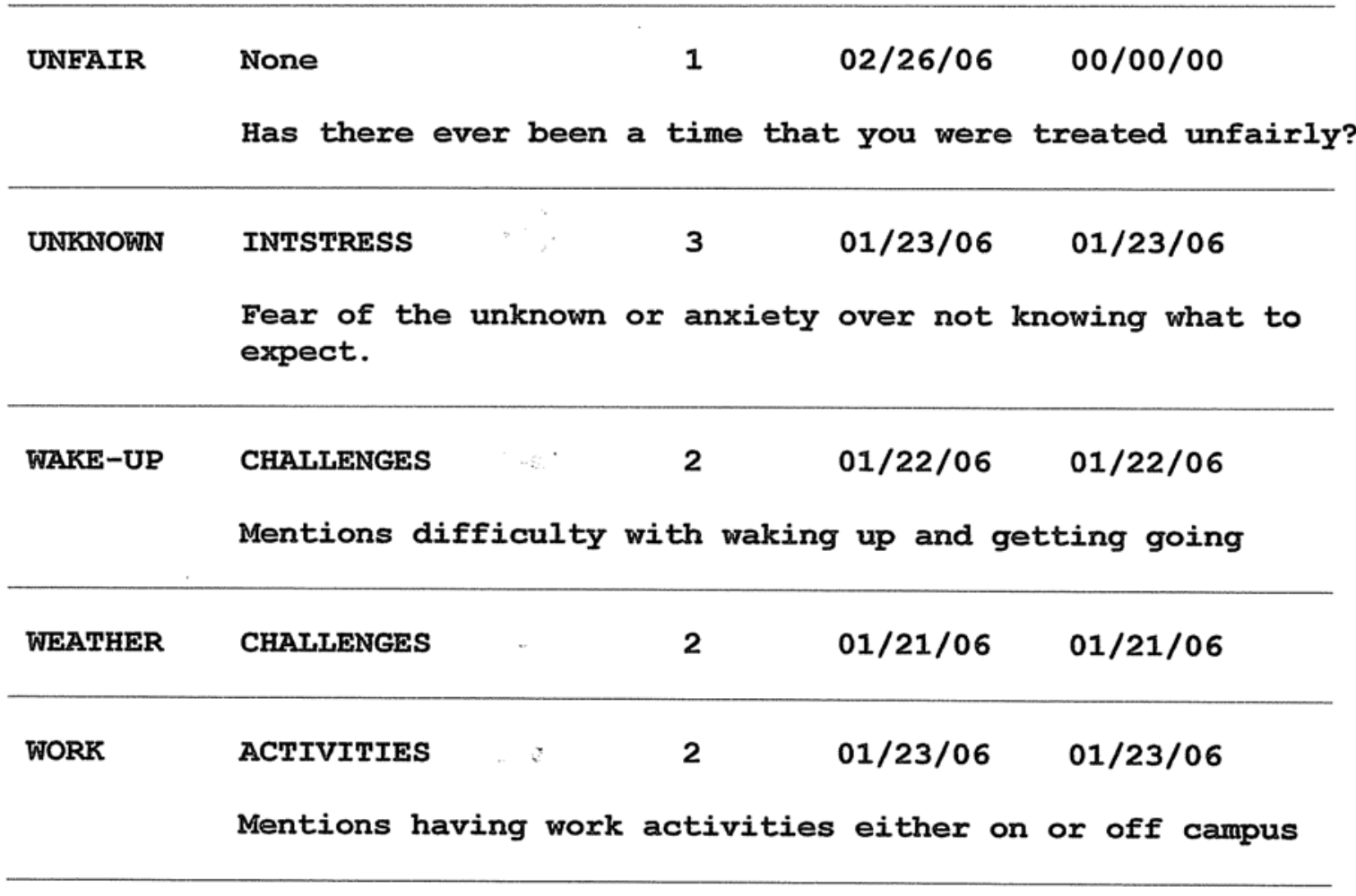




\section{Appendix E: ISEL - College Version}

\section{Instructions}

This scale is made up of a list of statements each of which may or may not be true about you. For each statement check "definitely true" if you are sure it is true about you and "probably true" if you think it is true but are not absolutely certain. Similarly, you should check "definitely false" if you are sure the statement is false and "probably false" is you think it is false but are not absolutely certain. Remember to CHECK only one of the alternatives for each statement. Remember that this is not a test and there are no right or wrong answers.

\section{Definitely Probably Probably Definitely

TRUE TRUE FALSE FALSE

1. I don't know anyone at school or in town who would loan me their car for a couple of hours.

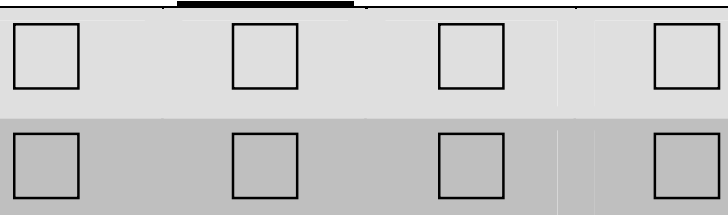

2. I can get a date who I enjoy spending time with whenever I want

3. There isn't anyone at school or in town with whom I would feel perfectly comfortable taking about any problems I might have getting
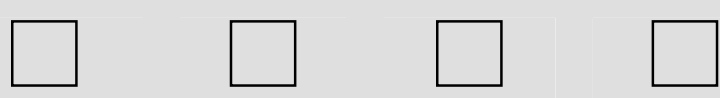
along with my parents.

4. Most of my friends don't do as well as I do in school
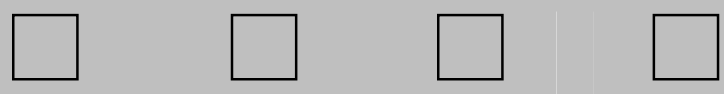

5. There isn't anyone at school or in town with whom I would feel perfectly comfortable talking about my feelings of loneliness and
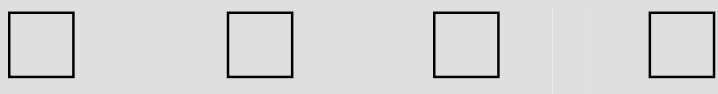
depression.

6. Most of my friends are more interesting than I am.
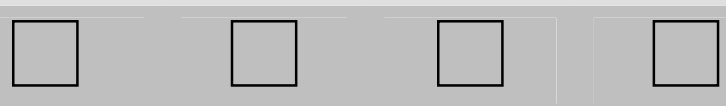

7. Lately, I often feel lonely, like I don't have anyone to reach out to.
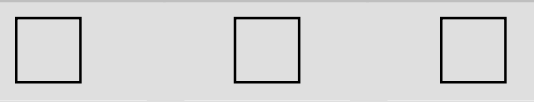

8. I know someone who would give me some old dishes if I moved into my own apartment.
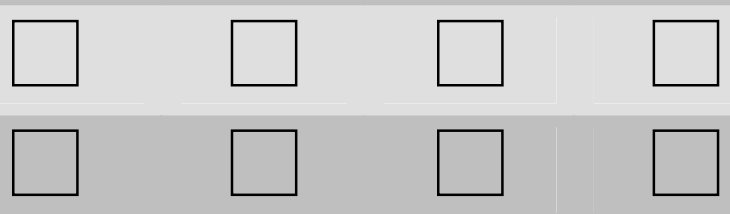

9. If I decided at dinner time to take a study break this evening and go to a movie, I could easily find someone to go with me.
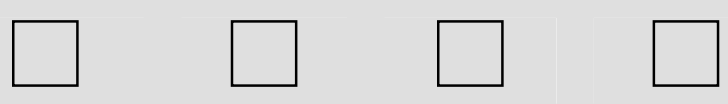

10. Most of my friends have not adjusted to college as easily as I have.
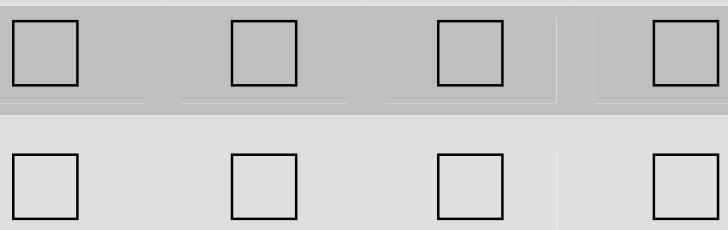
understand. 
12. I don't usually spend two evenings on the weekend doing something with others.

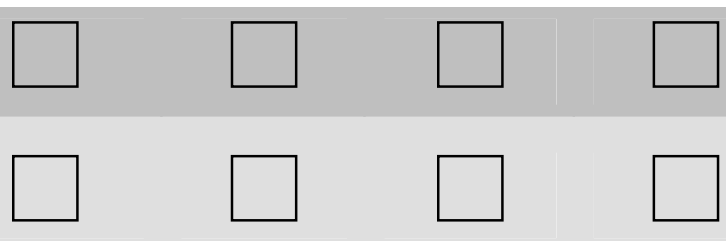

13. I don't know anyone who would give me some old furniture if I moved into my own apartment.

14. I know someone who I see or talk to often with whom I would feel perfectly comfortable talking about any problems I might have adjusting to college life.

15. Most of my friends are more popular than I am.

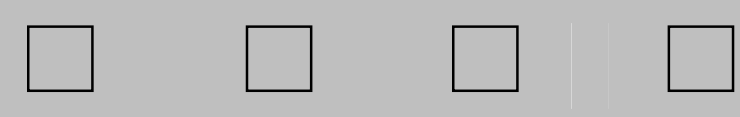

16. I know someone who I see or talk to often whom I would feel perfectly comfortable talking about any problems I might have with
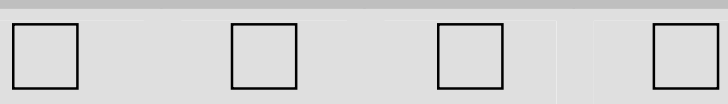
drugs.

17. I don't often get invited to do things with other people.
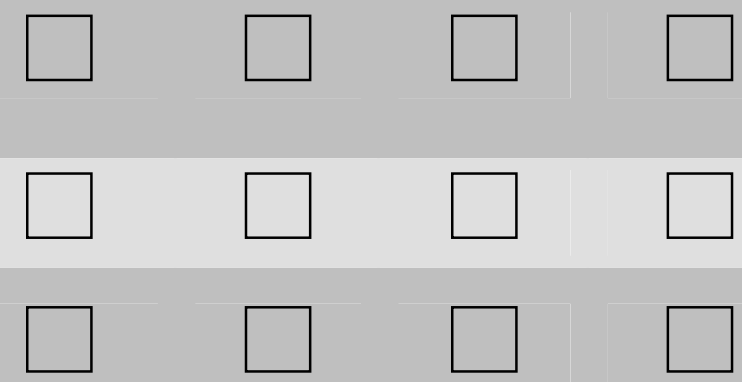

18. If I wanted a date for a party next weekend, I know someone at school or in town who would fix me up.
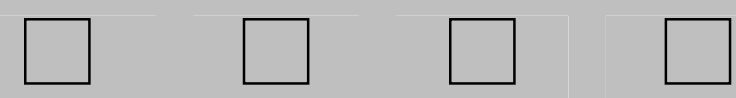

19. I know someone who I see or talk to often with whom I would feel perfectly comfortable talking about any problems I might have
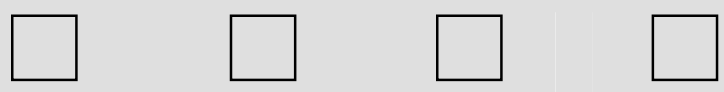
meeting people.

20. Most people who know me well think highly of me.
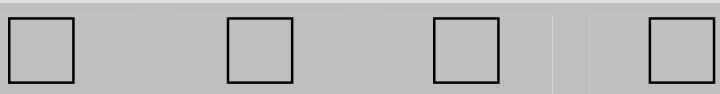

21. I don't know anyone at school or in town who would help me study for an exam by spending several hours reading me questions.

22. People hang out in my room or apartment during the day or in the evening.
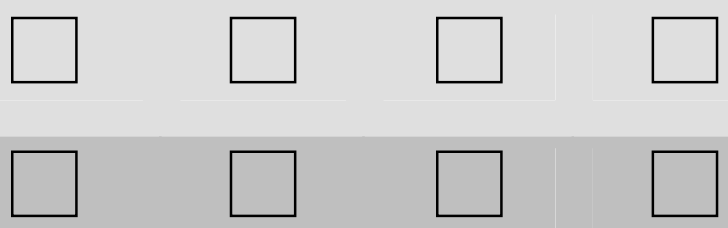

23. There isn't anyone at school or in town with whom I would feel perfectly comfortable taking about difficulties with my social life.
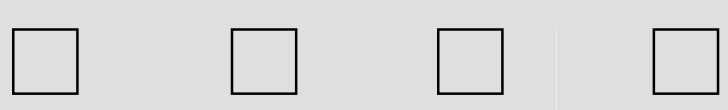

24. Most people are more attractive than I am.

25. There are people at school or in town who I regularly run with, exercise with, or play sports with.
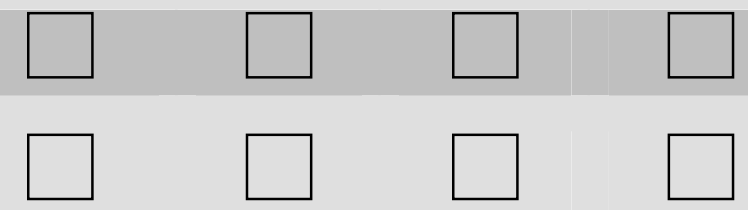

26. I know someone who I see or talk to with whom I would feel perfectly comfortable discussing any sexual problems I might have.
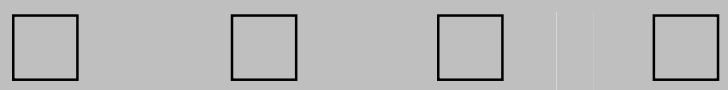
27. I know someone who would loan me $\$ 50$ so I could go away for the weekend.

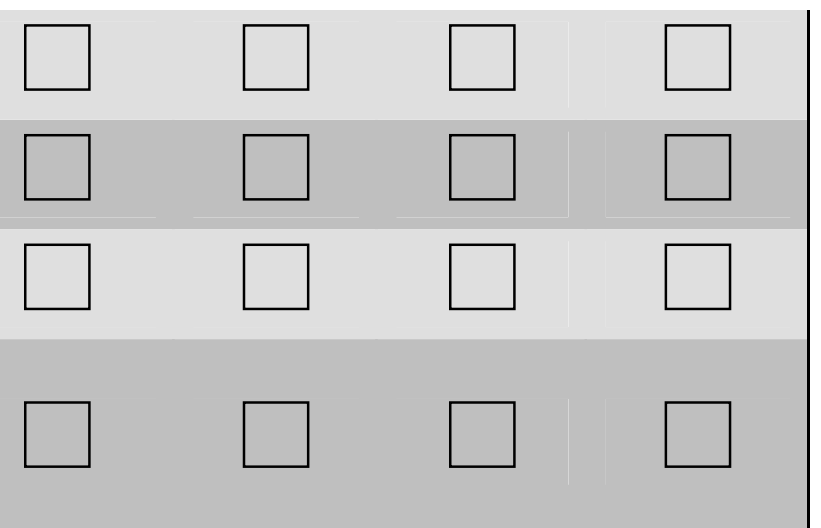

31. I don't feel friendly with any teaching assistants, professors, campus or student officials.
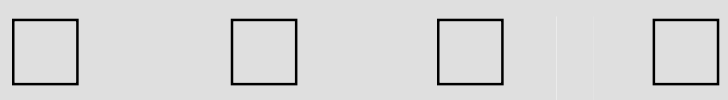

32. I don't know anyone at school or in town who would get assignments for me from my teachers if I was sick.
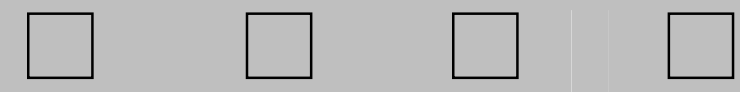

33. I will have a better future than most other people will.

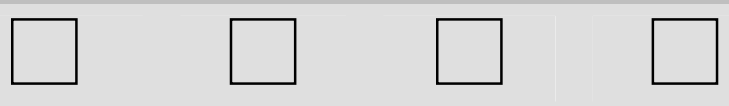

34. Lately, when I've been troubled, I keep things to myself.
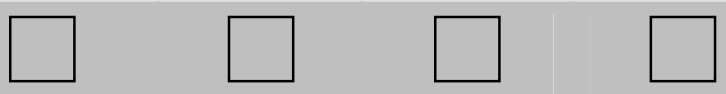

35. I belong to a group at school or in town that meets regularly or does things together regularly.
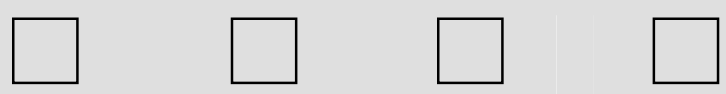

36. I know someone who I see or talk to often with whom I would feel perfectly comfortable talking about sexually transmitted diseases.
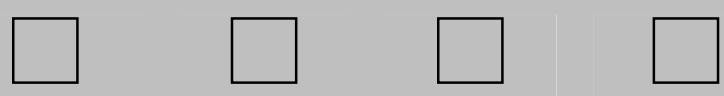

37. I know someone who would loan me $\$ 100$ to help pay my tuition.

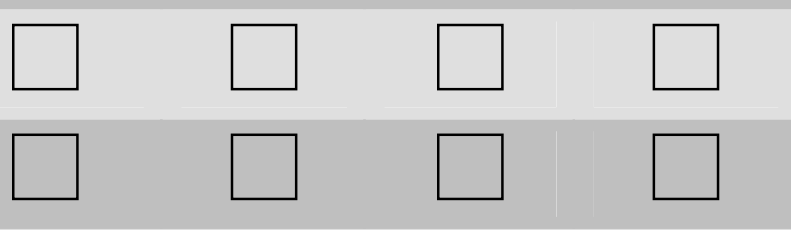

38. I don't talk to a member of my family at least once a week.

39. Most of my friends have more control over what happens to them than I.
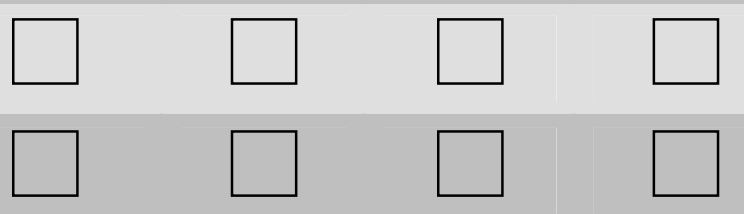

41. I know someone who I see or talk to often with whom I would feel perfectly comfortable talking about problems I might have budgeting
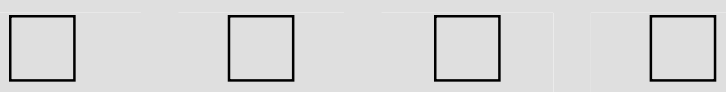
my time between school and my social life.

42. I don't have friends at school or in town who would comfort me by showing some physical affection.
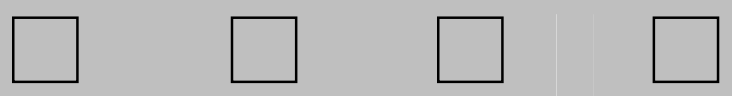
43. Even if I needed it my family would (or could) not give me money for tuition and books.
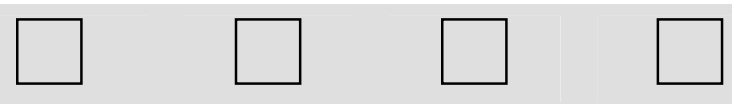

44. Most of my friends are more satisfied or happier with themselves than I am.
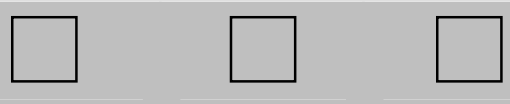

45. I am not a member of any social groups (such as church groups, clubs, teams, etc.)
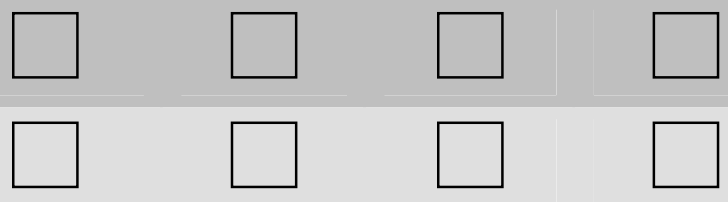

46. I don't know anyone who would loan me several hundred dollars to pay a doctor bill or dental bill.

47. If I needed it, my family would provide me with an allowance and spending money.
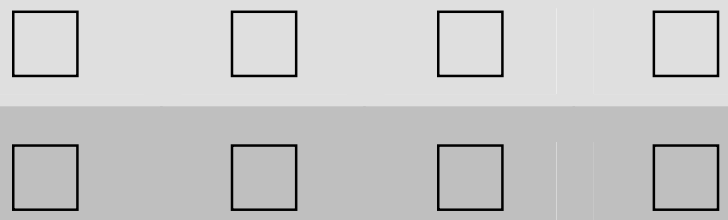

48. I know someone at school or in town who
would bring my meals to my room or

48. I know someone at school or in town
would bring my meals to my room or apartment if I were sick.
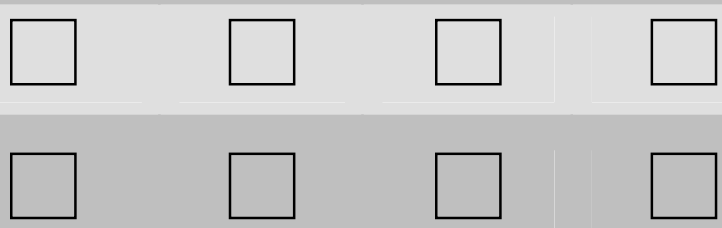
apartment if I were sick. 
Appendix F: Coping Inventory for Stressful Situations (CISS)

\section{CISS - Adult}

by Norman S. Endler, Ph.D., F.R.S.C. \& James D.A. Parker, Ph.D.

Instructions: The following are ways people react to vanous difficult, stressful, or upsetting situations. Please circle a number from 1 to 5 for each item. Indicate how much you engage in these types of activities when you encounter a difficult, stressful, or upsetting situation.

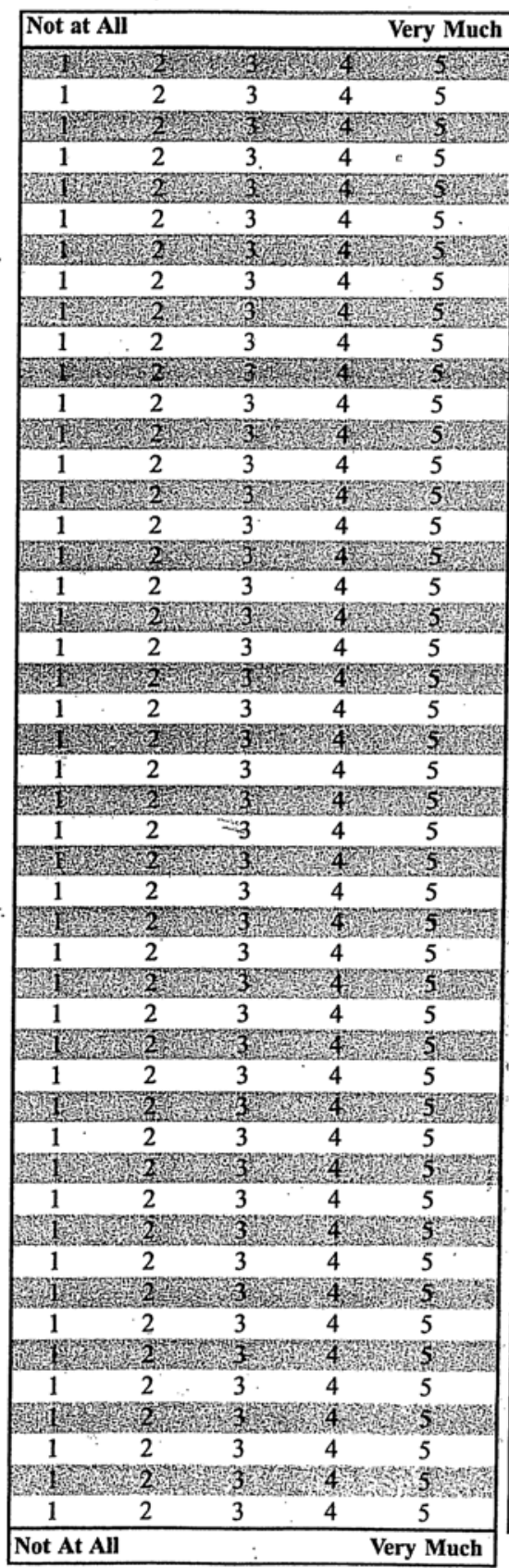

1. Schedule my rime betret

2. Focus on the problem and see how I can solve it.

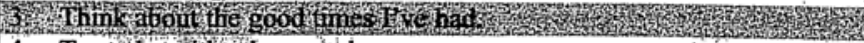

4. Try to be with other people.

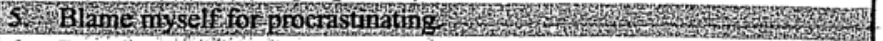

6. Do what I think is best.

7 . Become procupied W ith aches and pains

8. Blame myself for having gotten into this situation.

9. Wiridow shop

10. Outline my priorities:

11 To to

12. Treat myself to a favorite food or snack.

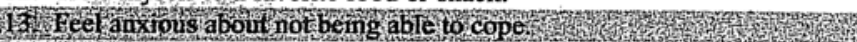

14. Become very tense.

15. Think about how I solved smilar problems

16. Tell myself that it is really not happening to me.

17. B lame myself for being too emorional about the situation

18. Go out for a snack or meal.

19 Become very upset

20. Buy myself something.

21 Determme course or aetion and follow it w

22: Blame myself for not knowing what to do.

24. Work to understand the situation.

25. Ereeze and not know what to do

26. Take corrective action immediately:

27. Think abou the exentand tear finm my mistakess

28. Wish that I could change what had happened or how I felt.

29.7 isit a frend

30. Worry about what I am going to do.

3 . Spend fime with a special person

32. Go for a walk.

33. Tei nyself that it Wil neve bappen again

34. Focus on my general inadequacies.

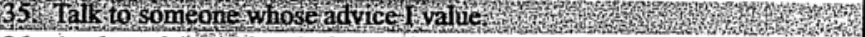

36. Analyze the problem before reacting.

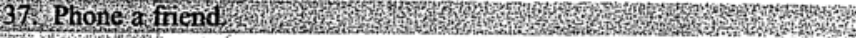

38. Get angry.

39 Adjust my pronifies

40. See a movie.

41 Get contro of the sitoation.

42. Make an extra effort to get things done.

43 Cone un with several different solntons to the problem

44. Take some time off and get away from the situation.

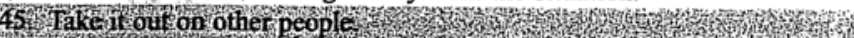

46. Use the situation to prove that I can do it.

47 Try to betganized sol can be on top of the situation 48. Watch TV.

Copyright 0 1990, Multi-Health System, Inc. All rights reserved. In the U.S., P.O. Box 950, North Tonawanda, NY 14120-0950, 1-800-456-3003. In Canada, 3770 Victoria Park Ave, Toronto, ON M2H 3M6, 1-800-268-6011, 1-416-492-2627, fax 1-416-492-3343 


\section{Appendix G: The Self-Efficacy Scale}

Directions: This questionnaire is a series of statements about your personal attitudes and traits. Each statement represents a commonly held belief. Reach each statement and decide to what extent it describes you. There are no right or wrong answers. You indicate your won personal feelings about each statement below by circling the number that best describes your attitude or feeling. Please be very truthful and describe yourself as you really are, not as you would like to be.

$$
\begin{aligned}
& \text { Rating Scale } \\
& \begin{array}{l}
1=\text { Strongly Disagree } \\
2=\text { Moderately Disagree } \\
3=\text { Neither Agree Nor Disagree } \\
4=\text { Moderately Agree } \\
5=\text { Strongly Agree }
\end{array}
\end{aligned}
$$

\begin{tabular}{|c|c|c|c|c|c|}
\hline & $\begin{array}{l}\text { Disagree } \\
\text { Strongly }\end{array}$ & $\begin{array}{l}\text { Disagree } \\
\text { Mod }\end{array}$ & $\begin{array}{l}\text { Neither } \\
\text { Agree or } \\
\text { Disagree }\end{array}$ & $\begin{array}{l}\text { Agree } \\
\text { Mod }\end{array}$ & $\begin{array}{l}\text { Agree } \\
\text { Strongly }\end{array}$ \\
\hline 1. I like to grow house plants. & 1 & 2 & 3 & 4 & 5 \\
\hline $\begin{array}{l}\text { 2. When I make plans, I am certainly to make } \\
\text { them work. }\end{array}$ & 1 & 2 & 3 & 4 & 5 \\
\hline $\begin{array}{l}\text { 3. One of my problems is that I cannot get down } \\
\text { to work when I should. }\end{array}$ & 1 & 2 & 3 & 4 & 5 \\
\hline $\begin{array}{l}\text { 4. If I can't do a job the first time, I keep trying } \\
\text { until I can. }\end{array}$ & 1 & 2 & 3 & 4 & 5 \\
\hline $\begin{array}{l}\text { 5. Heredity plays the major role in determining } \\
\text { one's personality. }\end{array}$ & 1 & 2 & 3 & 4 & 5 \\
\hline 6. It is difficult for me to make new friends. & 1 & 2 & 3 & 4 & 5 \\
\hline $\begin{array}{l}\text { 7. When I set important goals for myself, I } \\
\text { rarely achieve them. }\end{array}$ & 1 & 2 & 3 & 4 & 5 \\
\hline 8. I give up on things before completing them. & 1 & 2 & 3 & 4 & 5 \\
\hline 9. I like to cook. & 1 & 2 & 3 & 4 & 5 \\
\hline $\begin{array}{l}\text { 10. If I see someone I would like to meet. I go to } \\
\text { that person instead of waiting for him or her } \\
\text { to come to me. }\end{array}$ & 1 & 2 & 3 & 4 & 5 \\
\hline 11. I avoid facing difficulties. & 1 & 2 & 3 & 4 & 5 \\
\hline $\begin{array}{l}\text { 12. If something looks too complicated, I will not } \\
\text { bother to even try it. }\end{array}$ & 1 & 2 & 3 & 4 & 5 \\
\hline 13. There is some good in everybody. & 1 & 2 & 3 & 4 & 5 \\
\hline $\begin{array}{l}\text { 14. If I meet someone interesting who is very } \\
\text { hard to make friends with, I'll soon stop } \\
\text { trying to make friends with that person. }\end{array}$ & 1 & 2 & 3 & 4 & 5 \\
\hline $\begin{array}{l}\text { 15. When I have something unpleasant to do, I'll } \\
\text { stick to it until I finish it. }\end{array}$ & 1 & 2 & 3 & 4 & 5 \\
\hline
\end{tabular}




\begin{tabular}{|c|c|c|c|c|c|}
\hline & $\begin{array}{l}\text { Disagree } \\
\text { Strongly }\end{array}$ & $\begin{array}{c}\text { Disagree } \\
\text { Mod }\end{array}$ & $\begin{array}{l}\text { Neither } \\
\text { Agree or } \\
\text { Disagree }\end{array}$ & $\begin{array}{l}\text { Agree } \\
\text { Mod }\end{array}$ & $\begin{array}{c}\text { Agree } \\
\text { Strongly }\end{array}$ \\
\hline $\begin{array}{l}\text { 16. When I decide to do something, I go right to } \\
\text { work on it. }\end{array}$ & 1 & 2 & 3 & 4 & 5 \\
\hline 17. I like science. & 1 & 2 & 3 & 4 & 5 \\
\hline $\begin{array}{l}\text { 18. When trying to learn something new, I soon } \\
\text { give up if I am not initially successful. }\end{array}$ & 1 & 2 & 3 & 4 & 5 \\
\hline $\begin{array}{l}\text { 19. When I'm trying to become friends with } \\
\text { someone who seems uninterested at first, I } \\
\text { don't give up very easily. }\end{array}$ & 1 & 2 & 3 & 4 & 5 \\
\hline $\begin{array}{l}\text { 20. When unexpected problems occur, I don't } \\
\text { handle them well. }\end{array}$ & 1 & 2 & 3 & 4 & 5 \\
\hline $\begin{array}{l}\text { 21. If I were an artist, I would like to draw } \\
\text { children. }\end{array}$ & 1 & 2 & 3 & 4 & 5 \\
\hline $\begin{array}{l}\text { 22. I avoid trying to learn new things when they } \\
\text { look too difficult for me. }\end{array}$ & 1 & 2 & 3 & 4 & 5 \\
\hline 23. Failure just makes me try harder. & 1 & 2 & 3 & 4 & 5 \\
\hline $\begin{array}{l}\text { 24. I do not handle myself well in social } \\
\text { gatherings. }\end{array}$ & 1 & 2 & 3 & 4 & 5 \\
\hline 25. I very much like to ride horses. & 1 & 2 & 3 & 4 & 5 \\
\hline 26. I feel insecure about my ability to do things. & 1 & 2 & 3 & 4 & 5 \\
\hline 27. I am a self-reliant person. & 1 & 2 & 3 & 4 & 5 \\
\hline $\begin{array}{l}\text { 28. I have acquired my friends through my } \\
\text { personal abilities at making friends. }\end{array}$ & 1 & 2 & 3 & 4 & 5 \\
\hline 29. I give up easily. & 1 & 2 & 3 & 4 & 5 \\
\hline $\begin{array}{l}\text { 30. I do not seem capable of dealing with most } \\
\text { problems that come up in my life. }\end{array}$ & 1 & 2 & 3 & 4 & 5 \\
\hline
\end{tabular}




\section{Appendix H: Demographics Questionnaire}

Directions: Please check the most appropriate answer in the boxes provided.

1. What is your gender? $\square$ Male $\square$ Female

2. What university or college do you attend?

$\square$ Edinboro $\square$ UW - Whitewater

$\square$ University of Illinois $\quad \square$ Other:

3. What is your current class standing?

$\square$ Freshmen $\square$ Sophomore $\square$ Junior $\square$ Senior $\square$ Other:

4. What is your current age? years old

5. Are you currently registered with Disability Services on your college campus?

$\square$ YES $\square$ NO (If NO, please skip Question 6).

6. What percentage of time do you utilize a wheelchair/scooter while you are awake?

$\square$ Under $25 \% \quad \square 25 \%$ to $50 \% \quad \square 51 \%$ to $75 \% \quad \square 76 \%$ to $100 \%$

7. Do you currently participate in any organized Intercollegiate sport?

$\square$ YES $\quad \square$ NO (If NO, please skip Question 8).

8. What sport do you participate in?

Directions: For the following FIVE questions, CIRCLE the most appropriate answer. Rate each question on a scale from 1 to 10, with $1=$ VERY POOR and $10=$ VERY GOOD.

9. How would you rate your current level of academic achievement?

$\begin{array}{cccccccccc}1 & 2 & 3 & 4 & 5 & 6 & 7 & 8 & 9 & 10 \\ \text { Very } & & & & & & & & & \text { Very } \\ \text { Poor } & & & & & & & & & \end{array}$


10. How would you rate your current interpersonal experiences in college (e.g. meeting people, interacting with friends, participating in groups)?

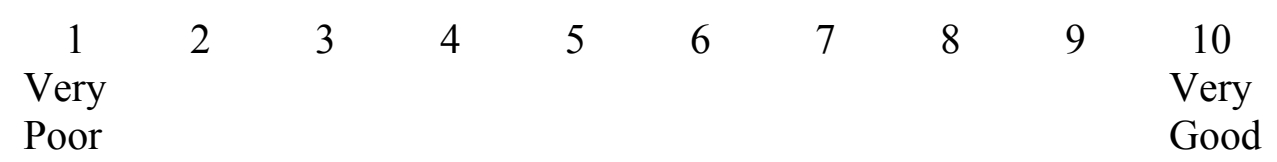

11. How would you rate your current level of psychological or mental well-being?

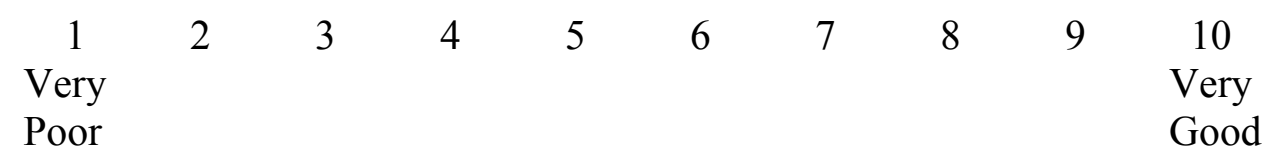

12. How would you rate your current level of physical health?

$\begin{array}{cccccccccc}1 & 2 & 3 & 4 & 5 & 6 & 7 & 8 & 9 & \begin{array}{c}10 \\ \text { Very } \\ \text { Very }\end{array} \\ \text { Poor } & & & & & & & & & \\ \text { Good }\end{array}$

13. How committed are you to completing your college education at your present institution?

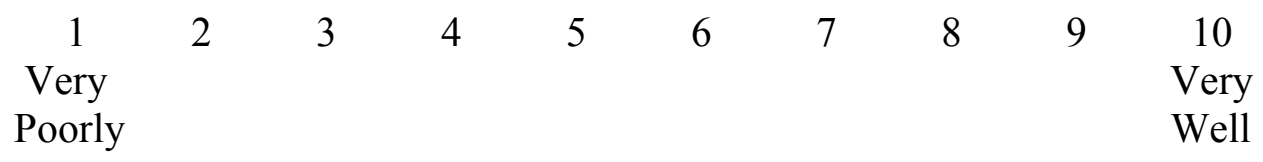




\section{Appendix I: Interview Script}

\section{Introduction}

Thank you [Person's Name] for agreeing to speak with me today. This interview is part of my dissertation research and I will be asking you questions about your college experience. So that I may be sure to understand and accurately represent what you choose to share with me today, I will be recording this interview. As a reminder, the interview will be transcribed and then the tape will be destroyed. Some of your comments maybe used in the publication of my study. However, I will never associate your name with the responses that you provide. Please remember that this interview is completely voluntary and you may opt to not answer any questions or to stop at anytime. Do you have any questions?

\section{Interview Script}

1. If I followed you through a typical week, what activities would I see you engaging in?

Now I would like to ask you about the daily challenges you face and also what supports you have to help you. Let's start first with challenges...

2. So in a typical day, what are the challenges you face?

3. What kinds of supports do you have available to you?

4. I would like you to take a moment to reflect back on your past experiences. Has there ever been a situation when things have gotten to the point where you have thought, "I am done" or "I can't continue"?

a. Could you describe this situation?

b. Describe the process you went through to resolve the situation?

c. What others did to help \{Confirm\}

5. Has there ever been a time in your college career when you felt you were treated unfairly?

a. Describe that situation.

b. What did you do?

6. Reflecting back on the experiences we just discussed, explain as best you can how you think you did or could have advocated for yourself in those situations?

a. So based on your perspective and experiences, what may be a possible definition for self-advocacy?

I'd like to switch gears a bit and ask you about some other aspects of your college experience. One of the things I am interested in understanding better is how college students typically experience and manage stress. (Provide a visual rating scale form 1 to 10).

7. If you were to rate your average stress level during a semester, where would you say you are along the scale? 
a. What things contribute to your stress being rated as a [insert number given]? (Confirm)

b. Internal / External

8. How do you typically deal with academic stress?

9. How do you deal with stressful situations that involve others?

We have spoken about how you perceive and manage stress. Another issue I am interested in understanding is how other people help or hinder you in managing your life in college. Others can provide a variety of different types of support such as listening, encouragement, giving us a feeling of belonging, providing us information or advice, or providing us with material support like money.

10. Who are the people that have provided you with support?

a. Confirm Relationship

b. Go back through list and inquire about what type of support each person provides.

11. Of those individuals you just mentioned, who do you tend to rely on the most for support? What is it about those relationships that make them supportive?

12. In terms of adjusting and managing life in college, is there any type of support you wish you had that would make your time in college better?

I would like to take some time now to reflect back on your very first semester of college.

13. During your first semester, did any of the expectations you had about going to college differ from what you experienced once you got here? [What and How]

14. What was it like for you adjusting to college your first semester?
a. Academic adjustment
b. Social adjustment
c. Emotional adjustment

15. How did things change, if at all, in your
a. Sophomore Year?
b. Junior Year?
c. Senior Year?

16. How would you say that you are currently managing within college

a. Working toward your career goals 
For college students who participate in intercollegiate athletics

17. How has your participation in athletics affected your college experience?

a. Academically

b. Socially

18. How might your experiences at college be different if you did not participate in athletics?

For Everyone

19. Suppose I was going to be starting my first semester of college soon. What suggestions might you give me for adjusting and being successful in college? 


\section{Appendix J: Recruitment Forms}

\section{Recruitment Form 1}

\section{Instructions}

Part of my research project is comparing the similarities and differences between students with and without disabilities on the surveys you have just completed. If you could please refer some of your friends to my study, it would be very helpful. Your name will not be used when I contact these individuals. They will only be told that they were recommended to my study and invited to participate.

\section{Do you know of anyone who:}

1. Currently, attends your same university or college?

2. Is the same gender as you?

3 . Is the same year in school that you are?

4. Does not have a disability?

\section{Please try to identify at least two people that meet the above criteria:}

Student's Name:

Phone:

Email:

Student's Name:

Phone:

Email:

Student's Name:

Phone:

Email:

Student's Name:

Phone:

Email:

Student's Name:

Phone:

Email: 


\section{Recruitment Form 2}

\section{Instructions}

Part of my research project is comparing the similarities and differences between students with and without disabilities on the surveys you have just completed. If you could please refer some of your friends to my study, it would be very helpful. Your name will not be used when I contact these individuals. They will only be told that they were recommended to my study and invited to participate.

\section{Do you know of anyone who:}

1. Currently, attends your same university or college?

2. Is the same gender as you?

3. Is the same year in school that you are?

4. Does not have a disability?

5. If possible, is also an athlete?

Please try to identify at least two people that meet the above criteria:

Student's Name:

Phone:

Email:

Is this person an athlete? $\square$ Yes $\square$ No

Student's Name:

Phone:

Email:

Is this person an athlete? $\square$ Yes $\square$ No

Student's Name:

Phone:

Email:

Is this person an athlete? $\square$ Yes $\square$ No

Student's Name:

Phone:

Email:

Is this person an athlete? $\square$ Yes $\square$ No 
Appendix K: Contact Information Sheet

\section{Contact Information}

If you would like your name entered in the raffle for $\$ 25$, please give me your name and the best way to reach you if you win. Also, if you are interested in participating in a follow-up interview, please mark Yes in the place provided. You will be called at a later date with more specific information about the interview. Those participants completing the interview will each receive $\$ 10$ for their time. Marking "Yes" does not obligate you to participate if you are called. Thank you again for your time.

Name:

I would like to be contacted: $\square$ By Phone $\quad \square$ By Email

Phone \#:

Email:

Please consider me for a follow-up interview: $\quad \square$ YES $\square$ NO 


\title{
Appendix L: Recruitment Letter
}

\section{Dear Student,}

My name is Jennifer Hurst and I am a doctoral student at West Virginia University. I am asking for your participation in my dissertation research project. I am looking at how college students adjust to and manage life in college. In exchange for fill out my four surveys, I offer you a chance to win $\$ 25$.

If you would like to participate, you may access the study online at the following address:

$$
\text { http://www.wvu.edu/ physed/hurst }
$$

Read through the consent message and click at the bottom on "Continue to Surveys" to complete the questions and enter to win.

Please contact me via email at jhurst1@mix.wvu.edu if you have any difficulty accessing the surveys online or need clarification on how to access the website. Thank you for your consideration and time.

Sincerely,

\author{
Jennifer R. Hurst \\ Doctoral Student in Sport Psychology \\ West Virginia University \\ P.O. Box 6122 \\ Morgantown, WV 26506-6122
}


Appendix M: IRB Consent Form

CONSENT AND INFORMATION FORM

The Influence of Disability Status and Athletic Participation on Different Psychosocial Factors Related to Adjustment in a College Population.

Space for IRB stamp$15 / 8^{\prime \prime} \times 2^{\prime \prime}$

\section{Introduction}

I, , have been invited to participate in this research

study which has been explained to me by Jennifer Hurst. This research is being conducted by Jennifer R. Hurst, M.S. to fulfill the requirements for a doctoral dissertation in sport and exercise psychology in the Department of Physical Education at West Virginia University, under the supervision of Dr. Sam Zizzi, Ed.D.

\section{Purposes of the Study}

The purpose of this study is to explore differences and similarities between college students with and without disabilities on several psychosocial factors related to adjusting to and staying in college. Approximately 120 individuals will be recruited overall from three different universities within the United States.

\section{Description of Procedures}

I have been told to fill out 4 questionnaires asking me about dealing with stress, social support, my beliefs about my abilities, and some demographic questions which takes approximately 20 to 30 minutes to complete. I have been told that I may see the questionnaires before signing this consent and that I do not have to answer all the questions if I decide to participate.

In addition, I understand that I may participate in a follow-up interview, if I am interested and I am chosen to do so. This interview would occur either in person or on the phone. I have been told that the interview questions would be asking me about my thoughts and experiences in college and take approximately 2 hours to complete. I have also been told that the interview will be voice recorded and that I will be able to see the interview questions before beginning the interview. I understand that I do not have to answer all the interview questions if I decide to participate. It has been explained to me that I may be contacted for a second interview to clarify answers that I provided in the first interview. 
The Influence of Disability Status and Athletic Participation on Different Psychosocial Factors Related to Adjustment in a College Population.

\section{Risks and Discomforts}

There are no known or expected risks from participating in this study, except for the mild frustration sometimes associated with completing questionnaires or interviews. If you feel you would like counseling after answering the questionnaire, a referral list is attached for agencies in your area.

\section{Alternatives}

I understand that I do not have to participate in this study.

\section{Benefits}

I understand that this study is not expected to be of direct benefit to me, but the knowledge gained may benefit others.

\section{Financial Considerations}

I understand that that I will receive the opportunity to enter a raffle to win $\$ 25$ for completing the surveys. I also understand that I will receive $\$ 10$ if I complete the individual interview.

\section{Contact Persons}

For more information about this research, I can contact Jennifer Hurst, at (304) 293-3807 x 1218, or her supervisor, Dr. Zizzi at (304) 293-3295 x 5240. For information regarding my rights as a research subject, I may contact the Office of Research Compliance at (304) 293-7073.

\section{Confidentiality}

I understand that any information about me obtained as a result of my participation in this research will be kept as confidential as legally possible. If I chose to complete these surveys online, I understand that the confidentiality of information transmitted over the Internet cannot be guaranteed. However, I also understand that my e-mail address and computer IP address will not be tracked by the researchers and will not be associated with my responses. I understand that my research records, just like hospital records, may be subpoenaed by court order or may be inspected by the study sponsor or federal regulatory authorities without my additional consent. In any publications that result from this research, neither my name nor any information from which I might be identified will be published without my consent. 
The Influence of Disability Status and Athletic Participation on Different Psychosocial Factors Related to Adjustment in a College Population.

\section{Voluntary Participation}

Participation in this study is voluntary. I understand that I am free to withdraw my consent to participate in this study at any time and that such refusal to participate will not affect my future care, or my class standing or grades. Refusal to participate or withdrawal will involve no penalty to me. I have been given the opportunity to ask questions about the research, and I have received answers concerning areas I did not understand. In the event new information becomes available that may affect my willingness to continue to participate in the study, this information will be given to me so I may make an informed decision about my participation.

Upon signing this form, I will receive a copy.

I willingly consent to participate in this research.

Signature of Subject

Signature of Investigator or Co-Investigator $\overline{\text { Date }} \overline{\text { Time }}$

$\overline{\text { Date }} \overline{\text { Time }}$ 